\title{
Los romanceamientos castellanos de la Biblia hebrea compuestos en la Edad Media: manuscritos y traducciones*
}

\author{
F. Javier Pueyo Mena, Andrés Enrique-Arias ${ }^{* *}$ \\ Universitat de les Illes Balears
}

Este trabajo presenta un análisis exhaustivo de 28 lemas hebreos y de sus correspondientes traducciones al castellano en los once códices medievales que contienen romanceamientos cuatrocentistas de la Biblia hebrea. El objetivo es determinar, mediante la comparación cuantitativa de la coherencia léxica de los textos transmitidos en cada uno de estos manuscritos, cuántos traductores participaron en las traducciones que ahora se conservan o bien mezcladas o bien diseminadas en los distintos códices. Se concluye que se preservan solamente seis traducciones diferentes del siglo Xv hechas a partir del hebreo: la Biblia completa de E3, el Pentateuco de E19, la Biblia completa que supone la combinación de la traducción contenida en los códices E7 y E5, la Biblia completa que denominamos Biblia del Marqués de Santillana (y que es una combinación de partes del códice E4 y del códice completo de BNE), la Biblia de Arragel y los Profetas Anteriores contenidos en el códice de Oxford.

Palabras Clave: códices bíblicos; traductores hispano-judíos; traducciones medievales; español medieval; comparación lexicográfica; variación léxica.

Old Spanish Renderings of the Hebrew Bible: Manuscripts and Translations.This paper presents a comprehensive analysis of 28 Hebrew lemmas and their translations into Castilian in the eleven medieval codices containing $15^{\text {th }}$ century vernacular renderings of the Hebrew Bible into Old Spanish. The objective is to determine, through quantitative comparison of lexical coherence in the texts contained in each one of these manuscripts,

"Esta investigación se ha llevado a cabo en el marco del proyecto financiado del Ministerio de Ciencia e Innovación de España FFI2010-18214, cofinanciado con fondos FEDER. Andrés Enrique-Arias se ha beneficiado de una estancia en la Universidad de Harvard financiada con la beca Collaborative Research Fellowship del American Council of Learned Societies para los años 2011-2013. Agradecemos las sugerencias y comentarios de Ángel Sáenz-Badillos y Luis M. Girón Negrón, así como las recomendaciones de los evaluadores anónimos de Sefarad.

***javier.pueyo@gmail.com, andres.enrique@uib.es 
how many translators were involved in the translations now preserved, either mixed or scattered in the various codices. We conclude that there are only six different $15^{\text {th }}$ century translations from the Hebrew still stant: the complete Bible E3, the Pentateuch in E19, the complete Bible made up from the combination of the translations contained in the codices E7 and E5, the whole Bible that we call the Bible of the Marquis of Santillana (which is a combination of parts of the E4 codex and the BNE codex in its entirety), the Arragel Bible and the Former Prophets contained in the Oxford codex.

Keywords: Biblical Codices; Spanish-Jewish Translators; Medieval Translations; Medieval Spanish; Lexicographic Comparison; Lexical Variation.

Durante la primera mitad del siglo XV se produjo en Castilla una intensa actividad de traducción de la Biblia hebrea al castellano de la que han sobrevivido once códices con biblias completas o fragmentarias ${ }^{1}$. A día de hoy prácticamente todos estos ejemplares han recibido ediciones y han sido objeto de estudios detallados tanto en lo que respecta a sus características codicológicas como en lo tocante a sus contenidos e interrelaciones con otros manuscritos ${ }^{2}$. La Tabla 1 presenta los códices en cuestión con las abreviaturas que usamos en adelante para referirnos a ellos junto a una indicación resumida de sus contenidos e información sobre las interrelaciones en lo que se refiere a coincidencias textuales entre diferentes códices:

\footnotetext{
${ }^{1}$ No incluimos en nuestro estudio la traducción bíblica del hebreo contenida en la Fazienda de ultramar, en primer lugar, por tratarse de un texto de finales del siglo XII o comienzos del siglo XIII, y por ello claramente independiente de los romanceamientos del siglo XV y, en segundo lugar, porque no contiene el texto bíblico completo lo cual nos impide la consulta sistemática de todos los ejemplos necesarios. Por esta misma razón no se incluye en este trabajo el libro suelto de Ester conservado en el ms. 2015 de la Biblioteca Universitaria de Salamanca, así como otros pequeños fragmentos del XV cuya descripción puede encontrarse en la página Biblia Medieval (www.bibliamedieval.es).

${ }^{2}$ Para el trabajo más actualizado y exhaustivo sobre los aspectos codicológicos de estos ejemplares véase AvENOZA (2011a); para la descripción más detallada hasta la fecha de las interrelaciones entre los diferentes manuscritos bíblicos véase PuEyo Mena (1996: xv-xxii; 2008: 259-60).
} 


\begin{tabular}{|c|c|}
\hline \multicolumn{2}{|c|}{$\begin{array}{c}\text { TABLA 1: CONTENIDO, ABREVIATURAS Y RELACIONES TEXTUALES } \\
\text { ENTRE LOS CÓDICES }\end{array}$} \\
\hline Escorial I.i.3 (= E3) & Canon judío + Macabeos I-II \\
\hline $\begin{array}{l}\text { Biblioteca de Ajuda, Lisboa, } \\
\text { 52-xii-1 (= Ajuda) }\end{array}$ & $\begin{array}{l}\text { Pentateuco, Josué y Jueces. Todos los libros en } \\
\text { coincidencia textual con E3. }\end{array}$ \\
\hline $\begin{array}{l}\text { Escorial I.ii.19 } \\
(=\text { E19) }\end{array}$ & $\begin{array}{l}\text { Pentateuco y Profetas Anteriores. Josué y Jueces en } \\
\text { coincidencia textual con E7 y Samuel I-II y Reyes I-II en } \\
\text { coincidencia textual con E3. }\end{array}$ \\
\hline Escorial I.i.7 (= E7) & Pentateuco y Profetas Anteriores. \\
\hline Escorial I.i.5 (= E5) & Profetas Posteriores y Escritos. \\
\hline $\begin{array}{l}\text { Biblioteca Pública, Évora, } \\
\text { ms. cxxiv/1-2 } \\
\text { (= Évora) }\end{array}$ & Escritos. Todos en coincidencia textual con E5. \\
\hline Escorial I.i.4 (= E4) & $\begin{array}{l}\text { Canon judío + Deuterocanónicos. Los Profetas } \\
\text { Posteriores en coincidencia textual con E5; los Salmos } \\
\text { traducidos del latín; el resto de los Escritos del canon } \\
\text { judío en coincidencia textual con BNE, a excepción de } \\
\text { Rut, Ester y Esdras/Nehemías no presentes en este; los } \\
\text { Deuterocanónicos en coincidencia textual con BNE } \\
\text { (Sabiduría y Eclesiástico) o RAH (Macabeos I-II), a } \\
\text { excepción de Tobías y Judit que no aparecen en dichos } \\
\text { códices. }\end{array}$ \\
\hline $\begin{array}{l}\text { Biblioteca Nacional de España, ms. } \\
10.288 \text { (= BNE) }\end{array}$ & $\begin{array}{l}\text { Profetas Posteriores y Escritos (a excepción de } \\
\text { Rut, Ester y Esdras/Nehemías) + Deuterocanónicos } \\
\text { (solamente Sabiduría y Eclesiástico). }\end{array}$ \\
\hline $\begin{array}{l}\text { Real Academia de la Historia, Madrid, } \\
\text { ms. } 87 \text { (= RAH) }\end{array}$ & $\begin{array}{l}\text { Profetas Posteriores. Isaías, Jeremías y Ezequiel } \\
\text { 1:1-14:7 en relación textual con la Biblia de Arragel; } \\
\text { Ezequiel 14:7-48:35, Doce Profetas y Daniel en } \\
\text { coincidencia textual con BNE. Macabeos I-II en } \\
\text { coincidencia textual con E4. }\end{array}$ \\
\hline $\begin{array}{l}\text { Biblia de Arragel, Palacio de Liria, } \\
\text { Madrid (= Arragel) }\end{array}$ & $\begin{array}{l}\text { Canon judío. Salmos, Job y Proverbios probablemente } \\
\text { traducidos del latín o revisados profundamente sobre la } \\
\text { Vulgata. }\end{array}$ \\
\hline $\begin{array}{l}\text { Bodleian Library, Canon. Ital. 177, } \\
\text { Oxford (= Oxford) }\end{array}$ & $\begin{array}{l}\text { Profetas Anteriores y Rut. Jueces en coincidencia } \\
\text { textual con E7 y Rut en coincidencia textual con E5. }\end{array}$ \\
\hline
\end{tabular}

Gracias al trabajo hecho hasta la fecha resulta hoy relativamente sencillo enumerar los códices cuatrocentistas que han transmitido romanceamientos bíblicos a partir del hebreo así como identificar qué manuscritos, enteros o en parte, repiten contenidos reflejados en otros manuscritos. Sin embargo no tenemos un conocimiento cabal de cuántas traducciones 
contiene este corpus textual. Precisamente una de las confusiones que ha rodeado el estudio de estos textos es la práctica bastante extendida de mezclar el concepto de manuscrito en tanto que entidad codicológica, con el de traducción, o unidad textual, algo que ya advertía certeramente Margherita Morreale hace cinco décadas:

No hay que identificar las biblias romances con la signatura del manuscrito que las contiene; no hay, por ejemplo, una «biblia E4», sino varias traducciones compaginadas en el manuscrito escurialense al cual damos esa sigla [Morreale, 1962: 138].

En efecto, no hay una correspondencia biunívoca manuscritos $=$ traducciones sino que las relaciones entre los diferentes romanceamientos existentes y los manuscritos que los contienen dan lugar a una casuística bastante compleja. Por ejemplo, a veces tenemos la misma traducción en dos manuscritos (como es el caso de las versiones del Pentateuco, Josué y Jueces contenidas en la Biblia de Ajuda, que coinciden con las del códice E3); o un manuscrito puede contener varias traducciones (en E4 el Pentateuco y los Profetas son claramente, como expondremos con detalle, obra de diferente traductor); o dos manuscritos pueden contener libros diferentes, pero que son el resultado de una misma labor romanceadora (como parece ser el caso para E7 y E5, que juntos formarían una biblia completa dispuesta en dos volúmenes).

Nuestro desconocimiento de las relaciones precisas entre manuscritos y traducciones se debe a que no se ha estudiado la cuestión detenidamente ni con las herramientas apropiadas. Además de la ya comentada tendencia a identificar códice y manuscrito hay toda una serie de problemas metodológicos que han impedido estudiar la cuestión con una base empírica válida.

Un primer problema atañe a la perspectiva de las investigaciones hechas hasta la fecha, que comparan los diferentes romanceamientos «en horizontal», es decir, contrastan cómo se traduce el mismo pasaje del original hebreo en diferentes romanceamientos. Este proceder, que resulta muy adecuado para realizar análisis contrastivos o para la identificación de diferentes interpretaciones exegéticas, sin embargo por sí solo no nos permite conocer la estructura interna de la traducción o traducciones contenidas en un códice: para detectar discontinuidades a lo largo de un 
manuscrito es necesario comparar «en vertical», es decir, investigar si un contenido dado del texto fuente es siempre traducido de la misma manera a lo largo de todo un romanceamiento. Este tipo de perspectiva apenas ha sido explorada hasta la fecha.

Otro problema de las investigaciones anteriores tiene que ver con el tipo de análisis que se ha llevado a cabo. En general no se ha procedido de forma sistemática con aplicación de métodos cuantitativos para contrastar las diferentes versiones sino más bien mediante apreciaciones cualitativas a partir de la comparación de ejemplos seleccionados con criterios circunstanciales.

La extensión y representatividad de las selecciones de texto empleadas en las comparaciones es otro aspecto mejorable con respecto de los trabajos anteriores: en la mayoría de los casos se trata de conclusiones basadas en pequeñas colaciones. Hay por tanto un problema de exhaustividad pues no ha habido hasta la fecha ningún estudio que considerase secciones de texto representativo de todos los manuscritos existentes.

Por último cabe señalar que los investigadores que han abordado la cuestión de las interrelaciones entre códices se han fijado principalmente en factores externos, como el orden de los libros, la lengua fuente, la complementariedad de contenidos entre manuscritos o características codicológicas. Todo ello son cuestiones importantes, pero que obviamente deben ser complementadas con estudios sistemáticos y detallados de la lengua recogida en los manuscritos.

Ahora que gracias al proyecto Biblia Medieval tenemos acceso al texto completo de las traducciones de la Biblia en formato electrónico alineadas con su fuente hebrea es más fácil, a través del corpus y las herramientas de consulta, hacer investigaciones a gran escala sobre cómo un lema hebreo dado se traduce a lo largo de cada manuscrito. De este modo podemos llegar a conclusiones más sólidas sobre la continuidad y estructura interna del romanceamiento reflejado en cada ejemplar y deducir si se trata de la obra de un solo traductor o del ensamblaje de secciones compuestas por dos o más traductores. En el presente estudio nos proponemos explorar la perspectiva vertical señalada analizando cómo se traducen a lo largo de los textos disponibles 28 lemas hebreos de alta frecuencia en la Biblia hebrea. De este modo pretendemos dar los primeros 
pasos para establecer sobre bases empíricas sólidas las correspondencias entre códices y traducciones en el corpus de los romanceamientos medievales castellanos hechos a partir del hebreo ${ }^{3}$.

\section{Metodología y datos utilizados}

El método que se describe a continuación lo hemos diseñado específicamente para este trabajo como modelo para establecer una forma objetiva de responder -mediante la observación cuantitativa de las elecciones léxicas de los traductores- a dos cuestiones fundamentales: a) si un códice determinado contiene el trabajo de un solo traductor, o si por el contrario presenta varias traducciones distintas ensambladas en un proyecto codicológico único; y b) si los códices examinados presentan relaciones de traducción entre sí, es decir, si se han copiado en dos códices independientes partes bíblicas distintas -y por lo tanto no comparables textualmente- que corresponderían a un modelo de traducción común. Lógicamente se han excluido del análisis aquellos fragmentos bíblicos de cada códice que las investigaciones previas han determinado sin lugar a dudas que son copia o adaptación de otros fragmentos bíblicos contenidos en alguno de los otros manuscritos ${ }^{4}$. Igualmente se han excluido los libros

\footnotetext{
${ }^{3}$ El desarrollo de una metodología completa que explore exhaustivamente esta perspectiva requeriría el análisis de un número más amplio de lemas así como otros elementos que permitieran una caracterización lingüística más completa (conjunciones, cultismos, dialectalismos, características morfosintácticas). Asimismo sería necesario analizar cómo se traducen a lo largo de los códices los pasajes duplicados en la Biblia hebrea. En estos momentos hemos emprendido este tipo de investigaciones más exhaustivas en cada uno de los manuscritos. Dada la extensión de tal investigación planeamos publicar los resultados en artículos separados para cada una de las traducciones bíblicas detectadas en este trabajo y que se describen de forma condensada en nuestras conclusiones.

${ }^{4}$ Se excluyen los códices completos de Ajuda y Évora ya que coinciden textualmente con E3 y E5 respectivamente. De E19 se excluyen Josué y Jueces al ser adaptación y copia, respectivamente, del mismo texto que contiene E7. De E19 se excluyen también Samuel I-II y Reyes I-II por su coincidencia textual con E3. Del códice E4 se excluyen los Profetas Posteriores por coincidir textualmente con E5 así como algunos libros de los Ketubim (Job, Proverbios, Lamentaciones, Cantar, Eclesiastés, Daniel y Crónicas I-II) por coincidir textualmente con BNE. De RAH se excluyen Ezequiel 14:7-final, Doce Profetas y Daniel por coincidir textualmente con BNE.
} 
deuterocanónicos de cada códice ${ }^{5}$ y los Salmos traducidos del latín ${ }^{6}$ ya que no pueden compararse con el texto hebreo original (véase TABLA 1).

El resto de las partes bíblicas de los códices se han dividido en las partes tradicionales de la Biblia hebrea para su análisis ${ }^{7}$. Primero, porque tanto el uso litúrgico en la tradición judía, como el tipo de lenguaje presente en cada parte, afectan tanto a su transmisión oral y escrita, como a la forma de traducir cada una de ellas y por lo tanto es conveniente examinarlas separadamente. Segundo, porque los códices (con la excepción de E4) no siguen la ordenación por libros de la Vulgata y se copiaron habitualmente en volúmenes exentos que tenían en cuenta alguna de estas divisiones.

\subsection{Selección de los lemas hebreos}

Se han tenido en cuenta aquellos lemas hebreos con una frecuencia absoluta de entre 100 y 500 apariciones en la Biblia. Hay dos razones fundamentales en la elección de dicho rango de ocurrencia: el límite inferior se establece para asegurar que los lemas puedan aparecer de forma homogénea en las cuatro partes de la Biblia; el límite superior se establece para asegurar que la frecuencia de aparición no sea excesiva y permita codificar los ejemplos de forma exhaustiva. Aunque hay aproximadamente 330 lemas hebreos que se ajustan a dichas frecuencias, antes de codificarlos se excluyeron la mayor parte, de acuerdo a cuatro parámetros de selección previos:

\footnotetext{
${ }^{5}$ Se excluyen, por lo tanto, los libros de Tobit y Judit de E4, Sabiduría y Eclesiástico de E4 y BNE y Macabeos I-II de E3, E4 y RAH.

${ }^{6}$ Se excluyen los Salmos de E4, traducidos del latín y los Salmos de la Biblia de Arragel (también traducidos del latín o al menos revisados profundamente sobre la Vulgata). Aunque también es detectable cierta influencia de la Vulgata en los Proverbios y $J o b$ de Arragel hemos optado por mantenerlos dado que todavía no se ha analizado en detalle el alcance de dicha influencia.

${ }^{7}$ Los 24 libros del canon judío se agrupan tradicionalmente en cuatro partes: Torá (Génesis, Éxodo, Levítico, Números, Deuteronomio), Profetas Anteriores (Josué, Jueces, Samuel I-II, Reyes I-II), Profetas Posteriores (Isaías, Jeremías, Ezequiel, Doce Profetas) y Escritos (Salmos, Job, Proverbios, Rut, Cantar, Eclesiastés, Lamentaciones, Ester, Daniel, Esdras-Nehemías, Crónicas I-II).
} 
a) En principio solo se tuvieron en cuenta los sustantivos. No se codificaron ni las partículas sin contenido léxico (preposiciones, artículos, determinantes, pronombres posesivos, etc.), ni las interjecciones o los adverbios, ya que su carácter funcional y su pertenencia a inventarios cerrados de la lengua, hace que su variabilidad no sea lo suficientemente alta para observar diferencias apreciables en las traducciones ${ }^{8}$. Igualmente, se excluyeron los numerales y adjetivos, primero, porque como tal categoría gramatical son muy escasos en hebreo bíblico y segundo, porque en una observación preliminar mostraban muy poca variación en las diferentes traducciones castellanas. Sin embargo, como muestra del uso variable de esta categoría gramatical, se ha incluido guibor 'fuerte, valiente', que sí presenta cierta variación en los códices'. Las formas verbales se excluyeron por la dificultad metodológica de codificar los lemas castellanos correspondientes al lema hebreo, ya que se partía de textos castellanos paleográficos sin anotación gramatical y sin ningún tipo de normalización ni lematización ${ }^{10}$.

b) Se excluyeron igualmente los nombres propios, ya que no ofrecen una variación suficiente para observar diferencias apreciables, aunque en ocasiones el traductor se enfrente a la decisión de si un topónimo hebreo debe transcribirse como tal, o debe traducirse.

c) De los 138 sustantivos que se encuentran dentro del rango de frecuencia establecido, se excluyeron todos aquellos que, a pesar de su frecuencia absoluta, no ocurrían de forma equilibrada en las cuatro partes de la Biblia ${ }^{11}$.

\footnotetext{
${ }^{8}$ Aquellos casos en los que sí puede observarse dicha variación, quedan fuera del rango establecido para este trabajo por su elevada frecuencia. Sirva como ejemplo la interjección הִ̣נה (hinné), que aparece en más de 1.000 ocasiones en la Biblia hebrea, y además lo hace de forma bien distribuida en sus cuatro partes: 220 ocurrencias en la Torá, 279 en los PA, 274 en los PP y 131 en los Ket.

${ }^{9}$ Un buen ejemplo de la falta de variación encontrada en los adjetivos sería el lema

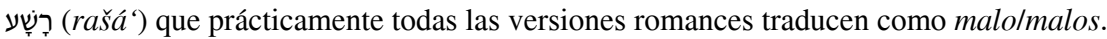

${ }^{10}$ Aunque se ha realizado manualmente la lematización y codificación de las formas verbales castellanas correspondientes al lema hebreo [נ][שאר ([ni]š'ar), para observar si su comportamiento es similar al de los sustantivos y para evaluar las necesidades metodológicas requeridas para la inclusión de dichas formas verbales en próximos trabajos.

${ }^{11}$ Es el caso, por ejemplo, de ('arón) 'arca': aunque su frecuencia absoluta en la Biblia supera las 200 ocurrencias, tan solo aparece en una ocasión (Je 3:16) en el conjunto de todos los libros de los Profetas Posteriores.
} 
d) Finalmente y tras un análisis preliminar, se excluyeron aquellos sustantivos hebreos cuyos correspondientes lemas romances no presentaban una variación apreciable en ninguno de los códices, por no existir sinónimos habituales en castellano o porque todas las tradiciones de traducción emplean el mismo término romance para traducirlos ${ }^{12}$.

El resto de los lemas hebreos se codificaron de forma completa, quedando la lista reducida a 28 términos, los cuales aparecen conjuntamente alrededor de 5.000 ocasiones en la Biblia. La Tabla 2 muestra la frecuencia individual de cada lema hebreo considerado en este estudio:

\begin{tabular}{|c|c|c|c|c|}
\hline \multicolumn{5}{|c|}{ TABLA 2: LEMAS HEBREOS ANALIZADOS POR ORDEN DESCENDENTE DE FRECUENCIA } \\
\hline 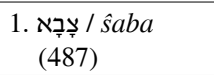 & 2. רַ / sar (419) & 3. الעלָה / 'olá (288) & $\begin{array}{c}\text { 4. מַטֶׁ / maté } \\
\text { (252) }\end{array}$ & 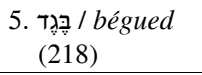 \\
\hline $\begin{array}{l}\text { 6. שֶֶׁׁ / šemen } \\
\text { (193) }\end{array}$ & $\begin{array}{l}\text { 7. / בְּה / behemá } \\
\text { (190) }\end{array}$ & 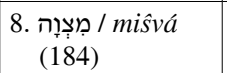 & 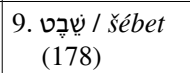 & 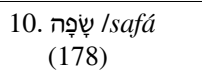 \\
\hline $\begin{array}{c}\text { 11. لעִדָ / 'edá } \\
\text { (174) }\end{array}$ & $\begin{array}{c}\text { 12. זִבְ / zébah } \\
\text { (162) }\end{array}$ & $\begin{array}{l}\text { 13. } \begin{array}{l}\text { 13. / guibor } \\
\text { (160) }\end{array} \\
\end{array}$ & 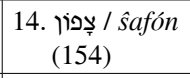 & 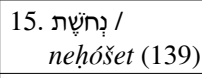 \\
\hline $\begin{array}{l}\text { 16. זִמִין / yamín } \\
\text { (139) }\end{array}$ & $\begin{array}{l}\text { 17. (136) / kisé } \\
\text { (13) }\end{array}$ & $\begin{array}{l}\text { 18. נָשׁׁיא / nasí } \\
\text { (134) }\end{array}$ & $\begin{array}{l}\text { 19. נַחַ / náhal } \\
\text { (134) }\end{array}$ & 20. רפ /par (133) \\
\hline 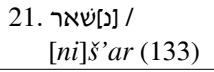 & 22. pin / hoc (128) & $\begin{array}{c}\text { 23. פ⿴囗大 / kóah } \\
\text { (127) }\end{array}$ & $\begin{array}{l}\text { 24. קָהָ / cahal } \\
\text { (123) }\end{array}$ & 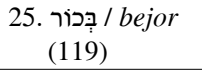 \\
\hline 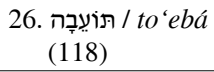 & $\begin{array}{l}\text { 27. שֶֶׁ, / šéquer } \\
\text { (113) }\end{array}$ & 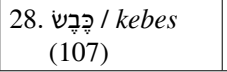 & & \\
\hline
\end{tabular}

\subsection{Procedencia de los textos y codificación de los ejemplos}

Se ha trabajado con los textos recogidos en Biblia Medieval ${ }^{13}$, usando la propia interfaz de consulta del corpus para localizar los 28 lemas hebreos analizados ${ }^{14}$. Una vez localizado un lema hebreo, se obtuvo un lista-

\footnotetext{
${ }^{12}$ Sirva como ejemplo el lema שِ prácticamente siempre, como 'cielos' (y en contadas ocasiones con el sing. 'cielo').

${ }^{13}$ Enrique-Arias (2008-2013). El texto hebreo que recoge Biblia Medieval se basa en la Biblia Hebraica Stuttgartensia, según la versión electrónica realizada por el Westmister Theological Seminary. La lematización del texto se basa en The GrovesWheeler Westminster Hebrew Morphology.

${ }^{14}$ Agradecemos a Juan-Carlos Conde y Amaranta Saguar-García el habernos permitido completar el corpus de los romanceamientos del siglo XV facilitándonos su transcripción del códice Bodl., Canon. Ital. 177.
} 
do de todos los versículos que lo contienen en la totalidad de los códices castellanos que se han analizado. Este listado se recuperó para cada uno de los lemas analizados y de los códices examinados.

El número total de ejemplos codificados, sumando todas las apariciones de los lemas en los 9 códices examinados, supera los 20.000 versículos. Realizar manualmente dicha codificación hubiera supuesto un tiempo desproporcionado para esta tarea, por lo que se decidió realizar una alineación preliminar a nivel de palabra de forma automatizada. Para ello se siguió el método descrito en Pueyo Mena (2013) para el corpus bíblico sefardí, el cual se apoya en el modelo tradicional de traducción sefardí, y que busca emparejar -mediante procedimientos estadísticos, el uso de diccionarios y de la información gramatical de cada palabra- todos los lemas hebreos con sus correspondientes formas romances. Aun teniendo en cuenta que nos encontramos ante textos medievales y no sefardíes, y que por lo tanto no siguen de la misma manera el modelo de traducción sefardí en el que se sustenta la metodología descrita, y teniendo en cuenta también que los textos medievales solamente están disponibles en transcripción paleográfica (es decir, sin normalizar, sin lematizar y sin etiquetar gramaticalmente), el modelo aplicado arrojó un porcentaje de precisión razonable, de aproximadamente el $90 \%$. No se excluyó ningún ejemplo y todos ellos fueron compulsados manualmente, necesitando el 10\% de ellos algún tipo de corrección en la alineación automática preliminar.

\subsection{Tablas de resultados y análisis individual de cada lema}

Los resultados numéricos para cada lema hebreo se han agrupado de forma condensada en 28 tablas que se ofrecen de forma electrónica para su consulta ${ }^{15}$, y se describen detalladamente en este trabajo. Las columnas representan las soluciones ofrecidas por los diferentes códices para cada lema, mientras que las filas dividen dichas soluciones en las cuatro partes de la Biblia. A lo largo de este trabajo, y también en las tablas, las diferentes formas paleográficas de los códices se han normalizado en una forma

\footnotetext{
${ }^{15}$ Las tablas pueden consultarse como archivo adicional de la versión electrónica de este artículo en la dirección http://sefarad.revistas.csic.es (Sefarad 73:1, 2013).
} 
única para posibilitar las comparaciones. Por ejemplo la forma normalizada sacrificio unifica las formas paleográficas sacreficio y sacrifiçio de los diferentes testimonios y las de sus respectivos plurales. Junto a la forma normalizada se ofrece la frecuencia absoluta de dicha forma para cada parte de la Biblia, junto al número total de ocurrencias del lema hebreo en dicha parte, a lo cual sigue el porcentaje que representa dicha forma respecto al número de ocurrencias: E3-Torá: alsación [140/148 = 94.59\%]. El segundo número puede variar de un códice a otro ya que, como se ha explicado anteriormente, en alguna de las versiones se han excluido ciertos libros porque son mera copia de algún otro o porque en ese códice en particular faltaban versículos e incluso capítulos debido a su pérdida durante la transmisión (sirva de ejemplo el códice I.ii.19, del cual se extraviaron los primeros 24 folios, por lo que no disponemos del texto para el fragmento 1:1-25:16 de Génesis).

En el análisis individual de cada lema hebreo se ofrecen los datos numéricos que le corresponden de forma organizada, para permitir una mejor lectura y comparación entre los mismos. Cada resumen se abre con un sumario del número de apariciones del lema en cada sección de la Biblia hebrea. A continuación se analizan los equivalentes castellanos que se encuentran en los diferentes códices, con especial atención a las coincidencias y divergencias que permiten identificar diferentes traducciones. Se han ordenado los lemas de acuerdo a su frecuencia de aparición en la Biblia (véase Tabla 2), excepto cuando dos lemas distintos presentan soluciones similares en castellano medieval (maté / šébet, sar / nasí, 'edá / cahal) pues su significado es muy parecido. En estos casos se presenta el análisis de forma contigua para simplificar al lector la comparación entre ambos.

\section{AnÁlisis INDIVIDUAL DE CADA LEMA}

\section{1. צִבָ / $\mathbf{s} a b a$}

El lema $\hat{s} a b a$ se distribuye de la siguiente manera: Torá 90 apariciones, Profetas Anteriores (PA) 58, Profetas Posteriores (PP) 266, Ketubim (Ket) 73. El análisis de este lema en las traducciones es complejo, ya que si en su uso genérico, con el significado de 'ejército', se traduce en castellano medieval como hueste, fonsado o cavallería, en otras ocasio- 
nes toma significados especiales según el contexto, particularmente en los Profetas Posteriores donde frecuentemente es parte del nombre de Dios: יהוה צָבָאוֹת (Isa 1:9), E3: Señor Sabaod, E5/E4: Señor de Sabaod, BNE: Señor de las huestes, RAH: Adonay Sabbaoth, Arragel: Señor de las cavallerías (Cantera-Iglesias: 'Yahveh-Ŝ'ba' ot'), dejándolo la mayor parte de los traductores en transcripción del hebreo, sin traducir (con las excepciones que muestra el ejemplo y que se señalan a continuación). En otras ocasiones, particularmente en los Profetas Anteriores, no se traduce individualmente ya que forma parte de la expresión sar ŝeba' que los traductores optan por traducir conjuntamente como condestable o mariscal:

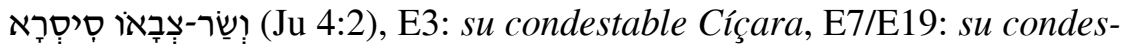
table era Cicra, BNE: nombre de su condestable era Sizra, Arragel: el su mariscal avía nombre Sisra (Cantera-Iglesias: 'El general de su ejército era Sísara').

E3 en la Torá usa indistintamente fonsado $(46,7 \%)$ y hueste $(38,9 \%)$. En PA ofrece preferentemente la lectura condestable $(37,9 \%)$, que como hemos explicado traduce la expresión sar ŝaba, usando en las otras ocasiones fonsado $(6,9 \%)$ o compaña $(6,9 \%)$ y la transcripción Sabaod $(24 \%)$ cuando es apelativo de Dios, uso que en PP asciende al 88,5\%, bajando de nuevo en los Ket a un 23,2\%. En los Ket, E3 ofrece una nueva forma dominante: guerra (26\%), aunque continúa usando compaña $(13,7 \%)$ o condestable $(2,7 \%)$.

Arragel, en la Torá, utiliza como opción más frecuente hueste (67\%) y en menor medida fonsado $(18,1 \%)$ o cavallería $(3,4 \%)$. Esta última es su elección preferente en PA (69\%) y PP (89,8\%), en los que el lema hebreo es normalmente parte del nombre de Dios, prefiriendo la traducción castellana 'Señor de las cavallerías' a la transcripción Sabaod (que usa solamente en el 6,9\% de las ocasiones). Contrasta este uso con los PP de RAH que prácticamente reflejan los porcentajes inversos: Sabaod (86\%), frente a cavallería $(5,7 \%)$.

Como es característico, E7 y E5 ofrecen gran variedad de sinónimos según el contexto en el que aparece el lema hebreo. En la Torá, E7 presenta gente $(37 \%)$, batalla $(31,4 \%)$, hueste $(15,7 \%)$, y real $(9 \%)$, como opciones principales, mientras que en PA presenta casi los mismos términos pero en proporciones distintas: hueste $(31 \%)$, corte $(8,6 \%)$, gente $(8,6 \%)$, batalla $(6,9 \%)$. Además traduce como condestable $(6,9 \%)$ cuando es par- 
te de la expresión sar ŝaba y transcribe Sabaod $(27,6 \%)$ cuando es apelativo de Dios. Por su lado, en PP E5 coincide con E7 en usar corte (3\%) en las pocas ocasiones en las que el lema hebreo no es parte del nombre de Dios, en las que también transcribe Sabaod (89,8\%), dejándolo sin traducir el resto de las ocasiones. En Ket continúa transcribiendo Sabaod $(26,4 \%)$, pero cuando se refiere al ejército, y no a Dios o a un individuo, vuelve a usar hueste $(25 \%)$, corte $(13,9 \%)$ o introduce el arabismo alcavela $(13,9 \%)$.

E4 y BNE se comportan de modo idéntico mostrando como opción mayoritaria hueste. E4 en la Torá la prefiere en el 97,8\% de los casos y en PA en el 50,9\%, complementada por condestable $(33,3 \%)$ para la expresión sar ŝaba, o con Sabaod (14\%) cuando aparece como apelativo de Dios. En los libros de los Ketubim que conserva E4 encontramos también hueste en el $100 \%$ de las ocasiones. Por su parte BNE, en los PP, usa igualmente hueste en el 95,5\% de las ocasiones, y en el $86 \%$ de los libros de Ketubim que contiene, evitando en todo momento transcribir el nombre de Dios como Sabaod, bien dejándolo sin traducir o bien usando las expresiones «Señor Dios de las huestes» o «Señor Dios de los exércitos».

E19 usa mayoritariamente fonsado $(88,4 \%)$ y es el único códice que desconoce hueste, mientras que Oxford prefiere hueste (72\%) y solo en ocasiones fonsado (14\%).

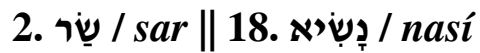

Para facilitar la comparación, agrupamos el análisis de ambos lemas en un mismo apartado ya que su significado es muy cercano y las soluciones castellanas muy similares. Sar aparece 57 veces en la Torá, 93 en PA, 88 en PP y 181 en Ket. En las traducciones castellanas presenta abundantes sinónimos: mayoral, cabdillo, capitán, príncipe, condestable, cavallero o adelantado, entre otros.

E3 prefiere mayoral en todas las partes (Torá 84,2\%, PA 69,9\%, PP $79,5 \%$, Ket $87,8 \%$ ).

Arragel muestra cierta variación en la Torá (mayor/mayoral 33,3\%, cavallero y príncipe $10,5 \%$ cada uno), aunque en las demás partes prefiere casi de forma exclusiva príncipe (PA 75\%, PP 97,8\%, Ket 93,3\%), al igual que los PP de RAH que utilizan príncipe en el 97,3\% de las ocasiones. 
En E5/E7 la distribución apoya la propuesta de parentesco entre ambas traducciones, pues predomina cabdillo para las diferentes partes de la Biblia. En E7 la distribución de este término es la siguiente: Torá 45,6\% y PA $64,1 \%$, mientras que en E5 tenemos: PP $86,5 \%$ y Ket $85 \%$. Además, ambas traducciones presentan una amplia variedad de equivalentes de traducción para este lema, aunque en porcentajes ciertamente bajos y generalmente en coincidencia entre ambos códices: cabecera, alguazil, mayor, príncipe, mayoral, grande, capitán, aunque no siempre: mensajero, carcelero, oficial, alcalde, mayordomo solo aparecen en E7, mientras que profeta y rey solo aparecen en E5.

E4 emplea en la Torá el término príncipe de forma mayoritaria $(42,1 \%)$, seguido de capitán $(24,6 \%)$ y en menor medida de cabecera y cavallero $(15,8 \%$ cada uno). En PA capitán es la forma preferida $(68,5 \%)$ seguida de condestable $(17,4 \%)$ aunque no desconoce cavallero $(6,5 \%)$ ni príncipe $(3,3 \%)$. En los Ket, E4 muestra también capitán $(86.1 \%)$ y cavallero (13.9\%). Por su lado, BNE presenta en los PP (73\%), de forma coincidente con E4, el término capitán seguido de cavallero $(14,6 \%)$ y príncipe (9\%); en los Ket prefiere también capitán $(75,5 \%)$ y después príncipe $(13,7 \%)$ o cavallero (4.3\%). Si bien hay considerable variación, observando ambos códices conjuntamente capitán es la opción predominante en las tres partes finales de una supuesta biblia única y la segunda opción en la Torá, mostrando además todas la partes el uso común de príncipe (opción principal en la Torá) y de cavallero.

Respecto a la Torá de E19 predomina mayoral/mayor (88,7\%) como en E3. Los PA de Oxford emplean fundamentalmente la traducción cabdillo $(85,5 \%)$ en la línea de E7/E5.

Por otro lado, nasí se distribuye de la siguiente manera: Torá 71 ocurrencias, PA 15, PP 39, y Ket 9. Las soluciones ofrecidas por los manuscritos son mayoral, mayor, príncipe, capitán y cabdillo. Hay muy pocos ejemplos -los cuales no tenemos en cuenta ya que su frecuencia es demasiado baja- en los que el plural de nasí tiene otra acepción y se interpreta como 'nuves' o 'vientos'.

Como es habitual E3 es la traducción más constante: emplea mayoral (o mayor en algún caso) exclusivamente en todas las secciones. E4 y BNE son también constantes en el empleo de príncipe $(98,6 \%$ en Torá y 
$100 \%$ en las demás secciones). Arragel emplea ambos príncipe y mayoral en Torá y PA (así 49,3\% mayoral y 39,4\% príncipe en Torá, y 53,3\% príncipe y $40 \%$ mayoral en PA) al tiempo que se decanta por príncipe en exclusiva en PP y Ket. Los PP de RAH emplean también príncipe en exclusiva.

Como se observa también en otros casos E7 y E5 se caracterizan por la amplia variedad de opciones léxicas empleadas: a lo largo del romanceamiento encontramos hasta dieciséis lexías diferentes. Las empleadas con mayor frecuencia son cabdillo (41), escogido (30), mayoral (24), capitán (13) y mayor (6) mientras que familiar, grande y cabecera aparecen dos veces cada una y contado, grande, juez, príncipe, real, varón, rey y alférez son empleadas una sola vez. En la Torá la forma preferida es escogido (42\%) seguida de cabdillo (23,2\%), capitán (14,5\%) y mayor-mayoral $(10,1 \%)$. En PA predomina cabdillo $(80 \%)$ mientras que en PP mayoral / mayor / mayoría (59,4\%) son las formas preferidas seguidas de cabdillo (27\%). Por último, en Ket tenemos cabdillo (50\%) y capitán (33.33\%). A pesar de la dispersión de los resultados es posible detectar una característica que relaciona las diferentes partes del romanceamiento y lo distingue de las demás versiones: nos referimos al empleo dominante de cabdillo en PA de E7 (80\%) y Ket de E5 (50\%), con cierta presencia de este vocablo en las demás secciones $(23,2 \%$ en Torá y $27 \%$ en PP). Se trata de un hecho relevante porque aparte de dos apariciones en Oxford y una en Arragel ningún romanceamiento emplea esta palabra para traducir nasí. Además, la gran mayoría de los vocablos que aparecen más de una vez a lo largo del romanceamiento (con la excepción de escogido y familiar) aparecen tanto en secciones transmitidas por E7 como por E5 (por ejemplo, cabdillo, mayoral, capitán, mayor, grande y cabecera).

\section{3. עלָד / 'olá}

Aparece 148 veces en la Torá, 44 en PA, 35 en PP y 61 en Ket. En las traducciones castellanas 'olá presenta pocos sinónimos, pero muy distribuidos según las tradiciones: alsación, sacrificio, templación, holocausto/a y algún otro menos frecuente.

El traductor de E3 se muestra consistente en utilizar la forma alsación a lo largo de toda la Biblia (Torá 94,6\%, PA 95,4\%, PP 91,4\%, Ket 98,4\%). 
Arragel, por su parte, se muestra igualmente consistente al usar casi exclusivamente el latinismo holocausta ${ }^{16}$ en todas las partes de la Biblia (Torá 98,5\%, PA 97,7\%, PP 94,29\%, Ket 100\%). Los PP de RAH muestran la misma preferencia que Arragel, en este caso al usar en el 90,9\% de las ocasiones el mismo latinismo holocausta.

E7/E5 prefieren la forma sacrificio, aunque en la Torá E7 se decanta por la forma alsación $(47,8 \%)$ frente a sacrificio que tampoco es infrecuente $(35,5 \%)$, comportamiento inverso a lo que observamos en PA (sacrificio $81,8 \%$ frente a alsación 13,6\%) y al que muestra E5 en PP (sacrificio $77,1 \%)$ y Ket $(68,8 \%)$.

E4 es consistente con la elección léxica del cultismo holocausto tanto en la Torá (94\%) como en PA (95\%) y en Ket (100\%). De nuevo encontramos porcentajes muy similares en BNE para el mismo cultismo: PP $(93,5 \%)$ y Ket $(100 \%)$.

E19, al igual que E3, prefiere derivados de alçar: alsación $(76,6 \%)$ y alçamiento $(19,1 \%)$, mientras que Oxford se agrupa en este caso con la tradición de E4/BNE al mostrar un 97,4\% de ocurrencias del cultismo holocausto.

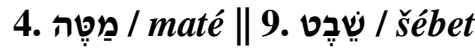

Comentamos juntas estas dos palabras por reunir significados semejantes: por un lado tienen un significado de 'palo', 'verga' o 'bastón' y al mismo tiempo tienen una acepción de 'tribu' o 'linaje'. No vamos a considerar los casos en que se emplea con esta última acepción por traducirse con tribu en todas las versiones. Respecto del otro significado, una circunstancia que cabe tener en cuenta es que estas palabras designan varias realidades según el contexto ('cayado', 'vara', 'cetro') y los traductores tienden a emplear opciones léxicas diferentes en la Torá con respecto a otras secciones.

Si eliminamos, como hemos dicho, los casos en que maté se interpreta como 'tribu' nos quedan 67 apariciones que se distribuyen como sigue: Torá 42, PA 2, PP 21, Ket 2. No vamos por tanto a considerar PA ni PP por contener solamente 2 casos cada una de estas secciones, de tal modo que tan solo podremos apreciar el contraste entre Torá y PP.

${ }^{16}$ En CORDE se recoge solamente una vez en los Sermones contra judios y moros de Clemente Sánchez, en una cita en latín de la Vulgata. Después solo aparece en las biblias RAH y Arragel, analizadas en este trabajo. 
E3, como suele ser el caso, es la más constante y emplea vara de manera consistente en las dos secciones (Torá 97,6\%, PP 95,2\%). Por el contrario, las demás traducciones presentan variación considerable entre estas dos partes de la Biblia: Arragel emplea blago en Torá $(94,7 \%)$ y sin embargo en PP combina verga $(42,1 \%)$, blago $(31,6 \%)$ y cebtro $(15,8 \%)$. Como es de esperar los PP de RAH exhiben opciones semejantes a las de Arragel: también predomina verga (61.54\%), pero alternando con báculo en vez del patrimonial blago (30.77\%). También E4-BNE presenta diferencias entre Torá, en que emplea blago $(47,7 \%)$ y verga $(38,6 \%)$ frente a PP donde encontramos vara (50\%) y verga (30\%). De nuevo en E7-E5 encontramos contrastes entre la Torá, que también emplea blago $(95,1 \%)$ mientras que en PP hay una enorme variedad de vocablos: piértego y verdugo (3 veces cada una o 16.7\%), blago y palo (2 veces cada una) y un ejemplo de cada una de las siguientes voces: acostamiento, lança, mando, saeta, tenimiento, venablo, verga y yugo. Por su parte E19 emplea blago (95\%).

En resumen, parece que en la Torá maté se refiere a una realidad muy específica, el cayado de Moisés, que se refleja blago en casi todos los romanceamientos (Arragel, E4-BNE, E7-E5 y E19) mientras que en PP refleja otras realidades, una 'vara' o un 'palo', que se expresa con otros términos. El amplio empleo de blago en la Torá llama la atención por ser un orientalismo que parece haber pasado a ser parte del vocabulario bíblico medieval ya que fuera de los romanceamientos no es tan usado ${ }^{17}$. La notable excepción sería E3 donde blago no se emplea ni una sola vez y se prefiere de forma sistemática vara a lo largo de todo el romanceamiento.

Al igual que maté, šébet combina los significados de 'vara' y 'tribu'. Si eliminamos los casos en que tienen esta segunda acepción, nos quedamos con 50 ocurrencias que se distribuyen así: Torá 4, PA 4, PP 22, Ket 20. Para esta palabra tendremos que tener en cuenta que en Torá y PA el número de ocurrencias es muy pequeño.

Al igual que observamos con maté, E3 es muy regular y emplea vara en todas las secciones (Torá 100\%, PA 66,7\%, PP 100\%, Ket 100\%). Arragel también muestra una preferencia a lo largo del romanceamien-

${ }^{17} \mathrm{Su}$ origen oriental parece atestiguarlo Corominas y Pascual (s.v. Báculo) al documentar su primer uso en Berceo. Por otro lado, de los 107 ejemplos de blago en CORDE, $62(57,9 \%)$ proceden de romanceamientos bíblicos. 
to pero en su caso es por verga (Torá 66,7\%, PA 75\%, PP 63,6\%, Ket $83,3 \%$ ) y secundariamente por cebtro (Torá 33\%, PP 31,8\%). Como es habitual RAH presenta el mismo resultado que los PP de Arragel (verga $77,8 \%$, cebtro $22,2 \%$ ). E4-BNE combinan vara y verga a lo largo de gran parte del romanceamiento, con cierto predominio de la primera (Torá: vara $50 \%$, verga $25 \%$; PA: vara $100 \%$; PP: vara 52,4\%, verga $42,8 \%$, Ket: vara $55 \%$, verga $35 \%$ ).

E7-E5 presentan, como es habitual, una gran dispersión en los resultados. En Torá y PA, donde como hemos dicho hay cuatro ocurrencias de šébet en el original con el significado de 'palo', tenemos tres equivalentes castellanos en la primera sección (verga, cayado y palo), y en PA hasta cuatro (dardo, lança, parte, verdugo). En PP y Ket hay también gran dispersión pero el mayor número de ocurrencias permite detectar preferencias; así en PP predomina verdugo $(42,1 \%)$ si bien también se emplea palo (3 veces), arma y verga (2 veces), y una vez cada una açote, blago, cayada y vara. La tendencia a la dispersión, y con las mismas opciones léxicas se da en los Ket: de nuevo predomina verdugo (40\%) junto a açote (35\%), con presencia además de verga, amenaza, cayado y premia.

Por último, E19 prefiere verdugo (75\%) y Oxford presenta considerable dispersión con una opción diferente para cada una de las 4 ocurrencias de la palabra en PA: alavesa, cabeça, palo y verdugo.

\section{5. בְֶֶֶ / bégued}

Aparece con la siguiente distribución: Torá 113, PA 42, PP 40, Ket 23. Todas las versiones usan en diferentes proporciones paño, ropa y derivados de vestir (vestimentalvestidura).

E3 es el único romanceamiento en que tenemos ropa como solución dominante en todas las secciones (48,7\% en Torá, 52,4\% en PA, 55\% en PP y 73,9\% en Ket) si bien alterna con paño en todas ellas (46\% en Torá, $47,6 \%$ en PA, $37,5 \%$ en PP y $26,1 \%$ en Ket).

Paño es la opción preferida en la mayoría de las traducciones. Así pues en Arragel paño es la opción predominante pero con porcentajes que van disminuyendo a lo largo del romanceamiento (91,9\% en Torá, 59,5\% en PA, $45 \%$ en PP y 15,8\% en Ket) al tiempo que la segunda opción más frecuente, vestimenta, iguala a paño en los PA (45\%) e incluso lo supera claramente en los Ket $(68,4 \%)$. Esta combinación de vestimenta y paño 
se refleja también en RAH, con porcentajes de 57,9\% y 15,8\% respectivamente. El empleo de vestimenta en estas versiones sería resultado de la tendencia a adoptar lecturas latinizantes.

En E7-E5 también es paño la opción más empleada alternando con ropa: así pues para paño tenemos Torá 53,6\%, PA 33,3\%, PP 42,5\%, Ket $47,8 \%$ y para ropa Torá $20,9 \%$, PA $50 \%$, PP $30 \%$, Ket $34,8 \%$, junto a los que cabe también señalar cierta presencia de vestimenta / vestidura con los siguientes porcentajes combinados: Torá 20,2\%, PA 9,5\%, PP 15\%, Ket $17,4 \%$; es decir, hay una notable continuidad entre las partes del romanceamiento transmitidas por estos dos manuscritos pues todas las secciones emplean paño, ropa, vestidura y vestimenta en proporciones comparables.

La preferencia por paño es asimismo bastante clara en E4-BNE (Torá 80\%, PA 76,2\%, PP 80\%, Ket 61,1\%).

Por último, E19 prefiere paño claramente $(99,1 \%)$ al tiempo que Oxford se distingue de los demás romanceamientos por contener la única versión de PA en los que predomina vestidura (61\%) que se emplea en combinación con ropa $(19,5 \%)$.

\section{6. שֶֶֶׁ / ̌̌emen (193)}

Aparece 106 veces en la Torá, 21 en PA, 35 en PP y 31 en Ketubim. Los principales sinónimos que se encuentran en las traducciones castellanas para traducir este lema son: azeite, olio, derivados de grueso (gruesa, grosura, gordura) y ungüento.

E3 presenta de nuevo una predilección consistente por una forma única, en este caso azeite: Torá (97,1\%), PA (72,2\%), PP (82,2\%), Ket $(90,3 \%)$.

Arragel de igual modo prefiere una sola lectura, en su caso olio: Torá (95,8\%), PA (80,9\%), PP (74,3\%), Ket (80,9\%), aunque en PP también emplea los derivados de grueso: grosura/gruesa $(11,4 \%)$ y ungüento $(8,1 \%)$. Los PP de RAH muestran los mismos términos usados por Arragel, pero en porcentajes algo distintos: grosura $(38,4 \%)$, olio $(30,8 \%)$ y ungüento $(15,3 \%)$.

E7 y E5 se comportan de la misma manera usando olio/azeite de forma alterna: en la Torá de E7 azeite $(64,7 \%)$ es más común que olio $(35,2 \%)$ mientras que en PA ocurre lo contrario: olio (45\%) es más común que azeite $(35 \%)$. Por su lado E5 prefiere azeite $(45,7 \%)$ sobre olio $(14,3 \%)$ 
en PP, mientras que en Ket prefiere olio (40\%) sobre azeite (30\%). Al igual que ocurría en Arragel, en los PP y Ket se encuentran también derivados de grueso (grueso, gordura, grosura, gruesa) en porcentajes del $20 \%$ (en PP) y del 10\% (en Ket). El término ungüento ocurre en un $14 \%$ (PP) y en un 6\% (Ket) de las ocasiones.

E4 y BNE se comportan de forma muy similar en la distribución de olio y azeite. Si en la Torá de E4 encontramos olio $(69,8 \%)$ / azeite $(17,9 \%)$, en los PA se da prácticamente la misma distribución: olio $(70 \%)$ / azeite (20\%), aunque en los Ket solo encontramos olio (100\%). En los PP de BNE tenemos olio $(57,1 \%)$ / azeite (20\%) y en Ket olio (42,8\%) / azeite $(21,4 \%)$. En los PP y Ket de BNE, al igual que el resto de las biblias, se observan también las formas derivadas de grueso (PP 2,8\% / Ket 7,1\%) y la forma ungüento (PP 11, 4\% / Ket 25\%).

Finalmente, E19 usa prácticamente siempre azeite $(96,2 \%)$, mientras que Oxford en PA se distribuye entre ambas opciones: olio $(47,6 \%)$ / azeite $(33,3 \%)$.

\section{7. בְּהָמָ / behemá}

Aparece 103 veces en la Torá, 10 veces en PA, en 48 ocasiones en PP y en 29 en los Ket. Los posibles sinónimos que ofrecen las traducciones castellanas para behemá son: bestia, cuatropea, animalia, res o ganado.

Prácticamente todas las versiones usan de forma mayoritaria bestia como lectura principal (véase la tabla para los porcentajes concretos), a excepción de E19 que en la Torá prefiere cuatropedia $(58,8 \%)$ que a su vez es la segunda lectura de E3 $(39,22 \%)$ y de E7 $(38,6 \%)$ para los mismos libros, pero no del resto de los romanceamientos que prefieren como segunda opción, en la primera parte de la Biblia, los términos animalia (E4 14,5\%) o res (Arragel 21,4\%).

\section{8. מִצִ מִוָה / miŝvá}

Se distribuye de la siguiente manera: Torá 66 ocurrencias, PA 26, PP 10 y Ket 82. Los códices ofrecen los siguientes términos de traducción: derivados de mandar (mandamiento, mandado, mando), de encomendar (encomienda, encomendança) y el cultismo precepto, entre otros menos frecuentes. 
E3 usa prácticamente en exclusiva la forma mandamiento: Torá (98,5\%), PA $(96,1 \%)$, PP $(90 \%)$, Ket $(84,1 \%)$, y ocasionalmente mandado y mando en Ket (7,3\% en ambos casos).

Arragel muestra también predilección por las formas derivadas de mandar y en particular por mandamiento Torá $86,1 \%$, PA $96,1 \%$, PP $90 \%$ (mandado $10 \%$ ) y Ket $75 \%$ (mandado / mando conjuntamente en un $10 \%$ de las ocasiones). Los PP de RAH usan indistintamente -como Arragel, pero en diferente porcentaje- mandamiento y mandado (un 37,5\% de las veces en ambos casos).

E7 utiliza tanto encomendança como mandamiento, aunque distribuidos de forma inversa en la Torá (encomendança 77,2\% / mandamiento $22,7 \%$ ) y en los PA (encomendança 19,2\% / mandamiento 76,9\%). E5 por su lado, hace uso exclusivo de mandamiento en los PP, pero incorpora también encomendança en los Ket con la misma distribución que los PA de E7 (encomendança 19,5\% / mandamiento 70,7\%).

E4 y BNE vuelven a mostrar su coincidencia -y también su exclusividad- al incorporar el latinismo precepto $^{18}$ como primera o segunda opción según las partes, aunque no desconocen ninguna de las demás. E4 en Torá usa precepto preferentemente en el $37,9 \%$ de las ocasiones (mandamiento $28,8 \%$, encomienda $21,2 \%$ y encomendança el $10,6 \%$ ). En PA reduce las opciones a dos: mandamiento $(73,1 \%)$ y encomienda $(27 \%)$, al igual que en Ket: mandamiento $(84,2 \%)$ y mandado $(10,5 \%)$. Por su parte, BNE en $\mathrm{PP}$ se divide casi equitativamente entre mandamiento (50\%) y precepto (40\%) y -al igual que E4 en la Torá- en los Ket BNE usa como forma principal precepto $(74,6 \%)$, mostrando en el resto de las ocasiones mandado o mandamiento.

\footnotetext{
${ }^{18}$ Precepto es un cultismo muy poco extendido en castellano medieval, incluido el léxico religioso, que para expresar este concepto prefiere las formas patrimoniales de 'mandar' (mandamiento, mandado, etc.), como hemos visto en las biblias judías, pero también en las cristianas como E6/E8 (incluido el Nuevo Testamento) y en los fragmentos bíblicos de la General Estoria. Excluyendo la Biblia, en CORDE no se documenta en castellano hasta un ejemplo aislado en la Crónica de 1344, después aparece muy pocas veces antes de 1458 (fecha de la muerte de Santillana). Lo encontramos en las siguientes obras: Cancioneros de Íxar y París, Libro de las Paradojas de Alonso Fernández el Tostado (1437), Tratados de Lope de Barrientos (1445), Diccionario eclesiástico o teológico moral (1450), Morales de Ovidio de Alfonso Gómez de Zamora, y en el Invencionario (1453-1467) de Alfonso de Toledo. Debemos destacar que en el Nuevo Testamento de Lucena se utiliza también en nueve ocasiones.
} 
E19 se decanta primordialmente y en solitario por la forma encomien$d a(91 \%)$ y Oxford usa en todas las ocasiones y sin excepción mandamiento.

\section{0. שָָּׁה / safá}

El análisis de la traducción de safá presenta cierta complejidad, pues desde su acepción primaria y más frecuente de 'labio', 'boca', 'lengua' ha desarrollado varios significados, como el de 'habla' o 'lenguaje', o por extensión metafórica a partir de 'labio', el significado de 'orilla', 'ribera' o 'borde de un objeto', como por ejemplo un vaso. Para organizar el análisis de los resultados, hemos agrupado las opciones léxicas de las versiones castellanas por cada uno de los tres campos semánticos principales que se relacionan con las acepciones de safá, distinguiendo las que designan una parte del cuerpo (labio, beço, boca), la acción o facultad de hablar (fabla, lenguaje) o accidente geográfico o borde de un objeto (orilla, ribera, parte) ${ }^{19}$.

Empezamos por analizar las expresiones que significan 'labio', 'boca'. Tenemos pocas apariciones en Torá y PA (entre una o dos y media docena para cada sección según la versión) y algunos casos más en PP (entre 15 y 24) y sobre todo Ket (más de 80). La diferencia más relevante es la competición entre beço ${ }^{20}$ frente a boca y labio / labrio. Hay dos versiones que emplean beço de manera regular: E3 (Torá 80\%, PA 100\%, PP 100\%, Ket $98,8 \%$ ) y E4-BNE (Torá 80\%, PA 100\%, PP 100\%, Ket 97,5\%). Por su parte E19 presenta boca (100\%) mientras que el resto de las versiones emplean una combinación de varios términos. Como suele ser la norma en E7E5 encontramos una variedad de opciones: en Torá y PA de E7 predomina boca (66,7\% en cada sección), si bien también hay dos ejemplos de labrio en Torá y uno de beço en PA. En E5 también tenemos una combinación de boca $(53,3 \%)$, beço $(40 \%)$ y labrio $(6,7 \%)$ que encontramos de nuevo, en diferentes proporciones en Ket: beço $(74,7 \%)$, labio $(13,8 \%)$, boca $(9,2 \%)$. De modo semejante en Oxford se combinan beço y labio al 50\%. Por úl-

\footnotetext{
${ }^{19}$ En el caso de lengua, que puede ser tanto una parte del cuerpo como referirse a un lenguaje, hemos analizado cada aparición en contexto para asignarla al campo apropiado. Por lo que respecta a rostro lo hemos asignado a la categoría de 'orilla' o 'borde' por emplearse siempre con esa acepción en Arragel.

${ }^{20}$ Término de origen y extensión occidental según Corominas y PAscual (s.v. BEzo).
} 
timo Arragel destaca por ser la única versión que desconoce beço (con un solo ejemplo en todo el romanceamiento) para decantarse claramente por labio: Torá 50\%, PA 100\%, PP 73,3\%, Ket 88,7\%, es decir, Arragel selecciona una vez más, de entre los términos castellanos disponibles, el que es cognado del correspondiente latino (en este caso labium). Como es habitual RAH refleja la misma tendencia que Arragel al emplear labio $(90,9 \%)$.

En lo que respecta a palabras castellanas con el significado de 'lenguaje', no hay una representación muy nutrida en las secciones analizadas (en torno a media docena de casos en Torá y PP, y cerca de la docena en Ket al tiempo que no hay ejemplos en PA). Las opciones presentes en los romanceamientos son principalmente fabla, lengua y lenguaje. E3 presenta preferencia por fabla (Torá 71,4\%, PP 100\%, Ket 72,7), al igual que E19 (66,7\%), mientras que E5-E7 prefiere lenguaje / lengua (Torá 100\%, PP 85,7\%, Ket 50\%). Por su parte E4-BNE presenta una combinación de términos con presencia de fabla, lengua y lenguaje en diferentes proporciones en todas las secciones. Arragel junto a RAH muestra una vez más su preferencia por el cognado del término latino lingua empleando lengua en algunas secciones $(83,3 \%$ en Torá y $100 \%$ en PP) si bien recurre a fabla en Ket (60\%).

Por último, las voces castellanas con el significado de 'orilla', 'borde' aparecen unas 20 veces en Torá, 15 en PA, 4 en PP y 7 en Ket, es decir, con una representación más reducida en las dos últimas porciones estudiadas. La opción más extendida es orilla, que aparece de manera casi exclusiva a lo largo de E3 (Torá 94,7\%, PA 100\%, PP 75\%, Ket 100\%), E4-BNE (Torá 90\%, PA 81,8\%, PP 100\% y Ket 100\%) y E19 $(94,7 \%)$. En Arragel también domina orilla pero destaca el hecho de que va perdiendo frecuencia relativa a lo largo del romanceamiento a expensas de rostro, término que no emplea ninguna otra biblia: así tenemos orilla (Torá $100 \%$, PA 69,2\%, PP 66,7\%, Ket 42,9\%) junto a rostro (PA 30,8\%, PP $33,3 \%$, Ket $57,1 \%$ ).

Los vocablos empleados en E7-E5 nos presentan una situación más variada y compleja. Por un lado E7-E5 sigue en las partes transmitidas por E7 la tendencia general hacia el empleo de orilla (Torá 68,4\% y PA 46,1\%) junto a otras opciones, en particular ribera (Torá 26,3\%, PA $15,4 \%)$. Al mismo tiempo las partes transmitidas en el códice E5 prefieren ribera con claridad (PP 75\% y Ket 100\%), y desconocen orilla por completo. Cabe señalar, no obstante, que aunque el empleo de ribera en 
E7 alcanza porcentajes más bien bajos, las 5 apariciones en Torá y las 2 de PA (7 en total) representan un número apreciable si tenemos en cuenta que este vocablo no aparece en E3 ni Arragel, y solo presenta un ejemplo en E19, 3 en E4 y 3 en Oxford; quiere ello decir que la presencia de ribera en la Torá y PA de E7 es comparativamente alta, lo cual permite establecer una relación con su uso en PA y Ket de E5. Por último cabe señalar que la Biblia de Oxford también emplea una combinación de orilla y ribera con un $37 \%$ para cada una de estas voces.

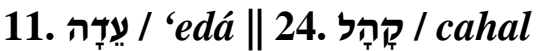

Al presentar estas dos palabras significados semejantes las comentamos juntas para facilitar su comparación. El lema 'edá presenta la siguiente distribución: Torá 115, PA 24, PP 3, Ket 32. La palabra tiene, además de su empleo general con el significado de 'congregación', una segunda acepción 'testimonio' o 'testigo' que no vamos a considerar. También hay que advertir que tiene muy pocas ocurrencias en PP por lo que los datos de esa sección no serán tan informativos de las tendencias de los traductores. Los equivalentes romances de esta palabra son compa$\tilde{n} a$, gente, concejo, entre otros.

En E3 la palabra dominante es en términos generales compaña. En Torá compaña $(44,4 \%)$ alterna con concejo $(40,9 \%)$, pero en las demás secciones es la opción prácticamente exclusiva (PA 95,4\%, PP 100\%, Ket $100 \%)$.

Al mismo tiempo Arragel presenta una enorme dispersión a la hora de traducir esta palabra sin que se pueda señalar una preferencia clara. En Torá encontramos gente (49\%) y pueblo $(23,6 \%)$ junto a otros ocho vocablos; en PA sinagoga $(30,4 \%)$ y congregacion $(26,1 \%)$ junto a otras cuatro voces diferentes, y en PP y Ket compaña, congregación y gente con uno o dos ejemplos cada uno. Los dos ejemplos registrados en los PP de RAH presentan las mismas opciones (compaña y gente).

Por su parte E4-BNE prefiere gente en todas las secciones (Torá $99,1 \%$, PA $82,6 \%$, PP 66,7\%, Ket 85,7\%), un dato interesante para vincular estos dos manuscritos por ser una opción diferente a la del grueso de los romanceamientos que prefieren compaña.

Por último, compaña es la opción preferida en E5-E7 (Torá 94,5\%, 
PA $80,9 \%$, PP $50 \%$, Ket $78,6 \%$ ) y en los romanceamientos parciales de E19 $(92,2 \%)$ y Oxford $(85,7 \%)$.

El lema cahal aparece con la siguiente distribución: Torá 34, PA 11, PP 21, Ket 57. Es traducido compaña o ayuntamiento principalmente.

Compaña es la opción empleada de forma regular en E19 (82,3\%) y en E3 (Torá 75\%, PA 100\%, PP 85,7\%, Ket 100\%). En la Biblia E7-E5 no hay un comportamiento uniforme: compaña es la opción preferida en las partes transmitidas por E7 (Torá \% 67,6, PA 45,4\%) mientras que encontramos mayor frecuencia de ayuntamiento en E5 (PP 61,9\%, Ket 50,9\%). $\mathrm{Al}$ mismo tiempo ayuntamiento no es completamente desconocido en las partes de E7: ayuntamiento y ayuntado aparecen dos veces cada una en Torá (11,2\% colectivamente) y una sola vez en PA mientras que compaña aparece de manera desigual en las partes de E5: una vez en PP pero 14 $(24,6 \%)$ en Ket.

Tampoco E4-BNE ofrecen resultados completamente regulares: la Torá prefiere pueblo $(44,1 \%)$ seguida de ayuntamiento $(29,4 \%$ o $35,3 \%$ si añadimos los dos casos de ayuntado) mientras que el resto de las secciones prefieren concilio (PA 63,6\%, PP 47,6\% o 66,7\% si le añadimos los casos de concejo, Ket 97,9\%). Esta distribución parece seguir la tendencia ya vista en otros casos en que Torá presenta una opción diferente al resto del romanceamiento, pues pueblo solamente aparece tres veces fuera del Pentateuco (dos veces en PA y una en Ket) y ayuntamiento tres veces en Ket.

Al igual que sucedía con 'edá la Biblia de Arragel presenta también una gran dispersión: por un lado presenta un alto número de lexías diferentes empleadas para traducir la palabra hebrea y al mismo tiempo tendencias diferentes en cada sección: en Torá predominan colación $(35,3 \%)$ y gente $(20,6 \%)$, en PA egleja $(27,3 \%)$, congregación $(18,2 \%)$ y sinagoga $(18,2 \%)$, en PP congregación $(23,8 \%)$ y gente $(23,8 \%)$ y en Ket gente $(54,2 \%)$ y república $(18,7 \%)$. En este caso no podemos detectar una afinidad con RAH, que presenta solamente tres ejemplos en la sección relevante y prefiere concilio (2 veces) y gente (una vez).

Por último hay que resaltar en Oxford una solución original, cabildo (50\%), que apenas se registra en los demás romanceamientos, junto a ayuntamiento $(30 \%)$ y compaña $(20 \%)$ que sí tienen presencia en las traducciones estudiadas. 


\section{2. זָָּ / zébah}

Se distribuye de la siguiente forma: Torá 72, PA 31, PP 30 y Ket 29 . No hay prácticamente variación entre las versiones, que prefieren $s a$ crificio entre el $90 \%$ y el $100 \%$ de las ocasiones. A pesar de la escasa variación, se ha optado por mantener el análisis de este lema porque se muestran dos fenómenos destacables que arrojan cierta luz sobre la posible autoría única de E3 y sobre la relación entre el códice de RAH y la Biblia de Arragel:

1) Mientras que en $P P$, las demás versiones muestran alguna variación importante en los porcentajes (E5 50\%, E4 75\%, RAH 76,9\%, Arragel 66,6\%) y ofrecen otros términos alternativos (presente, ofrenda, degoll-, etc.), E3 se mantiene consistente y ofrece sacrificio en el 96,6\% de los casos.

2) Hay una coincidencia muy significativa entre RAH (1 ocurrencia) y Arragel (4 casos) en el uso del infrecuente término degolleo ${ }^{21}$ en lugar de los más generales «degollamiento»o «degollación».

\section{3. רาำ / guibor}

Se distribuye de la siguiente manera: Torá 5, PA 38, PP 48, Ket 69. La variación en las versiones es mínima, ya que prácticamente todas las traducciones ofrecen de forma casi exclusiva el término tradicional barragán para traducir guibor $^{22}$ junto a otras opciones que las versiones usan en porcentajes residuales: fuerte, valiente, poderoso, rezio, etc. Frente a esta ten-

\footnotetext{
${ }^{21}$ Degolleo es un derivado desconocido en castellano medieval. Arragel lo usa 7 veces pero solamente en Isaías, Jeremías, Ezequiel (aquí como lectura alternativa a carnecería) y en Proverbios. RAH lo usa 4 veces en Isaías y Jeremías. Corominas y Pascual no lo documenta y en CORDE no aparece ni un solo ejemplo, a excepción de los de la Biblia de Ferrara de 1553, que lo usa abundantemente y los del Libro de Oraciones también de Ferrara de 1552, ambos en judeoespañol en letras latinas. También es habitual en otras biblias sefardíes, y en judeoespañol pervive en diversas formas como término especializado, para la šejitá o sacrificio ritual (véase NeHAMA s.v. DEGOYAR y derivados).

${ }^{22}$ E3 oscila entre el $80 \%$ y 95\% según las partes. E19 lo usa el 100\% de las ocasiones, E7 lo usa el $50 \%$ en la Torá, en competencia con caçador (50\%) y un 78,9\% en PA. E5 oscila entre el $91 \%$ y el $95 \%$. RAH lo usa un 50\% de las ocasiones en competencia con fuerte $(32,1 \%)$, al igual que Arragel que usa barragán el 72,9\% también en competencia con fuerte $(16,6 \%)$, y que Oxford: barragán $(74,1 \%)$ / fuerte $(12,9 \%)$. Es término de origen incierto y que desapareció en español, pero su uso tanto en las biblias medievales como en las biblias sefardíes propició su pervivencia en judeoespañol (véase CoROMINAS y Pascual s.v. BarRagán I).
} 
dencia, E4 y BNE coinciden en usar mayoritariamente dos cultismos poco comunes en la época: potente y estrenuo. Si bien podría postularse como casual el uso coincidente de potente, sin embargo, los porcentajes de uso son tan elevados en contraste con el resto de los testimonios que sugieren una relación familiar en el tipo de traducción. E4 usa potente de la siguiente manera: Torá (40\%), PA $(78,9 \%)$, Ket $(80 \%)$, mientras que BNE arroja los siguientes porcentajes: PP (85,4\%), Ket $(90,6 \%)$. Su uso, además, no parece motivado por la traducción de la Vulgata, ya que esta última -aunque también traduce guibor en 28 ocasiones con las diferentes formas de potens - prefiere las formas de fortes (102 ocasiones), cuyos derivados castellanos son al mismo tiempo ignorados sistemáticamente por E4 y BNE.

Por otro lado, el uso de estrenuo en ambos códices es todavía más significativo. No es desconocido en otras obras, pero ciertamente no es una forma ampliamente difundida en castellano ${ }^{23}$. No podemos atribuir tampoco su uso coincidente a la Vulgata, ya que en esta aparece solamente una vez (Éx 18:25, «et electis viris strenuis», que por su parte E4 traduce ad locum como «omnes cabdalosos»). En los casos en los que E4 y BNE usan estrenuo / estrenuos (y en general para traducir guibor), la Vulgata ofrece formas de robustus, de fortes o de potens.

\section{4. צִ̣ / safón}

Este término tiene la siguiente distribución en la Biblia hebrea: Torá 16, PA 33, PP 83, Ket 22.

En E3 domina meredión en todas las secciones (Torá 62,5\%, PA $100 \%$, PP 96,4\%, Ket 100\%); en Arragel la opción predominante es aquilón (PA 61,6\%, PP 98,8\%, Ket 89,5\%) en común con RAH (97,3\%) con la excepción de la Torá, donde encontramos 37,5\% aquilón y 37,5\% poniente. E5 y E7 utilizan una solución original que consiste en dejar el término sin traducir en tres de las partes: çafón (Torá 60\%, PP 91,6\%, Ket 90,9\%). En PA el término que domina es setentrión (71,9\%), pero çafón,

\footnotetext{
${ }^{23}$ Corominas y Pascual (s.v. Estrena) lo documenta por primera vez en la obra del Marqués de Santillana: "Estrenuo 'fuerte, valeroso' [...], tomado del lat. strenuus 'diligente, activo', 'enérgico'". CORDE ofrece documentación anterior, ya en el s. XIV, en 8 obras anteriores a los códices E4 y BNE; su difusión posterior fue también muy limitada, no llegando más allá de mediados del s. XVI.
} 
que no es empleado en ningún otro romanceamiento, aparece aquí dos veces $(6,25 \%)$. Otra coincidencia llamativa que relaciona los PA de E7 con las partes transmitidas por E5 en lo que respecta a la traducción de la palabra que nos ocupa es el empleo de occidente, desconocido en los demás romanceamientos, una vez en PA y cuatro veces en PP.

E4 y BNE por su lado prefieren setentrión o el derivado setentrional (Torá 93,3\%, PA 93,9\%, PP 100\%, Ket 100\%), opción que también sigue Oxford $(85,7 \%)$. Por último E19 usa cierço $(86,7 \%)$.

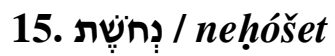

Neḥóšet se distribuye en la Biblia de la siguiente manera: Torá 48, PA 38, PP 25, Ket 28. Su significado principal refiere a un tipo de metal o aleación y las traducciones muestran diversas opciones: cobre, latón, alambre, azero, estaño, fierro. También se usa para referirse a objetos típicamente construidos con dicho metal, particularmente a los empleados para retener a los presos (las diferentes traducciones emplean los siguientes: cadena, grafio, armella, prisión, fierros, cárcel).

E3 emplea cobre o latón indistintamente, aunque en diferentes distribuciones según las partes de la Biblia. En la Torá cobre es prácticamente la única: $95,8 \%$ frente al 4,1\% de latón. En PA ambas formas se usan exactamente igual (45,9\% cada una) y en PP latón se emplea ligeramente más: $40 \%$ frente a $36 \%$ de cobre (en esta parte aparece estaño en un $4 \%$ de los casos). En Ket latón $(59,2 \%)$ es claramente la principal opción frente a cobre $(29,6 \%)$. Cuando el lema se refiere a un objeto construido en metal, E3 ofrece solamente una lectura: cadena: PA $(8,1 \%), \operatorname{PP}(8 \%)$ y Ket $(7,4 \%)$.

Arragel prefiere cobre como primera opción: Torá (62,5\%), PA $(73,7 \%)$, PP (72\%), Ket $(64,3 \%)$, si bien para la segunda opción muestra predilección por fierro: PA 15,8\%, PP 12\%, aunque no en la Torá en la que prefiere arambre (25\%) y luego fierro $(6,2 \%)$. Prácticamente el mismo patrón usa RAH en los PP: cobre $(86 \%)$, fierro $(11,1 \%)$.

E7 y E5 coinciden de nuevo en el uso de un número más elevado de opciones. Ambos códices prefieren principalmente el término arambre para expresar el significado del lema hebreo: E7 Torá 95,7\%, PA 34,2\% y E5 PP 44\%, Ket 35,7\%. Como segunda opción, E7 en PA prefiere latón $(31,6 \%)$ seguido de azero $(15,8 \%)$, mientras que E5 muestra más variedad: azero (PP 20\%, Ket 3,8\%), cobre (PP 20\%, Ket 20\%), latón (PP 8\%, 
Ket 14,3\%). Cuando el lema se refiere a un objeto, E7 y E5 coinciden en el término prisión/prisiones (PA 2,6\%, PP 4\%, Ket 3,8\%), pero también discrepan en otras partes: E7 usa armella en la Torá y E5 usa cadena, aunque son tan pocos los ejemplos que no pueden extraerse conclusiones, ni de las coincidencias ni de las discrepancias, sobre todo teniendo en cuenta que ambos códices se caracterizan por un uso más variado de los términos castellanos que el resto de las versiones.

E4 y BNE coinciden de nuevo en el uso del par cobrelazero como opciones principales. E4 en la Torá muestra de forma preeminente cobre $(97,7 \%)$ y residualmente azero $(2,1 \%)$; en PA, de forma semejante, presenta cobre $(73,7 \%)$ y azero $(18,42 \%)$; y en Ket el único caso que aparece es cobre. BNE, por su parte, presenta las siguientes distribuciones: en PP cobre un 76\%, azero un $8 \%$ y arambre también en un $8 \%$ de las ocasiones. En Ket, al igual que E4, BNE solamente ofrece cobre $(85,7 \%)$ y residualmente azero $(3,6 \%)$.

Por otro lado E19 se decanta exclusivamente por alambre $(93,6 \%)$ al igual que E7. Oxford, en la misma línea, se divide entre arambre (63\%) y cobre $(22,2 \%)$.

\section{6. יָמִּין / yamín}

No muestra casi variación, de hecho casi siempre se traduce como diestra o derecha. Sin embargo, sí resulta significativa la distribución de ambas opciones: mientras que en E3, E19, E7/E5, Arragel y Oxford diestra es la mayoritaria con gran diferencia, en E4 (Torá y PA) y en $\mathrm{BNE}(\mathrm{PP})$ ocurre el caso contrario, es decir, derecha es la opción preferida también con gran diferencia ${ }^{24}$. Además, el uso relativamente alto del infrecuente manderecha ${ }^{25}$ en E4 y BNE -exclusivo y común en todas las

\footnotetext{
${ }^{24} \mathrm{E} 3:$ diestra $(70,6 \%) /$ derecha $(21 \%)$; E19: diestra (53,6\%) / derecha (30\%); E7: diestra (56\%) / derecha (31\%); E5: diestra (85\%) / derecha (5,5\%); RAH: diestra (75\%) / derecha (25\%); Arragel: diestra (50,9\%) / derecha (28,7\%); Oxford: diestra (95\%) / derecha (4,3\%). Sin embargo en E4 tenemos: diestra (26\%) / derecha $(63 \%)$ y en los Profetas de BNE: diestra $(17,4 \%) /$ derecha $(82,6 \%)$.

${ }^{25}$ Una búsqueda en Biblia Medieval revela que, en la acepción adverbial, manderecha es palabra exclusiva de las partes de E4 que estamos considerando (Pentateuco, PA y Ket), de BNE (Profetas Posteriores y Ket) y del Nuevo Testamento del Marqués de Santillana, traducido por Martín de Lucena. No aparece nunca en ninguna otra de las partes de E4, ni en ningún otro códice bíblico.
} 
partes de ambos códices- resulta muy significativo para postular una posible relación entre ambas traducciones: Torá (20\%), PA (22,2\%), Ket-E4 $(66,7 \%)$, PP-BNE $(26,1 \%)$, Ket-BNE $(9,4 \%)$.

\section{7. כִִִּ / kisé}

Aparece con la siguiente distribución: Torá 4, PA 50, PP 34, Ket 44. No es palabra que presente gran variación; tres son las opciones silla, cátedra y trono. De estas tres opciones silla es la empleada de manera regular en las cuatro partes de E3 (Torá 100\%, PA 100\%, PP 94,1\%, Ket 100\%). Lo mismo podemos decir de E7-E5 (Torá 100\%, PA 94\%, PP $96,9 \%$, Ket 84,8\%). Silla es asimismo la opción empleada en las biblias fragmentarias E19 (75\%) y Oxford $(93,7 \%)$.

Por su parte, E4-BNE prefiere cátedra, pero emplea silla de forma alternativa: en Torá cátedra y silla se reparten al 50\%; en Ket hay un reparto semejante con $57,1 \%$ para cátedra y $42,9 \%$ para silla. En las otras partes cátedra domina de forma más clara (PA 96\%, PP 79,4\%) con presencia minoritaria de silla $(2 \%$ y $20,6 \%)$. El hecho relevante que relaciona a $\mathrm{E} 4$ con $\mathrm{BNE}$ es la alta proporción en el empleo de cátedra, de al menos $50 \%$ en todas las partes, algo que no se da en ningún otro romanceamiento.

El caso de Arragel es algo más complejo pues combina silla, trono y cátedra en diferentes proporciones. En Torá encontramos $75 \%$ silla y $25 \%$ cátedra; en PA trono $56 \%$, cátedra $20 \%$ y silla $20 \%$; en PP silla $64,7 \%$ y trono $32,3 \%$; en Ket silla $51,8 \%$ y trono $37 \%$. RAH también presenta un reparto de formas, con silla $53,6 \%$ y cátedra $46,4 \%$; es llamativa la presencia de cátedra, con 13 apariciones, pues no aparece ni una sola vez en los PP de Arragel, si bien tienen cierta presencia en las otras secciones: una vez en Torá (5\%), 10 en PA (20\%), y 3 en Ket $(11,1 \%)$.

\section{9. נֵַِ / náhal}

El lema hebreo náhal se distribuye de la siguiente manera: Torá 34, PA 44, PA 25 y Ket 31. Las traducciones que se encuentran en las distintas versiones son: arroyo, río, ribera, corriente, orilla, siendo las dos primeras las más usadas. 
Respecto a E3, destaca su clara preferencia por arroyo en todas las partes: Torá 61\%,7 (en competencia con río 20,6\%), PA 86,4\%, PP $100 \%$ y Ket 90,3\%, y el poco (PA 2,3\%) o ningún uso (PP y Ket) que hace de río.

Arragel muestra preferencia por río en tres de las partes: Torá 55,9\%, PP 92\%, Ket 47,8\% y por arroyo en PA: 53,6\% (siendo río la segunda opción con el 43,9\% de los casos). A su vez arroyo es siempre la segunda y prácticamente la única opción adicional en Torá $(38,2 \%)$, PP (8\%) y Ket $(30,4 \%)$. Los PP de RAH muestran la misma preferencia por río $(84,6 \%)$, pero para el resto de los casos usan ribera $(7,7 \%)$ desconociendo completamente arroyo.

E7 y E5 muestran de nuevo un uso peculiar y mutuamente compartido al incorporar como primera, segunda o tercera opción, según las partes, la forma corriente (la cual solamente se encuentra muy residualmente en la Torá de E3). Si en la Torá de E7 el porcentaje es ciertamente bajo (corriente $5,8 \%$ frente a río $52.9 \%$ o arroyo $38,2 \%$ ), en PA sube hasta el $40,8 \%$ pasando a ser la segunda opción, muy cerca de río. En los PP de E5 corriente es también la segunda opción (32\% frente a río 60\%) y en Ket corriente pasa a ser la primera opción con el 58,6\% de los casos frente al $36,7 \%$ de río.

E4 y BNE se caracterizan en el uso exclusivo y bastante equilibrado de río y arroyo, no mostrando ninguno de los dos códices ni una sola opción diferente a estas dos. Torá (río 55,8\% / arroyo 44,1\%), PA (río $69,3 \%$ / arroyo 30,6\%), Ket-E4 (arroyo, 100\%), PP (río 76\% / arroyo $24 \%$ ), Ket-BNE (arroyo 56,6\% / río 43,3\%).

E19 muestra también un uso equilibrado de las formas río $(35,5 \%)$ y arroyo (32,2\%), pero destaca por su uso de ribera en el 32,2\% de los ejemplos, forma que ignoran algunos romanceamientos y que E3, RAH y Arragel usan solo de forma residual. Por su parte Oxford usa río en el $100 \%$ de los casos y desconoce cualquier otra forma.

\section{0. פู / par}

Este lema aparece principalmente en la Torá (92), con menor presencia en las demás secciones: PA 12, PP 17, Ket 12.

La opción dominante e incluso exclusiva en algunas de las versiones es toro. Solamente cabe señalar el empleo de novillo en E5-E7 y de ter- 
nero en Oxford. En efecto, toro es la traducción empleada en E3 (83,7\%, $91,7 \%, 94,1 \%, 100 \%)$ y en Arragel $(100 \%, 100 \%, 88,2 \%, 100 \%)$, que coincide a su vez con RAH (100\%). También coinciden en esta opción E4 $(98,9 \%, 100 \%)$ y BNE $(88,2 \%, 90,9 \%)$ así como E19 $(98,9 \%)$. Por su parte E5 se diferencia de las demás por preferir novillo (PP 88,2\% y Ket 91,7\%). En E7 domina toro, como en la mayoría de los romanceamientos, (Torá 58,7\%, PA 83,3), pero es interesante señalar que emplea también novillo (Torá 32,6\%, PA 16,7\%) opción que fuera de E5 prácticamente no se da en ninguna otra biblia. Por último Oxford también usa una opción que le distingue de los demás romanceamientos (ternero 67\%) con empleo también de novillo $(33,3 \%)$.

\section{1. שמאר] / [ni]š’ar}

Como se explicaba en el apartado de metodología, a pesar de la dificultad de codificar las formas verbales, se ha realizado el análisis de una de ellas para ejemplificar el comportamiento léxico de los romanceamientos medievales respecto a los verbos hebreos. [Ni] š' ar se distribuye en la Biblia de la siguiente forma: Torá 29, PA 49, PP 39 y Ket 16. Presenta las siguientes opciones de traducción en las versiones castellanas: formas de quedar, de dexar, de remanecer, de fincar, de escapar y de sobrar, entre otras menos habituales. La distribución del verbo remanecer / remaner / romanecer es quizá lo más destacable en el análisis, ya que es forma antigua, especializada y característica de las traducciones bíblicas judías ${ }^{26}$.

E3 muestra como opción preferente el genérico quedar (Torá 62,5\%, PA 67,3\%, PP 38,4\%, Ket 75\%), seguido de fincar, remanecer y dexar, los cuales usa en diferentes porcentajes según las partes. Llama la atención el uso relativamente alto de fincar en la Torá $(10,3 \%)$ y en PP $(28,2 \%)$, con una aparición residual en PA (2\%), ya que esta opción es prácticamente ignorada por el resto de los códices (excepto Oxford, que muestra un

\footnotetext{
${ }^{26}$ Es forma antigua que, como muestra CORDE, ya en el s. XV es un arcaísmo difícilmente documentable, a excepción de los textos bíblicos, en los que el arcaísmo se ha especializado desde antiguo (aparece en la Fazienda de Ultramar) y se perpetúa en judeoespañol bíblico con la forma aragonesa en ro-, prácticamente desconocida en castellano (todos los casos de CORDE son fueros aragoneses o textos judeoespañoles, a excepción de un ejemplo en el $\mathrm{Cid}$ ). Véase SEPHIHA p. 515, s.v. ROMANESER y Corominas y PASCUAL, s.v. MANIDO (deriv. MANER).
} 
22,2\%). Remanecer se distribuye homogéneamente en las cuatro partes bíblicas (Torá 10,3\%, PA 10,2\%, PP 10,2\%, Ket 15,5\%) y dexar fluctúa un poco más (Torá 3,4\%, PA 18,4\%, PP 15,4\%, Ket 6,2\%).

Arragel y RAH muestran de nuevo una coincidencia peculiar en el porcentaje de uso de las formas de remanecer, las cuales eclipsan a las demás en los PP de ambos códices y superan ampliamente su uso en cualquier otro códice o parte bíblica. En los PP, Arragel usa remanecer en un $74,3 \%$ de las ocasiones y RAH en un $60,7 \%$. Arragel, en toda la Biblia, muestra porcentajes de uso crecientes para esta forma: en Torá $(13,8 \%)$, en PA $(28,5 \%)$, en PP $(74,3 \%)$ y finalmente en Ket $(87,5 \%)$. El resto de las ocasiones, tanto Arragel como RAH, usan los genéricos quedar o dexar.

E7 y E5 muestran menos variación en el uso verbal que en los sustantivos que se han ido analizando. Ambos muestran clara preferencia por los genéricos quedarldexar, aunque en la Torá E7 relega dexar al cuarto puesto incorporando formas de sobrar (10,7\%) como tercera opción. El tratamiento de remanecer es peculiar en E7, ya que lo ignora en PA mientras que en la Torá lo prefiere como segunda opción (25\%) frente a los otros. E5 sigue la línea de E7 y prefiere remanecer como segunda opción en PP $(12,82 \%)$ y como tercera en Ket $(6,25 \%)$.

E4 y BNE vuelven a mostrar un comportamiento coincidente que aleja a ambos códices del tratamiento que los demás traductores dan a [ni] $s^{\prime} a r$. Los dos códices muestran un rechazo absoluto a las formas del arcaísmo remanecer. No se encuentra ni un solo caso del tradicional verbo en ninguna de las tres partes de E4, ni en los PP y Ket de BNE. E4 prefiere las formas de quedar/dexar tanto en la Torá (69\% / 10,3\%) como en los PA $(77,5 \% / 18,4 \%)$ y en los Ket $(75 \% / 12,5 \%)$. De forma coincidente, BNE sigue las mismas opciones: PP (82\% / 17,9\%) y Ket (quedar $100 \%)$.

E19 y Oxford muestran una clara preferencia por las formas de remanecer: $55,5 \%$ y $40,7 \%$, respectivamente.

\section{2. ח / hoc}

No presenta prácticamente variación, ya que en todas las versiones y en todas las partes bíblicas se traduce principalmente como fuero, seguido a mucha distancia por otras opciones minoritarias como costumbre. La única versión que se desvía de esta elección es la de Oxford, que ignora 
fuero completamente sustituyéndolo por establecimiento en el 77,8\% de las ocasiones y por costumbre en el 11,1\%. A su vez establecimiento, como traducción de hoc, es completamente desconocido para las demás versiones, que no lo usan en ninguna ocasión ${ }^{27}$.

\section{3. ño / kóah}

Este lema, con el significado de 'fuerza', tiene la siguiente distribución: Torá 14, PA 18, PP 24, Ket 71. Los romanceamientos emplean sobre todo fuerça y en menor medida derivados (fortaleza, esfuerço). Otras opciones son palabras de la familia de poder (poder, poderío, potencia) así como virtud.

La opción dominante a lo largo de prácticamente todos los romanceamientos es fuerça, con la única excepción de Oxford, que prefiere fortaleza $(66,7 \%)$ antes que fuerça $(26,7 \%)$.

E3 emplea fuerça de manera regular (Torá 92,9\%, PA 100\%, PP 95,8\%, Ket 100\%), al igual que E19 (76,9\%), Arragel (Torá 57,1\%, PA $83,3 \%$, PP 83,3\%, Ket 75,9\%) y E5-E7 (Torá 61,5\%, PA 70,6\%, PP $66,7 \%$, Ket 52,9\%). Esa preferencia es menos acusada en secciones de E4-BNE (Torá 50\%, PA 94,4\%, PP 50\%, Ket 50,7\%) que también emplea potencia en PP $(37,7 \%)$ y Ket $(31,3 \%)$; no encontramos potencia en Torá ni en PA.

\section{5. רבּּ / bejor}

Este lema, con el significado de 'primogénito', se distribuye del siguiente modo: Torá 72, PA 8, PP 4, Ket 35. Las traducciones emplean básicamente dos opciones: el patrimonial mayor (y sus derivados: mayoral, mayoría, etc.) o compuestos cultos del tipo primogénito, primero génito, primo engendrado. En un pequeño número de casos hay además palabras de la familia de primero (primado, primerizo, primicia, etc).

\footnotetext{
${ }^{27}$ Una búsqueda en Biblia Medieval muestra que la forma establecimiento no pertenece en ninguno de sus significados a la tradición judía, con 4 ejemplos en E7 (con el significado de 'estatua') y un único ejemplo en E5 (con el significado de 'permanencia'). Sí encontramos ejemplos en las biblias traducidas del latín (en E6/E8, en General Estoria, en los libros deuterocanónicos de E4/BNE y en los Salmos de Arragel, probablemente también traducidos del latín).
} 
En E3 predomina mayor y derivados. En Torá es la opción más usada $(55,5 \%)$ alternando con derivados de primero $(33 \%)$. En PA (100\%) y PP $(75 \%)$ es claramente preponderante y sin ser mayoría presenta un porcentaje sustancial en Ket $(42,9 \%)$, por detrás del cultismo primogénito $(57,1 \%)$, el cual tiene cierta presencia en otras secciones (Torá 9,7\%; PP 25\%). También en E19 mayor predomina con claridad (84\%).

En el resto de versiones predominan las variantes de primogénito: en E4-BNE este predominio es más acentuado (Torá 97,2\%, PA 100\%, PP 100\%, Ket 94,1\%) como también lo es en Arragel (Torá 81,9\%, PA 77,8\%, PP 75\%, Ket 100\%). En E5-E7 primogénito es en general la opción preferida (Torá $63,4 \%$, PA $22,2 \%$, PP 75\%, Ket 62,9\%) con la excepción de PA donde también se emplea mayor $(44,4 \%)$ y primero $(22,2 \%)$. Caso aparte es la Biblia de Oxford que emplea, junto a primogénito, un compuesto no visto en ningún otro romanceamiento: primo engendrado (60\%).

\section{6. תנוֹעָדָ / to 'ebá}

To 'ebá se distribuye en las cuatro partes de la Biblia de la siguiente manera: Torá 27, PA 5, PP 55 y Ket 31. Las formas principales sobre las que los traductores realizan su elección son, por un lado, los derivados de aborrecer o de aborrir (aborrecimiento, aborrecido, aborrimiento, aborrición, etc.), y por el otro, los derivados de abominar (abominación, abominable, etc.), aunque hay otras opciones que aparecen residualmente: falsedad, maldad, enconamiento, etc.

E3 utiliza exclusivamente las formas de aborrecer (aborrecimiento, aborrecido, aborreciones, aborrecencia, aborrecido, etc.) y solamente se desvía ligeramente de su propia norma en los PP, en donde -aunque utiliza mayoritariamente las formas de aborrecer $(76,4 \%)$ también incorpora maldad (10,9\%) y enconamiento (7,2\%). En los Ket muestra también la forma maldad en el 6,4\% de los casos.

Arragel y RAH prefieren el cultismo abominación en PA (100\%), PP (Arragel 96,3\% / RAH 100\%) y Ket (66,6\%), aunque en la Torá, Arragel muestra predilección, al igual que E3, por las varias formas de aborrecer y de sus derivados (aborrida, aborrimiento, aborrecencia, aborrecimiento, aborrición) que todas juntas suman un $59,2 \%$ de los casos frente al 33,3\% de abominación. 
Es muy significativa de nuevo la variación compartida entre E7 y E5. Además de las formas de aborrecer que ambos presentan como mayoritarias (E7: Torá 55,5\% / PP 60\%; E5: PP 78,18\% / Ket 90,33\%), los dos códices coinciden en el uso de numerosas opciones minoritarias: heregía (en Torá y PP), creencia (en Torá, PA y Ket) maldad (en Torá y PP) y falsedad (en Torá, y PP). Aunque también muestran otros sinónimos residuales que no comparten: en E7 encontramos contrario, enconamiento e ídolo y en E5 enemigança, perjuizio y traición.

Al igual que Arragel y RAH, destaca la coincidencia de E4 y BNE en su preferencia casi exclusiva hacia el cultismo abominación ${ }^{28}$ en todas las partes de la Biblia. E4 lo muestra en la Torá el 88,9\% de las ocasiones y tanto en PA como en Ket aparece el cultismo de forma exclusiva. De forma coincidente, BNE lo presenta en los PP el $92,7 \%$ de las ocasiones y en los Ket el $100 \%$. Solamente se encuentran casos de aborrecimiento en la Torá $(11,1 \%)$.

E19 presenta exclusivamente formas de aborrecer: aborrición, aborrecer, aborrida. Oxford de nuevo se destaca del resto de las traducciones con la forma enconamiento ${ }^{29}$ que solamente usaban, como se ha observado antes, E3 en los PP y E7 en los PA (y ambos en un porcentaje muy bajo).

\section{7. שֶׁק / šéquer}

Este lema, con el significado de 'mentira', tiene las siguientes apariciones: Torá 8, PA 5, PP 54, Ket 46. Los romanceamientos presentan bá-

\footnotetext{
${ }^{28}$ De nuevo hay que destacar su aparición en el Nuevo Testamento de Lucena, en donde aparece en nueve ocasiones. En Arragel su uso asciende a 99 ocurrencias, combinando las partes de E4 en consideración (29) con las de BNE (84) suman 113 ocurrencias. Las formas que hemos documentado son: abhominación, abominación, abuminación.

${ }^{29}$ Enconar, enconado, enconamiento no son formas léxicas desconocidas en las biblias judías que estamos analizando. Normalmente no se usa como traducción del lema analizado, sino de טמא/טָמֵא, con el sentido ritual de 'volverse o ser impuro'. De hecho se usa frecuentemente en todas las biblias traducidas del hebreo para dichos lemas, pero nunca en las traducidas del latín. Es igualmente habitual en la tradición bíblica sefardí (por ejemplo, en la Biblia de Ferrara se emplea siempre en las más de 200 ocasiones que aparecen dichos lemas en la Biblia).
} 
sicamente dos opciones: bien derivados de falso (falso, falsedad, falsía) o de mentira (mentira, mentir, mentiroso); para simplificar los resultados sumaremos los derivados de cada una de estas raíces. Hay otras opciones usadas puntualmente (engaño, traición, balde) pero en proporciones muy pequeñas.

Varios son los romanceamientos que prefieren falsedad junto a otras palabras de la familia de falso, como es el caso de E3 (Torá 87,5\%, PA $60 \%$, PP 96,3\%, Ket 97,8\%), E19 (87,5\%), Oxford (60\%). En E7-E5 predomina la familia de falso (Torá $50 \%$, PA 60\%, PP 81,5\%, Ket $80 \%$ ) pero como es habitual en este romanceamiento en combinación con un amplio número de lexías (engaño, balde, traición, mentira, vanidad, maldad). Por el contrario todas las secciones de E4-BNE prefieren mentira o palabras de la misma familia claramente: Torá $100 \%$, PA $80 \%$, PP 96,3\%, Ket 97,8\%. La traducción de Arragel se reparte entre las dos opciones: también emplea la familia de falso, que es dominante en las dos primeras secciones (Torá 100\%, PA 75\%, PP 20,4\%, Ket 40,9\%) y por otro lado la familia de mentira que predomina en la dos últimas (PP 79,6\%, Ket 54,5\%). La distribución de los PP de Arragel, con dominio de mentira en combinación con falsedad se da también en RAH: mentira $(64,4 \%)$, falsedad $(35,6 \%)$.

\section{8. כָּבֶ / kebes}

No aparece en los PA, en el resto de la Biblia se distribuye así: Torá 87, PP 12, Ket 8. Es traducido como cordero o carnero. En E3 la opción es carnero (Torá 86,2\%, PA 75\%, Ket 87,5\%). Lo mismo sucede con E7-E5 (Torá 97,7\%, PA 83,3\%, Ket 100\%) y E4-BNE, con $100 \%$ en todas las partes. La Torá de E19 también prefiere carnero $(97,7 \%)$.

Por el contrario Arragel prefiere cordero aunque también emplee carnero con cierta frecuencia. En Torá tenemos $61,5 \%$ de cordero pero $33,8 \%$ de carnero, en PP 58,3\% y $25 \%$ respectivamente, y de nuevo en Ket $75 \%$ de cordero. En este caso RAH se distancia de Arragel y sigue la tendencia de la mayoría de los romanceamientos, con $75 \%$ carnero y $25 \%$ de cordero, pero teniendo en cuenta que solamente hay 4 ocurrencias de la palabra en este romanceamiento. 


\section{ANÁlISIS POR CÓDICES}

Una vez analizadas las opciones léxicas presentes en los códices para cada lema hebreo estudiado estamos en condiciones de proponer el inventario de traducciones contenidas en los romanceamientos castellanos hechos a partir del hebreo: la Biblia completa de E3, el Pentateuco de E19, la Biblia completa que supone la combinación de la traducción contenida en los códices E7 y E5, la Biblia completa que denominamos Biblia del Marqués de Santillana (y que es una combinación de partes del códice de E4 y del códice completo de BNE), la Biblia de Arragel y los Profetas Anteriores contenidos en el códice de Oxford. En las páginas que siguen exponemos las características principales de cada uno de estos romanceamiento a partir de los datos léxicos analizados.

\subsection{Una biblia tradicional judía para cristianos: Escorial I.i.3}

Diversos autores han postulado que la traducción bíblica contenida en el manuscrito E3 supone una única traducción del texto canónico judío (Llamas 1944: 220-222, 1953: 302-307 o Morreale 1960: 86-87, 94-95). Lazar (1995a: xliii-xliv) aporta algunos detalles lingüísticos, y asume una traducción unitaria «by the use of some specific linguistic features and, also, by a number of idiosincratic errors». Hay que exceptuar, desde luego, los dos libros de los Macabeos, clara adición tanto al proyecto codicológico como al proyecto intelectual del resto de la traducción (Avenoza 2011a: 136, 143-146). La presencia de disposiciones propias del texto hebreo original, como es la división de la Torá en perícopas semanales o parašiyot, o la presentación en forma de verso del cap. 15 del Éxodo, así como la adecuación del orden de los libros al canon judío, ha hecho pensar que la traducción de E3 era la más cercana a una tradición judía de traducción (Sachs 1948-49, Lazar 1995a:xix).

Igualmente, al cotejar el estilo de traducción de E3 con los ladinamientos sefardíes se ha destacado en numerosas ocasiones (Amigo Espada 1983, Hauptmann 1953: 15-50, Lazar 1994, 1995a: xli, 1995b, 2000: xvi-xxx, Pueyo Mena 2008, 2011, 2012) que, entre los romanceamientos medievales, E3 es el más cercano a la tradición sefardí, tradición que se plasmaría en papel en los ladinamientos impresos de los siglos XVI al 
XIX. Tanto es así que Lazar (1995a), en la portada de su edición de E3, decidió usar el apelativo Biblia ladinada, en lugar de Biblia medieval romanceada. Aunque podría postularse que ambas cosas significan esencialmente lo mismo, es decir, «Biblia traducida a una lengua romance», el uso del término ladinamiento implicaría la adhesión completa de E3 al método sefardí de traducción, lo cual, como veremos, es cierto de forma solo parcial, ya que aún cumpliéndose algunos de los requisitos del método (orden de palabras, cohesión textual, traducción de los tiempos y conjugaciones verbales del hebreo mediante correspondencias romances limitadas, etc.), se llevan a cabo de forma mucho más contenida que en las versiones sefardíes, teniendo siempre en cuenta al público cristiano al que se dirige, que presumiblemente desconocía el hebreo ${ }^{30}$.

En este trabajo no solo hemos mostrado que la traducción completa de la Biblia que contiene el códice I.i.3 se debe a un único traductor, o al menos a una única tradición léxica, sino que, en su método de traducción, E3 supone también el testimonio más cercano al método tradicional de traducción hispano-judío (véase Bunis 1996, Hassán 2004 y Pueyo Mena 2008), ya que cumple fielmente uno de los requisitos más destacables de dicho método: la estricta coherencia léxica a lo largo de toda la Biblia en la elección de los mismos equivalentes romances para cada lema hebreo, requisito que supone dejar de lado el embellecimiento estilístico del texto con sinónimos o matices semánticos, que solo serán aceptables siempre que haya una interpretación tradicional o exegética que así lo demande.

La Tabla 3 resume, en lo tocante a E3, el análisis de cada lema hebreo realizado a lo largo de este trabajo. Se muestra de forma evidente la citada coherencia interna en las elecciones léxicas realizadas por su traductor para todas las partes del códice.

Del carácter marcadamente tradicional de E3 da cuenta el hecho de que, si bien la combinación de variantes léxicas que presenta es singular, y la coherencia interna en la elección de las mismas es mayor que la que encontramos en los demás romanceamientos, no emplea, sin embargo, ninguna variante léxica que no sea conocida por algún otro de los romanceamientos. Este dato es interesante porque, como se verá, las demás traducciones sí

${ }^{30}$ Para otra pespectiva sobre la relación entre las traducciones judeo-españolas postExpulsión y los romanceamientos medievales, véanse ScHWARzWALD 2010 y 2012, en donde se discute la naturaleza judía de las traducciones medievales. 
muestran «impronta de autor», en el sentido de que hay algunas opciones que son exclusivas de una de ellas en particular, y que en muchos casos suponen neologismos recién introducidos en la lengua del siglo XV.

\begin{tabular}{|c|c|c|c|c|}
\hline \multicolumn{5}{|c|}{$\begin{array}{l}\text { TABLA 3: COMPARACIÓN DE TODAS LAS PARTES BÍBLICAS CONTENIDAS } \\
\text { EN EL CÓDICE E3 }\end{array}$} \\
\hline Lema & Torá & $\begin{array}{l}\text { Profetas } \\
\text { Anteriores }\end{array}$ & $\begin{array}{l}\text { Profetas } \\
\text { Posteriores }\end{array}$ & Ketubim \\
\hline 1. $\hat{s} a b a$ & fonsado / hueste & fonsado & $\begin{array}{l}\text { fonsado / } \\
\text { compaña }\end{array}$ & guerra / compaña \\
\hline 2. $s a r$ & mayoral & mayoral & mayoral & mayoral \\
\hline 18. nasí & mayoral & mayoral & mayoral & mayoral \\
\hline 3. 'olá & alsación & alsación & alsación & alsación \\
\hline 4. maté & vara & vara & vara & vara \\
\hline 9. šébet & vara & vara & vara & vara \\
\hline 5. bégued & ropa / paño & ropa / paño & ropa / paño & ropa / paño \\
\hline 6. šemen & azeite & azeite & azeite & azeite \\
\hline 7. behemá & $\begin{array}{l}\text { bestia / } \\
\text { cuatropea }\end{array}$ & bestia & bestia & bestia \\
\hline 8. miŝvá & mandamiento & mandamiento & mandamiento & mandamiento \\
\hline 10. safá & $\begin{array}{l}\text { orilla } \mid \text { beço } \mid \\
\text { fabla }\end{array}$ & $\begin{array}{l}\text { orilla } \mid \text { beço } \mid \\
\text { fabla }\end{array}$ & $\begin{array}{l}\text { orilla } \mid \text { beço } \mid \\
\text { fabla }\end{array}$ & $\begin{array}{l}\text { orilla } \mid \text { beço } \mid \\
\text { fabla }\end{array}$ \\
\hline 11. 'edá & $\begin{array}{l}\text { compaña / } \\
\text { concejo }\end{array}$ & compaña & compaña & compaña \\
\hline 24. cahal & compaña & compaña & compaña & compaña \\
\hline 12. zébah & sacrificio & sacrificio & sacrificio & sacrificio \\
\hline 13. guibor & barragán & barragán & barragán & barragán \\
\hline 14. safón & meridión & meridión & meridión & meridión \\
\hline 15. nehóšet & cobre / latón & cobre / latón & latón / cobre & latón / cobre \\
\hline 16. yamín & diestra / derecha & diestra / derecha & derecha / diestra & diestra / derecha \\
\hline 17. kisé & silla & silla & silla & silla \\
\hline 19. náhal & arroyo / río & arroyo / río & arroyo & arroyo \\
\hline 20. par & toro & toro & toro & toro \\
\hline 21. [ni] š'ar & $\begin{array}{l}\text { quedar / fincar / } \\
\text { remanecer }\end{array}$ & $\begin{array}{l}\text { quedar / dexar / } \\
\text { remanecer }\end{array}$ & $\begin{array}{l}\text { quedar / fincar / } \\
\text { remanecer }\end{array}$ & $\begin{array}{l}\text { quedar / dexar / } \\
\text { remanecer }\end{array}$ \\
\hline 22. hoc & fuero & fuero & fuero & fuero \\
\hline 23. kóah & fuerça & fuerça & fuerça & fuerça \\
\hline 25. bejor & $\begin{array}{l}\text { mayor / primero } \\
\text { / primogénito }\end{array}$ & mayor & $\begin{array}{l}\text { mayor / } \\
\text { primogénito }\end{array}$ & $\begin{array}{l}\text { primogénito / } \\
\text { mayor }\end{array}$ \\
\hline
\end{tabular}


TABLA 3: COMPARACIÓN DE TODAS LAS PARTES BíBLICAS CONTENIDAS EN EL CÓDICE E3

\begin{tabular}{|l|l|l|l|l|}
\hline Lema & Torá & $\begin{array}{l}\text { Profetas } \\
\text { Anteriores }\end{array}$ & $\begin{array}{l}\text { Profetas } \\
\text { Posteriores }\end{array}$ & Ketubim \\
\hline 26. to'ebá & $\begin{array}{l}\text { deriv. de } \\
\text { aborrecer }\end{array}$ & $\begin{array}{l}\text { deriv. de } \\
\text { aborrecer }\end{array}$ & $\begin{array}{l}\text { deriv. de } \\
\text { aborrecer }\end{array}$ & $\begin{array}{l}\text { deriv. de } \\
\text { aborrecer }\end{array}$ \\
\hline 27. śéquer & falsedad & falsedad & falsedad & falsedad \\
\hline 28. kebes & carnero & carnero & carnero & carnero \\
\hline
\end{tabular}

Además de su preservación en el códice escurialense I.i.3, otros fragmentos de esta traducción se han conservado en diferentes copias en otros manuscritos: el códice Ajuda 52-xii-1 (Pentateuco, Josué y Jueces), un bifolio del ms. 167 del Archivo de la Catedral de Córdoba (Salmos 6567 y 105-108), además de los citados Samuel I-II y Reyes I-II del códice I.ii.19. Todos estos testimonios, destinados a cristianos, nos hablan de un texto de origen judío, muy apegado a la tradición bíblica comunitaria, que hubo de tener una cierta difusión entre lectores cristianos durante la Edad Media.

\subsection{Una Torá exenta: Escorial I.ii.19}

Como se ha indicado en el apartado sobre metodología, el códice Escorial I.ii.19 es un compendio de varios proyectos de traducción dispares. Mientras que Josué y Jueces son copia de la traducción de la familia de E7, tanto Samuel I-II como Reyes I-II son una copia de algún modelo de la misma traducción que encontramos en E3. Desde el punto de vista de la codicología, Avenoza (2011a: 87-89) confirma que existen dos proyectos iconográficos en el códice I.ii.19: uno para el Pentateuco, y otro bien diferenciado para el resto de los libros. La existencia de dos proyectos iconográficos claramente distinguibles en el códice, sugiere también dos modelos de copia de diferente factura y origen, uno para la Torá y el otro para el resto.

El Pentateuco, además, presenta características peculiares que lo alejan en cierta manera de la traducción más tradicional de E3, pero también de las más innovadoras, como E4/BNE o Arragel. Llamas (1949: 53-74), Amigo Espada (1983: 236) y Littlefield (1992: xx) han llamado la aten- 
ción sobre el uso más o menos sistemático del Targum Onquelos para la traducción de la Torá de E19.

Como complemento a las observaciones codicológicas y exegéticas, nuestro análisis léxico parece confirmar tres hechos destacables:

1) Aunque no se ha realizado un análisis individual de cada libro, E19 muestra siempre una única lectura mayoritaria (en porcentajes que se acercan casi siempre al 90\%) para cada lema hebreo. La ausencia de variación interna sugiere la existencia de un único traductor para los cinco libros del Pentateuco.

2) El traductor de E19 muestra cierta independencia en las elecciones léxicas de su traducción. Concretamente se han observado dos tipos de desviaciones particulares del traductor con respecto al resto de los romanceamientos. En primer lugar, el uso exclusivo y constante de un término, desconocido o muy residual para el resto de los traductores: encomienda para traducir miŝvá, cierço para ŝafón o capitán para nasí. En segundo lugar, el uso relativamente alto de algunos lexemas respecto al resto de las traducciones, mostrando además la propia coherencia interna de la Torá de E19 frente al resto de los testimonios, que siempre muestran mayor variación: fonsado para $\hat{s} a b a$ (desconociendo hueste, que es la mayoritaria para el resto, al menos en combinación con la primera), blago para maté, verdugo para šébet, paño en todas las ocasiones de bégued, alambre para nehóšet, remanecer para [ni]š'ar, mayor para bejor, el uso exclusivo de formas de aborrecer (y aborrición prácticamente en exclusiva como término preferido) para to 'ebá o el uso destacado de ribera para náhal.

3) En el resto de los términos analizados, la Torá de E19 se comporta siempre de la misma manera que E3 y, salvando algunas excepciones, que E7 (alsación, cuatropedia, azeite, compaña, diestra, silla, compaña, barragán, fonsado, mayoral) y se aleja siempre de las correspondientes soluciones de los testimonios de E4 y Arragel, mucho más innovadoras (holocausto/holocausta, animalia, olio, gente, derecha, cátedra, pueblo/colación/gente, estrenuo/potente/poderoso, hueste, príncipe/cabdillo/capitán). Lógicamente cuando los traductores de dichas versiones presentan también un término tradicional común, E19 coincide con ellos. 
La visión de conjunto de sus convergencias y divergencias, desde la perspectiva puramente lexicográfica, nos permite clasificar la Torá de E19 como una traducción con un fondo léxico tradicional, aunque con destacables elecciones individuales. Estos usos particulares nos hablan de un traductor diferente al resto de los romanceamientos, aunque sin duda inserto en la tradición común comunitaria que, como hemos señalado arriba, está más fielmente representada en la Edad Media por el testimonio de E3.

El hecho de haber podido aislar la Torá contenida en I.ii.19 como una traducción independiente, tanto del resto de los libros que contiene como del resto de los testimonios conocidos, resulta de particular importancia a la hora de renovar los estudios que se han realizado en el pasado sobre su caracterización linguiística, su datación y su origen geográfico, así como sobre la exégesis utilizada por su traductor.

\subsection{Una traducción interpretativa: E5/E7}

La idea de que los códices E5 y E7 forman un Antiguo Testamento copiado en dos volúmenes fue propuesta por Llamas (1950: xxxviii; 1951: 303304) y seguida por varios autores (Lazar 1994: 356; Morreale 1994: 201) a partir del examen de elementos externos como las semejanzas en el formato, la complementariedad de los libros que contienen, o la observación de que en los dos casos se trata de una traducción hecha por alguien conocedor de la lengua y costumbres de los judíos. Avenoza ha abordado la cuestión a partir de un detallado estudio codicológico (Avenoza 2011a: 111; 2011b) en el que concluye que probablemente estos dos ejemplares tienen origen en un mismo taller, pero sería cada uno de ellos un volumen superviviente de una biblia completa y no dos partes de una misma biblia. Lo que no se ha hecho hasta ahora es un examen sistemático de las opciones del traductor a lo largo de cada uno de estos manuscritos para ver si, más allá de lo que indican los elementos externos, estamos en efecto ante romanceamientos emparentados.

Como se ha podido apreciar en el examen de cada lema estudiado, en E5 y E7 es relativamente más difícil apreciar la continuidad de las opciones léxicas del traductor a lo largo de cada uno de estos manuscritos pues el romanceador casi nunca se adhiere decididamente a un vocablo sino que hace una traducción interpretativa en la que despliega una variación 
léxica bastante más diversificada que la de otras versiones ${ }^{31}$. Consideramos, no obstante, que esta característica, por ser observable de manera consistente a lo largo de los romanceamientos recogidos en cada uno de estos dos manuscritos, es un elemento que apoya el parentesco entre los dos códices, pues indica que comparten un mismo modo de traducir. Además, como veremos a continuación, la variación que hemos indicado no nos impide apreciar globalmente una consistencia léxica considerable: como se puede observar en el resumen de las correspondencias que recoge el cuadro a continuación el examen de las opciones mayoritarias para cada lema, o la combinación de opciones cuando se da más de una, nos da un esquema coherente en el que no se aprecian rupturas evidentes entre las diferentes secciones.

\begin{tabular}{|c|c|c|c|c|}
\hline \multicolumn{5}{|c|}{ TABLA 4: CoMPARACIÓN DE TODAS LAS PARTES BíbliCAS CONTENIDAS EN LOS CóDICES E7 y E5 } \\
\hline & \multicolumn{2}{|c|}{ E7 } & \multicolumn{2}{|c|}{ E5 } \\
\hline LEMA & TORÁ & $\begin{array}{l}\text { PROFETAS } \\
\text { ANTERIORES } \\
\end{array}$ & $\begin{array}{l}\text { ProfETAS } \\
\text { Posteriores }\end{array}$ & KeTUBim \\
\hline 1. $\hat{s} a b a$ & $\begin{array}{l}\text { gente / batalla } \\
\text { / hueste / real / } \\
\text { corte }\end{array}$ & $\begin{array}{l}\text { hueste / corte / } \\
\text { gente / batalla }\end{array}$ & corte & $\begin{array}{l}\text { hueste / corte / } \\
\text { alcavela }\end{array}$ \\
\hline 2. sar & cabdillo & cabdillo & cabdillo & cabdillo \\
\hline 18. nasí & $\begin{array}{l}\text { escogido / } \\
\text { cabdillo / capitán } \\
\text { / may- }\end{array}$ & cabdillo & may- / cabdillo & cabdillo / capitán \\
\hline 3. 'olá & $\begin{array}{l}\text { alsación / } \\
\text { sacrificio }\end{array}$ & $\begin{array}{l}\text { sacrificio / } \\
\text { alsación }\end{array}$ & sacrificio & sacrificio \\
\hline 4. maté & blago & --- & $\begin{array}{l}\text { piértego / } \\
\text { verdugo / blago } \\
\text { / palo }\end{array}$ & --- \\
\hline 9. šébet & «varios» & «varios» & verdugo & verdugo \\
\hline
\end{tabular}

\footnotetext{
${ }^{31}$ En el caso de E7 LiTTLEFIELD (1996:vii) ya había observado el carácter marcadamente interpretativo del romanceamiento, que caracteriza en los siguientes términos: «a radical departure from the translation tradition found in the other extant manuscripts. [...] the E7 text is often paraphrastic and interpretative, expanding upon the M[asoretic] T[ext]». Asimismo, en el detallado trabajo cuantitativo de Menéndez Aneiros sobre el léxico de los romanceamientos medievales del Cantar de los cantares se pone de manifiesto que E5 es la versión que más se aparta de emplear un mismo vocablo romance para cada lema del original hebreo al exhibir el mayor grado de riqueza léxica de todas las traducciones (MenÉndeZ ANeiros 2010: 33).
} 


\begin{tabular}{|c|c|c|c|c|}
\hline \multirow[b]{2}{*}{ LEMA } & \multicolumn{2}{|c|}{ E7 } & \multicolumn{2}{|c|}{ E5 } \\
\hline & TORÁ & $\begin{array}{l}\text { PROFETAS } \\
\text { ANTERIORES }\end{array}$ & $\begin{array}{l}\text { ProfETAS } \\
\text { POSTERIORES }\end{array}$ & Ketubim \\
\hline 5. bégued & $\begin{array}{l}\text { paño / ropa / } \\
\text { vest- }\end{array}$ & ropa / paño / vest- & $\begin{array}{l}\text { paño / ropa / } \\
\text { vest- }\end{array}$ & paño / ropa / vest- \\
\hline 6. šemen & azeite / olio & olio / azeite & azeite / olio & olio / azeite \\
\hline 7. behemá & $\begin{array}{l}\text { bestia / } \\
\text { cuatropedia }\end{array}$ & bestia & bestia & bestia \\
\hline 8. miŝvá & $\begin{array}{l}\text { encomendança / } \\
\text { mandamiento }\end{array}$ & $\begin{array}{l}\text { mandamiento / } \\
\text { encomendança }\end{array}$ & mandamiento & $\begin{array}{l}\text { mandamiento / } \\
\text { encomendança }\end{array}$ \\
\hline 10. safá & $\begin{array}{l}\text { boca \| lenguaje / } \\
\text { lengua || orilla / } \\
\text { ribera }\end{array}$ & $\begin{array}{l}\text { boca }\|---\| \text { orilla } \\
\text { / ribera }\end{array}$ & $\begin{array}{l}\text { boca / beço / } \\
\text { labio || lenguaje / } \\
\text { lengua || ribera }\end{array}$ & $\begin{array}{l}\text { beço / labio / } \\
\text { boca || lenguaje / } \\
\text { lengua || ribera }\end{array}$ \\
\hline 11. 'edá & compaña & compaña & compaña & compaña \\
\hline 24. cahal & compaña & compaña & ayuntamiento & ayuntamiento \\
\hline 12. zébah & sacrificio & sacrificio & sacrificio & sacrificio \\
\hline 13. guibor & barragán & barragán & barragán & barragán \\
\hline 14. ŝafón & çafón & setentrión & çafón & çafón \\
\hline 15. nehóšet & arambre & arambre & arambre & arambre \\
\hline 16. yamín & diestra & diestra & diestra & diestra \\
\hline 17. kisé & silla & silla & silla & silla \\
\hline 19. náhal & río / arroyo & río / corriente & río / corriente & corriente / río \\
\hline 20. par & novillo & novillo & toro / novillo & toro / novillo \\
\hline 21. [ni] š'ar & quedar / dexar & quedar / dexar & quedar / dexar & quedar / dexar \\
\hline 22. hoc & fuero & fuero & fuero & fuero \\
\hline 23. kóaḥ & fuerça & fuerça & fuerça & fuerça \\
\hline 25. bejor & primogénito & $\begin{array}{l}\text { mayor / } \\
\text { primogénito }\end{array}$ & primogénito & primogénito \\
\hline 26. to 'ebá & aborrecer & aborrecer & aborrecer & aborrecer \\
\hline 27. šéquer & fals- & fals- & fals- & fals- \\
\hline 28. kebes & carnero & carnero & carnero & carnero \\
\hline
\end{tabular}

La comparación de las opciones léxicas mayoritarias que se dan a lo largo de estos dos códices confirma el parentesco entre los romanceamientos que transmiten. En primer lugar vemos que en la gran mayoría de los casos la opción preferida por el traductor es coincidente en las cuatro secciones. Al mismo tiempo, en los casos en los que hay una combinación de más de un lexema, suele darse con los mismos componentes a lo largo de las diferentes secciones, aunque sea en proporciones diferentes. Por último destaca el uso compartido por E7 y E5 de vocablos que no apare- 
cen en otros romanceamientos o si lo hacen es de forma muy reducida: corriente para náhal, ribera para safá en su acepción de 'orilla', novillo para par, cabdillo para nasí, o el empleo de un hebraísmo crudo, çafón, para el punto cardinal expresado por este lema hebreo ${ }^{32}$.

La traducción contenida en los códices E7 y E5 es en definitiva un romanceamiento con un fondo tradicional judío sobre el que destaca, por un lado, el empleo de innovaciones cultas propias de la lengua del XV y, sobre todo, la tendencia a un estilo interpretativo en el que se emplea una amplia variedad de sinónimos para expresar matices mostrando así una peculiar intención de adaptar las opciones léxicas a su contexto preciso de aparición.

\subsection{La Biblia del Marqués de Santillana}

Tal y como se ha ido mostrando a lo largo del análisis de los 28 lemas hebreos estudiados, resulta evidente el alto grado de similitud en las elecciones léxicas entre la traducción del Pentateuco, Profetas Anteriores y Ketubim del códice E4 por un lado, y la traducción de los Profetas Posteriores y Ketubim del códice BNE, por el otro. Creemos que puede proponerse con suficiente certeza que los fragmentos citados conforman una única traducción del texto bíblico hebreo, conservada de forma completa entre los dos códices. Se puede también afirmar, como proponemos más abajo, que esta traducción completa perteneció y fue usada por el Marqués de Santillana. En las siguientes tablas se resume lo observado durante el cotejo léxico realizado:

a) El Pentateuco, los Profetas Anteriores y los libros de Rut, Ester y Esdras/Nehemías de E4 son todos una misma y única traducción, como muestran las coincidencias casi exactas de prácticamente todos los lemas considerados en las tres partes de la Biblia (véanse las columnas correspondientes a E4 en la TABLA 5).

\footnotetext{
${ }^{32}$ Hemos detectado además otras coincidencias que no entran en el ámbito de este estudio pero que ponen de manifiesto el parentesco entre estos dos manuscritos y los singularizan frente a otras traducciones: el abundante empleo de la expresión exceptiva

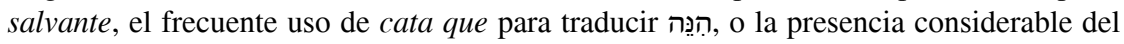
verbo adecir 'bajar', entre otras. Reservamos la exposición pormenorizada de estos y otros aspectos para un estudio posterior más amplio dedicado a esta Biblia.
} 
b) Los Profetas Posteriores de BNE, y los libros de los Ketubim que contiene, son igualmente una única traducción, como muestran las coincidencias léxicas del códice en las dos partes que contiene de la Biblia (véanse las dos últimas columnas de la TABLA 5).

\begin{tabular}{|c|c|c|c|c|c|}
\hline \multirow[b]{2}{*}{ LEMA } & \multicolumn{3}{|c|}{$\mathrm{E} 4$} & \multicolumn{2}{|c|}{$\mathrm{BNE}$} \\
\hline & TORÁ & $\begin{array}{l}\text { PROFETAS } \\
\text { ANTERIORES }\end{array}$ & $\begin{array}{l}\text { КетUвім } \\
(\text { Rut, Ester, } \\
\text { Esdr/Neh. })\end{array}$ & $\begin{array}{l}\text { Profetas } \\
\text { Posteriores }\end{array}$ & \begin{tabular}{|l} 
KeTUBIM \\
(Salmos, Job, \\
Proverbios, \\
Lamentaciones, \\
Cantar, \\
Eclesiastés, \\
Daniel, \\
Crónicas I y II)
\end{tabular} \\
\hline 1. $\hat{s} a b a$ & hueste & hueste & hueste & hueste & hueste \\
\hline 2. sar & $\begin{array}{l}\text { príncipe / } \\
\text { capitán / } \\
\text { cavallero }\end{array}$ & $\begin{array}{l}\text { capitán / } \\
\text { condestable / } \\
\text { príncipe }\end{array}$ & $\begin{array}{l}\text { capitán / } \\
\text { cavallero }\end{array}$ & $\begin{array}{l}\text { capitán / } \\
\text { cavallero / } \\
\text { príncipe }\end{array}$ & $\begin{array}{l}\text { capitán / } \\
\text { príncipe / } \\
\text { cavallero }\end{array}$ \\
\hline 18. nasí & príncipe & príncipe & príncipe & príncipe & príncipe \\
\hline 3. 'olá & holocausto & holocausto & holocausto & holocausto & holocausto \\
\hline 4. maté & blago / verga & lança & --- & vara / verga & verga \\
\hline 9. šébet & vara / verga & vara & --- & vara / verga & vara / verga \\
\hline 5. bégued & paño & paño & paño & paño & paño \\
\hline 6. šemen & olio / azeite & olio / azeite & \begin{tabular}{|l|} 
olio \\
\end{tabular} & olio / azeite & olio /azeite \\
\hline 7. behemá & $\begin{array}{l}\text { bestia / } \\
\text { animalia }\end{array}$ & $\begin{array}{l}\text { bestia / } \\
\text { animalia }\end{array}$ & $\begin{array}{l}\text { bestia / } \\
\text { animalia } \\
\end{array}$ & $\begin{array}{l}\text { bestia / } \\
\text { animalia } \\
\end{array}$ & bestia \\
\hline 8. miŝvá & $\begin{array}{l}\text { precepto/ } \\
\text { mandamiento }\end{array}$ & $\begin{array}{l}\text { mandamiento / } \\
\text { encomienda }\end{array}$ & mandamiento & $\begin{array}{l}\text { mandamiento } \\
/ \text { precepto }\end{array}$ & $\begin{array}{l}\text { precepto / } \\
\text { mandamiento }\end{array}$ \\
\hline 10. safá & $\begin{array}{l}\text { orilla | beço | } \\
\text { lengua }\end{array}$ & orilla | beço & --- & $\begin{array}{l}\text { orilla | beço } \\
\text { | lengua / fabla }\end{array}$ & $\begin{array}{l}\text { orilla | beço | } \\
\text { fabla / palabra }\end{array}$ \\
\hline 11. 'edá & gente / pueblo & $\begin{array}{l}\text { gente / pueblo } \\
\text { / ayuntamiento }\end{array}$ & --- & $\begin{array}{l}\text { gente / } \\
\text { compaña }\end{array}$ & compaña / gente \\
\hline 24. cahal & $\begin{array}{l}\text { pueblo / } \\
\text { ayuntamiento } \\
\text { / concilio }\end{array}$ & $\begin{array}{l}\text { concilio / } \\
\text { pueblo / gente }\end{array}$ & $\begin{array}{l}\text { concilio / } \\
\text { pueblo / gente }\end{array}$ & $\begin{array}{l}\text { concilio / } \\
\text { concejo }\end{array}$ & $\begin{array}{l}\text { concilio / } \\
\text { pueblo }\end{array}$ \\
\hline 12. zébah & sacrificio & sacrificio & sacrificio & $\begin{array}{l}\text { sacrificio / } \\
\text { degollamiento }\end{array}$ & $\begin{array}{l}\text { sacrificio / } \\
\text { degollamiento }\end{array}$ \\
\hline 13. guibor & $\begin{array}{l}\text { estrenuo, } \\
\text { potente }\end{array}$ & $\begin{array}{l}\text { potente, } \\
\text { estrenuo }\end{array}$ & $\begin{array}{l}\text { potente, } \\
\text { estrenuo }\end{array}$ & potente, fuerte & $\begin{array}{l}\text { potente, } \\
\text { estrenuo }\end{array}$ \\
\hline 14. safón & setentrión & setentrión & --- & setentrión & setentrión \\
\hline 15. nehóšet & cobre / azero & cobre / azero & cobre & $\begin{array}{l}\text { cobre / } \\
\text { arambre / } \\
\text { azero }\end{array}$ & $\begin{array}{l}\text { cobre / cadena / } \\
\text { azero }\end{array}$ \\
\hline
\end{tabular}




\begin{tabular}{|c|c|c|c|c|c|}
\hline \multicolumn{6}{|c|}{ TABLA 5: COMPARACIÓN DE LAS PARTES BÍBLICAS CONTENIDAS EN LOS CÓDICES E4 Y BNE } \\
\hline & \multicolumn{3}{|c|}{ E4 } & \multicolumn{2}{|c|}{$\mathrm{BNE}$} \\
\hline LEMA & TORÁ & $\begin{array}{l}\text { PROFETAS } \\
\text { ANTERIORES }\end{array}$ & $\begin{array}{l}\text { КетUвім } \\
\text { (Rut, Ester, } \\
\text { Esdr/Neh.) }\end{array}$ & $\begin{array}{l}\text { Profetas } \\
\text { Posteriores }\end{array}$ & $\begin{array}{l}\text { KетUвім } \\
\text { (Salmos, Job, } \\
\text { Proverbios, } \\
\text { Lamentaciones, } \\
\text { Cantar, } \\
\text { Eclesiastés, } \\
\text { Daniel, } \\
\text { Crónicas I y II) }\end{array}$ \\
\hline 16. yamín & $\begin{array}{l}\text { derecha / } \\
\text { diestra / } \\
\text { manderecha }\end{array}$ & $\begin{array}{l}\text { derecha / } \\
\text { diestra / } \\
\text { manderecha }\end{array}$ & manderecha & $\begin{array}{l}\text { derecha / } \\
\text { manderecha / } \\
\text { diestra }\end{array}$ & $\begin{array}{l}\text { diestra / derecha } \\
\text { / manderecha }\end{array}$ \\
\hline 17. kisé & cátedra / silla & cátedra / silla & cátedra & cátedra / silla & cátedra / silla \\
\hline 19. náhal & río / arroyo & río / arroyo & arroyo & río / arroyo & arroyo / río \\
\hline 20.par & toro & toro & toro & toro & toro \\
\hline 21. [ni] š'ar & quedar / dexar & quedar / dexar & quedar / dexar & quedar / dexar & quedar \\
\hline 22. hoc & fuero & fuero & fuero & fuero & fuero \\
\hline 23. kóah & fuerça & fuerça & $\begin{array}{l}\text { poder / fuerça } \\
\text { / potencia }\end{array}$ & $\begin{array}{l}\text { fuerça / } \\
\text { potencia }\end{array}$ & fuerça / potencia \\
\hline 25. bejor & primogénito & primogénito & primogénito & primogénito & primogénito \\
\hline 26. to'ebá & abominación & abominación & abominación & abominación & abominación \\
\hline 27. šéquer & mentira & mentira & --- & mentira & mentira \\
\hline 28. kebes & carnero & --- & carnero & carnero & carnero \\
\hline
\end{tabular}

c) Las traducciones de $\mathrm{E} 4$ y BNE, en las partes citadas, son el trabajo de un mismo traductor, como se muestra en la tabla 6 . En la presentación de la tabla hemos descartado las divisiones bíblicas, sumando por un lado todos los porcentajes de E4 y, por el otro, todos los de BNE, unificando así las diferentes partes de cada códice. De esta manera se muestra de forma más clara la identidad total de ambas traducciones, tanto en las elecciones léxicas de los dos códices, como en la forma preferida mayoritariamente cuando se usa más de una.

d) Deben destacarse los numerosos ejemplos en los que, además de coincidir entre sí, E4 y BNE se distancian de manera clara de las elecciones realizadas por los traductores del resto de los códices, tal y como se ha detallado en el análisis individual de cada lema hebreo. Son los casos de capitán para sar, holocausto para 'olá, precepto para miŝvá, potente I estrenuo para guibor, setentrión para safón, gente para 'edá, manderecha para yamín, cátedra para kisé, concilio para cahal, abominación para to 'ebá o mentira para šéquer. 


\begin{tabular}{|c|c|c|}
\hline \multicolumn{3}{|c|}{ TABLA 6: COMPARACIÓN CONJUNTA DE E4 y BNE } \\
\hline LEMA & $\begin{array}{c}\text { E4: Torá, Profetas } \\
\text { Anteriores, KetUBim } \\
(\text { Rut }, \text { Ester, Esdr/Neh. })\end{array}$ & $\begin{array}{c}\text { BNE: Profetas Posteriores, KetUBim } \\
\text { (Salmos, Job, Proverbios, } \\
\text { Lamentaciones, Cantar, Eclesiastés, } \\
\text { Daniel, Crónicas I y II) }\end{array}$ \\
\hline 1. $\hat{s} a b a$ & hueste & hueste \\
\hline 2. sar & capitán / príncipe & capitán / príncipe \\
\hline 18. nasí & príncipe & príncipe \\
\hline 3. 'olá & holocausto & holocausto \\
\hline 4. maté & blago / verga & verga / vara \\
\hline 9. šébet & vara / verga & vara / verga \\
\hline 5. bégued & paño & paño \\
\hline 6. šemen & olio / azeite & olio /azeite \\
\hline 7. behemá & bestia / animalia & bestia / animalia \\
\hline 8. miŝvá & mandamiento / precepto & precepto / mandamiento \\
\hline 10. safá & orilla | beço | lengua & orilla | beço | fabla \\
\hline 11. 'edá & gente / pueblo & compaña / gente \\
\hline 24. cahal & $\begin{array}{l}\text { pueblo / concilio / } \\
\text { ayuntamiento }\end{array}$ & concilio / ayuntamiento / pueblo \\
\hline 12. zébaḥ & sacrificio & sacrificio / degollamiento \\
\hline 13. guibor & potente / estrenuo & potente / fuerte / estrenuo \\
\hline 14. safón & setentrión & setentrión \\
\hline 15. nehóšet & cobre / azero & cobre / azero \\
\hline 16. yamín & derecha / diestra / manderecha & derecha / diestra / manderecha \\
\hline 17. kisé & cátedra & cátedra \\
\hline 19. náhal & río / arroyo & río / arroyo \\
\hline 20. par & toro & toro \\
\hline 21. [ni] š'ar & quedar / dexar & quedar / dexar \\
\hline 22. hoc & fuero / ración & fuero / ración \\
\hline 23. kóah & fuerça & fuerça / potencia \\
\hline 25. bejor & primogénito & primogénito \\
\hline 26. to'ebá & abominación & abominación \\
\hline 27. šéquer & mentira & mentira \\
\hline 28. kebes & carnero & carnero \\
\hline
\end{tabular}

A la espera de un análisis monográfico más amplio podemos proponer que en el códice E4 se han conservado las partes bíblicas del primer volumen perdido (de los tres tomos originales) de la Biblia que perteneció al Marqués de Santillana. El códice BNE, con los Profetas Posteriores y parte de los Ketubim, representa el segundo volumen, el cual podemos afirmar que tuvo en 
sus manos don Íñigo López de Mendoza ${ }^{33}$. De este segundo volumen nos faltaban algunos libros de los Ketubim, no conservados en el códice BNE: Rut, Ester, Esdras/Nehemías, libros que ahora podemos afirmar que se encuentran conservados en E4. Igualmente el códice E4 contiene los libros deuterocanónicos de Tobit y Judit traducidos del latín. Estos libros también faltan en BNE y podemos igualmente suponer que eran parte de la Biblia de Santillana (ya que BNE también incluye otros libros deuterocanónicos, como Sabiduría y Eclesiástico, ambos en coincidencia textual con E4). La razón por la que estos cinco libros no se encuentran en el segundo volumen del Marqués es sencilla de explicar: estaban en el primer volumen perdido, colocados entre los libros históricos, junto a los Profetas Anteriores, siguiendo la organización más común de la Vulgata (tal y como ocurre en el códice E4). Por lo tanto, el primer volumen perdido de la Biblia del Marqués contenía el Pentateuco, los Profetas Anteriores, los libros de Rut, Ester y Esdras/Nehemías, traducidos del hebreo, además de Tobit y Judit traducidos del latín, todos ellos conservados en el códice E4. El tercer volumen que completa la Biblia del Marqués de Santillana nada tiene que ver con la tradición textual hebrea, ya que contiene parte del Nuevo Testamento (Evangelios y epístolas paulinas) traducido por Martín de Lucena para el Marqués de Santillana ${ }^{34}$.

La confirmación de la existencia completa de la Biblia del Marqués de Santillana pone de manifiesto la necesidad de realizar análisis completos y exhaustivos tanto desde el punto de vista lingüístico como del codicológico. El método de análisis empleado en este trabajo ha permitido algo irrealizable mediante el cotejo textual de pasajes paralelos: comparar fragmentos textuales diferentes en el eje vertical, observando el trabajo de traducción de un mismo traductor a lo largo de toda la Biblia. Al mismo tiempo, tal y como se explicaba en la introducción, se pone de manifiesto

\footnotetext{
${ }^{33}$ Véanse Pueyo Mena (1996: xxxiv-xxxvi) y Avenoza (2011a: 149) para una explicación detallada de los aspectos de encuadernación, glosa, factura del códice, y otros datos textuales y codicológicos que indican que los mss. BNE 10288 (Profetas y Escritos) y BNE 9556 (Evangelios y epístolas paulinas) fueron encargados y realizados al mismo tiempo para el Marqués de Santillana.

${ }^{34}$ El hecho de que Martín de Lucena trabajara para el Marqués, fuera converso y conociera bien el hebreo, lo convierte en candidato posible como traductor de la Biblia hebrea del Marqués. Un análisis comparado del léxico exclusivo compartido por E4, BNE y Lucena, y por lo tanto ausente en el resto de las traducciones bíblicas, así parece confirmarlo de forma preliminar.
} 
la falta de precisión de las comparaciones puntuales que se han realizado entre los diversos textos, y que, en el campo de los romanceamientos bíblicos, ha llevado tanto a errores fundamentales (que siguen difundiéndose en la bibliografía), como a la falta de descubrimientos clave. No solo podemos confirmar en este caso que no debe confundirse el códice E4 con la traducción o traducciones que contiene, como pedía la profesora Morreale, sino que ahora podemos afirmar que la llamada Biblia E4, tantas veces analizada y editada con dicho nombre, nunca existió en realidad. Escorial I.i.4 es un códice realizado a partir de varios modelos diferentes de traducción ensamblados en un proyecto codicológico único (Avenoza 2011a: 53-78), pero no es en absoluto un proyecto de traducción original, como sería el caso de E3 o de Arragel. El hecho de que hayamos recuperado la Biblia del Marqués de Santillana, y que podamos afirmar con casi total seguridad que fue traducida enteramente (tanto el hebreo, como el latín) por el converso Martín de Lucena, abre la posibilidad de estudiar dicho romanceamiento en su adecuado contexto linguiístico, histórico y social.

\subsection{Las Biblias de Arragel: RAH y la Biblia compuesta para don Luis de Guzmán}

La Biblia que Mosé Arragel compuso para don Luis de Guzmán es el único romanceamiento bíblico medieval en que tenemos cumplida información sobre autor, promotor y destinatarios gracias al detallado prólogo de 25 folios que la acompaña y que nos informa de que fue compuesta en su totalidad por el judío de Guadalajara ${ }^{35}$. Tal como revela el estudio pormenorizado de la traducción que estamos llevando a cabo en otro trabajo ${ }^{36}$ nos encontramos ante un traductor con una decidida personalidad; lejos de hacer una traducción calco Arragel se vuelca en buscar a cada paso la expresión justa para reflejar el texto hebreo. El resultado de su trabajo es un texto entreverado de lecturas influidas por la exégesis rabínica en el

\footnotetext{
${ }^{35}$ Con la probable excepción, ya señalada, del libro de los Salmos que parece ser traducción de la Vulgata o al menos el resultado de una revisión profunda sobre el texto de Jerónimo y por tanto no ha sido incluido en el análisis.

${ }^{36}$ Nos referimos a la edición crítica de la traducción y las glosas de Arragel que estamos llevando a cabo con un equipo multidisciplinar formado por L. M. Girón-Negrón, Á. Sáenz-Badillos y los que suscriben.
} 
que al mismo tiempo da cabida a frecuentes ecos de la Vulgata, pero sin abandonar del todo el fondo tradicional judío vernacularizante característico de las biblias medievales castellanas. Además Arragel muestra una gran sensibilidad como escritor que explora las capacidades expresivas del castellano y se adapta a la moda estilística latinizante del momento (Enrique-Arias 2004, 2006). Esta Biblia nos sirve por tanto como corpus de control para examinar el grado de consistencia de las opciones léxicas de una traducción interpretativa e innovadora como la de Arragel a lo largo de las cuatro secciones en que hemos dividido la Biblia hebrea.

\begin{tabular}{|c|c|c|c|c|}
\hline \multicolumn{5}{|c|}{$\begin{array}{c}\text { TABLA 7: COMPARACIÓN DE LAS PARTES BÍBLICAS CONTENIDAS } \\
\text { EN LA BIBLIA DE ARRAGEL }\end{array}$} \\
\hline LEMA & TORÁ & $\begin{array}{l}\text { PROFETAS } \\
\text { ANTERIORES }\end{array}$ & $\begin{array}{l}\text { Profetas } \\
\text { POSTERIORES }\end{array}$ & Ketubim \\
\hline 1. $\hat{s} a b a$ & hueste / fonsado & cavallería & cavallería & cavallería \\
\hline 2. sar & $\begin{array}{l}\text { may- / cavallero / } \\
\text { príncipe }\end{array}$ & príncipe & príncipe & príncipe \\
\hline 18. nasí & mayoral / príncipe & príncipe / mayoral & príncipe & príncipe \\
\hline 3. 'olá & holocausta & holocausta & holocausta & holocausta \\
\hline 4. maté & blago & - & $\begin{array}{l}\text { verga / blago / } \\
\text { ceptro }\end{array}$ & - \\
\hline 9. šébet & verga / ceptro & verga & verga / ceptro & verga \\
\hline 5. bégued & paño & paño & paño / vestimenta & $\begin{array}{l}\text { verstimenta / } \\
\text { paño }\end{array}$ \\
\hline 6. šemen & olio & olio & olio & olio \\
\hline 7. behemá & bestia / res & bestia & bestia & bestia \\
\hline 8. miŝvá & mand- & mand- & mand- & mand- \\
\hline 10. safá & $\begin{array}{l}\text { labio \| lengua } \| \\
\text { orilla }\end{array}$ & $\begin{array}{l}\text { labio }\|-\| \text { orilla } \\
\text { / rostro }\end{array}$ & $\begin{array}{l}\text { labio \| lengua } \| \\
\text { orilla / rostro }\end{array}$ & $\begin{array}{l}\text { labio \| fabla \| } \\
\text { rostro / orilla }\end{array}$ \\
\hline 11. 'edá & gente / pueblo & $\begin{array}{l}\text { sinagoga / } \\
\text { congregación }\end{array}$ & varios & varios \\
\hline 24. cahal & colación / gente & $\begin{array}{l}\text { egleja / } \\
\text { congregación / } \\
\text { sinagoga }\end{array}$ & $\begin{array}{l}\text { congregación / } \\
\text { gente }\end{array}$ & gente / república \\
\hline 12. zébah & Sacrificio & sacrificio & sacrificio & sacrificio \\
\hline 13. guibor & barragán & barragán & barragán & barragán \\
\hline 14. safón & aquilón / poniente & aquilón & aquilón & aquilón \\
\hline 15. nehóšet & cobre & cobre & cobre & cobre \\
\hline 16. yamín & diestra & diestra & diestra & diestra \\
\hline 17. kisé & silla / cátedra & $\begin{array}{l}\text { trono / cátedra } \\
\text { / silla }\end{array}$ & silla / trono & silla / trono \\
\hline 19. náhal & río / arroyo & arroyo / río & río & río / arroyo \\
\hline 20.par & toro & toro & toro & toro \\
\hline
\end{tabular}




\begin{tabular}{|l|l|l|l|l|}
\hline \multicolumn{5}{|c|}{ TABLA 7: COMPARACIÓN DE LAS PARTES BÍBliCAS CONTENIDAS } \\
EN LA BIBLIA DE ARRAGEL \\
\hline LEMA & TORÁ & $\begin{array}{l}\text { PROFETAS } \\
\text { ANTERIORES }\end{array}$ & $\begin{array}{l}\text { PROFETAS } \\
\text { PosTERIORES }\end{array}$ & KETUBIM \\
\hline 21. [ni] š'ar & $\begin{array}{l}\text { quedar-dexar / } \\
\text { remanecer }\end{array}$ & $\begin{array}{l}\text { quedar-dexar / } \\
\text { remanecer }\end{array}$ & $\begin{array}{l}\text { remanecer / } \\
\text { quedar-dexar }\end{array}$ & $\begin{array}{l}\text { remanecer / } \\
\text { quedar-dexar }\end{array}$ \\
\hline 22. hoc & fuero & fuero & fuero & fuero \\
\hline 23. kóah & fuerça & fuerça & fuerça & fuerça \\
\hline 25. bejor & primogénito & primogénito & primogénito & primogénito \\
\hline 26. to'ebá & $\begin{array}{l}\text { abor- / } \\
\text { abominación }\end{array}$ & abominación & abominación & abominación \\
\hline 27. šéquer & falso & falso & mentira / falso & falso / mentira \\
\hline 28. kebes & cordero / carnero & - & cordero / carnero & cordero \\
\hline
\end{tabular}

Como podemos apreciar en el cuadro de correspondencias, si bien los vocablos empleados para traducir cada lema hebreo no tienen que ser necesariamente idénticos, el análisis de conjunto de las opciones dominantes empleadas para traducir cada lema nos da una traducción con un grado considerable de homogeneidad. Es cierto que en unos pocos casos encontramos variaciones entre diferentes secciones, pero en una visión global no es posible detectar un punto de ruptura interpretable como cambio de traductor; más bien al contrario, una amplia mayoría de lemas se traducen con lecturas coincidentes a lo largo de las cuatro secciones.

Además de la riqueza de matices reflejada en la variedad léxica desplegada por Arragel cabe destacar su clara preferencia por usar vocablos castellanos que coinciden con el cognado latino correspondiente: el uso de verga para šébet, holocausta para olá, príncipe para sar y nasí, olio para šemen, aquilón para safón, abominación para to 'ebá, y labio y lengua para safá nos acercan respectivamente a los virga, holocaustum, princeps, oleum, aquilo, labium y lingua que predominan en la Vulgata para traducir estos vocablos hebreos. Estas lecturas más cercanas al latín singularizan este romanceamiento frente a otros que prefieren términos patrimoniales como blago, alsación, mayoral, azeite, beço o fabla. Asimismo, algunas de las oscilaciones que encontramos a lo largo del romanceamiento se pueden atribuir a la tendencia arragelina a acercarse al texto de Jerónimo: por ejemplo, el uso variable de mentira y falsía para traducir šéquer sigue en gran medida el reparto de mendacium y falsus de la Vulgata. Obviamente, las lecturas de la versión de Arragel que más claramente demuestran su independencia de las demás versiones son aquellas que no son compartidas por 
ningún otro romanceamiento, como el empleo de holocausta para traducir 'olá, el uso de lengua y desconocimiento total de beço para safá, remanecer para [ni] š ar, el uso ocasional de degolleo para zébaḥ, a los que debemos añadir rostro en la acepción de 'orilla' para safá.

El análisis pormenorizado de la traducción de cada lema demuestra asimismo que la traducción de los profetas posteriores transmitida en el códice RAH es prácticamente la misma que la de la traducción hecha para don Luis de Guzmán. Las únicas discrepancias son: el empleo de sabaod para ŝaba (frente a cavallería), el hecho de que para maté RAH emplea báculo y no blago como traducción alternativa a verga y la preferencia por grossura y carnero frente a olio y cordero para šemen y kebes respectivamente (en la Biblia de Arragel la preferencia es la inversa). El amplio número de coincidencias añade más datos al nutrido repertorio de semejanzas entre los textos transmitidos por estos dos códices, expuestas en Lazar et al. (1994: xx-xxx), Enrique-Arias (2007) y especialmente en Enrique-Arias (2006). En estos trabajos se propone que el texto de RAH refleja una primera versión de Arragel, más pegada al texto hebreo y a los métodos judíos tradicionales de traducción, que habría sido revisada con la introducción de un mayor número de lecturas influidas por la Vulgata y la eliminación de hebraísmos para ser adaptada al encargo de don Luis de Guzmán. Al menos dos de las discrepancias que encontramos entre las dos versiones, como la preferencia por cavallería frente a sabaod y olio frente a grossura son explicables como adaptaciones para el público destinatario de la Biblia encargada por el maestre Luis de Guzmán.

\subsection{La Biblia de Oxford}

El ms. Canon Ital. 177 de la Biblioteca Bodleiana de Oxford, recientemente descubierto por Juan-Carlos Conde ${ }^{37}$, contiene parte de los Profetas Anteriores e incluye también el libro de Rut, lo cual indica que la supuesta biblia completa a la que pertenecería el fragmento conser-

\footnotetext{
${ }^{37}$ Para una descripción del códice véase ConDE (2013).
} 
vado seguía la ordenación de la Vulgata (al igual que los códices E4 y BNE). Tal y como se ha señalado en la metodología, el libro de Josué y el libro de Rut son copia de la traducción que encontramos en E7 y en E5 respectivamente.

El resto de los libros no tienen relación textual directa con ningún otro romanceamiento conocido, por lo que las siguientes conclusiones, a partir de la comparación léxica realizada, ayudarán a situar esta traducción en el marco del resto de traducciones que ya se han identificado:

a) En términos generales Oxford se muestra como una traducción independiente, como revelan muchas de las elecciones léxicas de su traductor, las cuales o no coinciden con ningún otro de los códices estudiados o son solamente residuales en alguno de ellos: alavesa/cabeça/palo para šébet, vestidura para bégued, ternero para par, primo-engendrado I primero-engendrado para bejor, establecimiento para hoc, fortaleza para kóah, cabildo para cahal o enconamiento para to 'ebá.

b) Al igual que observábamos para E19, Oxford también recoge parcialmente el fondo común de léxico tradicional representado por E3, con el cual coincide en algunas de sus lecturas: vara para maté, bestia para behemá, mandamiento para miŝvá, beço para safá, barragán para guibor, sacrificio para zébah, compaña para 'edá, diestra para yamín, silla para kisé, remanecer para [ni]š’ar y falsedad para šéquer.

c) Sin embargo, y al contrario que E19, Oxford se nos presenta también como una traducción innovadora, al estilo de la Biblia de Santillana o Arragel, con los cuales comparte algunos cultismos: olio para šemen, holocausto para 'olá, setentrión para ŝafón y príncipe para nasí, además del patrimonial hueste como traducción de $\hat{s} a b a$.

d) Oxford coincide también en ocasiones, incluso de forma exclusiva, con E7: cabdillo para nasí, alambre para nehóšet y verdugo para šébet.

En definitiva, el códice de Oxford nos ofrece una traducción diferente a las del resto de códices conocidos, que innova en ocasiones, que se inserta en la tradición común en otras, y que en el resto de los casos presenta soluciones cercanas, aunque de forma alternante, a todas las familias de traducción que hemos analizado. 


\section{Conclusiones finales}

Los datos y análisis presentados en las páginas precedentes pretenden ser un primer acercamiento sistemático al problema de las correspondencias entre códices y traducciones en el corpus de los romanceamientos cuatrocentistas castellanos hechos a partir del hebreo. Los hallazgos más relevantes se pueden resumir del siguiente modo:

En lo que respecta a la cuestión principal que hemos abordado, la de determinar el número de traducciones contenidas en los once manuscritos de que disponemos, podemos concluir que se conservan seis traducciones diferentes del siglo XV a partir del hebreo: la Biblia completa de E3, el Pentateuco de E19, la Biblia completa que supone la combinación de la traducción contenida en los códices E7 y E5, la Biblia completa que hemos denominado Biblia del Marqués de Santillana (y que es una combinación de partes del códice de E4 y del códice completo de BNE), la Biblia de Arragel (transmitida además en parte en el códice RAH) y los Profetas Anteriores contenidos en el códice de Oxford.

Por lo que concierne al análisis del tipo de léxico empleado por los traductores vale la pena prestar atención a dos perspectivas que apenas hemos desarrollado en este trabajo y merecen un estudio más profundo. Por un lado cabe considerar el grado de correspondencia entre lemas del original y equivalentes romances, es decir, hasta qué punto los traductores se ciñen al sistema tradicional judío que tiende a emplear un único vocablo romance para reproducir una misma palabra hebrea. En este respecto contrastan las correspondencias más estrictas de $\mathrm{E} 3$ frente al grado más amplio de variación que encontramos en E7 y E5 quedando las demás versiones en un punto intermedio. Y por otro lado cabe considerar el reparto de léxico vernáculo tradicional frente a innovaciones cultas, que podemos resumir de la siguiente manera: mientras la Biblia del Marqués de Santillana y Arragel se muestran inmersos en la tendencia de principios del siglo XV hacia el uso abundante de cultismos latinizantes, E3 y E19 no los presentan de forma apreciable. Esta distribución posiblemente tenga implicaciones para situar cronológicamente los romanceamientos - es decir que E3 y E19 fueran traducciones más antiguas— pero no necesariamente, puede ser que sus traductores simplemente se muestren mucho más conservadores. E5/E7 y Oxford, por otro lado, quedan a medio camino respecto del resto de las versiones, haciendo uso por lo general de opciones tradicionales en la línea de E3 y E19, pero incorporando igualmente formas cultas del tipo de las que encontramos en mayor medida en la Biblia de Santillana y Arragel. 


\section{BIBLIOGRAFÍA}

Amigo Espada, L. (1983). El Pentateuco de Constantinopla y la Biblia medieval romanceada: criterios y fuentes de traducción (Salamanca: Universidad Pontificia).

Avenoza, G. (2011a). Biblias castellanas medievales (San Millán de la Cogolla: CiLengua, Instituto Orígenes del español).

- (2011b). «Relaciones entre los Ms. Esc. I.I.5 y Esc. I.I.7: ¿Dos proyectos codicológicos independientes o una Biblia en dos volúmenes?», Anuario de Filologia. Antiqua et Mediaeualia, 1, 1-22.

Bunis, D. M. (1996). «Translating from the Head and from the Heart: The Essentially Oral Nature of the Ladino Bible-Translation Tradition», en W. Busse - M.-C. VArol Bornes (eds.), Hommage à Haïm Vidal Sephiha (Berne: Peter Lang), 337-357.

Conde, J. -C. (2013). «A Neglected Old Spanish Biblical Translation: the 'Biblia de Alfonso Ximénez'», en B. TAYLOR - G. West - J. Whetnall (eds.), Text, Manuscript, and Print in Medieval and Modern Iberia: Studies in Honour of David Hook (Madison: The Hispanic Seminary of Medieval Studies), 88-117.

CORDE. Real Academia Española: Corpus Diacrónico del español. $<$ http://corpus.rae.es/cordenet.html>

Corominas, J. y J. A. Pascual (1991). Diccionario crítico etimológico castellano e hispánico (Madrid: Gredos), 5 vols.

Cantera, F. y M. Iglesias (2000). Sagrada Biblia. Versión crítica sobre los textos hebreo, arameo y griego, $3^{\mathrm{a}}$ ed. (Madrid: Biblioteca de $\mathrm{Au}-$ tores Cristianos).

EnriQue-Arias, A. (2004). «Texto subyacente hebreo e influencia latinizante en la traducción de la Biblia de Alba de Moisés Arragel», en V. Alsina - J. Brumme - C. Garriga - C. Sinner (eds.) Traducción y estandarización. La incidencia de la traducción en la historia de los lenguajes especializados (Madrid - Frankfurt: Iberoamericana Vervuert), 99-112.

- (2006). «Sobre el parentesco entre la Biblia de Alba y la Biblia de la Real Academia de la Historia ms. 87», Romance Philology 59, 2, 241263. 
- (2007). «Diferentes modelos de traducción en las versiones castellanas del libro de Isaías: un estudio cuantitativo», en D. TrotTer (ed.) Actes du XXIV Congrès International de Linguistique et Philologie Romanes (Aberystwyth, 1-6 aout 2004 ) (Tubinga: Max Niemeyer), I, 339-349.

- (2008-2013). Corpus Biblia Medieval. <http://corpus.bibliamedieval. es>

Hassán, I. M. (2004). «¿Es el ladino judeoespañol calco? (cfr. DRAE)», Quaderns de Filologia. Estudis Lingüístics 9, 87-99.

Hauptmann, O. H. (1953). Escorial Bible i.j.4. Vol. 1. The Pentateuch (Philadelphia: University of Pennsylvania - Grinnell College).

LAZAR, M. (1994). «Ladinando la Biblia entre los sefardíes mediterráneos: Italia, Imperio otomano y Viena», en Introducción a la Biblia de Ferrara. Actas del Simposio Internacional sobre la Biblia de Ferrara (Sevilla, 25-28 de noviembre de 1991), eds. J. HASSÁn - A. BerENGUER AMADOR (Madrid: Sefarad 92 - Comisión Nacional Quinto Centenario), 347-442.

- (1995a). Biblia Ladinada I.J.3. 2 vols. (Madison: The Hispanic Seminary of Medieval Studies).

- (1995b). Siddur Tefillot. A Woman's Ladino Prayer Book [Paris BN Esp. 668. $15^{\text {th }}$ c.] (Culver City: Labyrinthos).

- (2000). The Ladino Scriptures. [Constantinople-Salonica 1540-1568] (Lancaster: Labyrinthos).

Lazar, M. - Pueyo Mena, F. J. - Enrique-Arias, A. (1994). Biblia Romanceada. Ms. Real Academia de la Historia 87. Edition, study and notes (Madison: The Hispanic Seminary of Medieval Studies).

Llamas, J. (1944). «La antigua Biblia castellana de los judíos españoles», Sefarad 4, 219-244.

- (1949). «Nueva Biblia medieval judía e inédita, en romance castellano», Sefarad 9, 53-74.

- (1950). Biblia medieval romanceada judío-cristiana. Versión del Antiguo Testamento en el siglo XIV, sobre los textos hebreo y latino (Madrid: CSIC), 2 vols.

- (1951). «Antigua biblia judía medieval romanceada», Sefarad 11, 289-304.

- (1953). «Muestrario inédito de prosa bíblica en romance castellano», La Ciudad de Dios 165, 303-312. 
LitTlefield, M. G. (1992). Escorial Bible I.ii.19. Edition, study and notes (Madison: The Hispanic Seminary of Medieval Studies).

- (1996). Escorial Bible I.I.7. Edition, study, notes and glossary (Madison: The Hispanic Seminary of Medieval Studies).

MenÉndez Aneiros, M. (2010). Variación léxica en las versiones medievales romanceadas del «Cantar de los Cantares» (Palma de Mallorca, Universidad de las Islas Baleares, tesis de licenciatura).

Morreale, M. (1960). «Apuntes bibliográficos para la iniciación al estudio de las Biblias medievales en castellano», Sefarad 20, 66-109.

— (1962). «El códice de los Profetas en latín y castellano que se conserva en la Biblioteca de la Academia de la Historia (87)», BRAH 150, 133-149.

- (1994). «La Biblia de Ferrara y los romanceamientos medievales: 2SM 22 y PS 18», en Introducción a la Biblia de Ferrara, 69-139.

Nehama, J. (1977). Dictionnaire du Judéo-Espagnol (Madrid: CSIC).

Pueyo Mena, F. J. (1996). Biblia Romanceada Biblioteca Nacional de Madrid Ms. 10288. Edición, estudio y notas (Madison: The Hispanic Seminary of Medieval Studies).

- (2008). «Biblias romanceadas y en ladino», en I. M. Hassán y R. IzQUIERdo BENITO (coords.), E. Romero (ed. lit.). Sefardies: Literatura y lengua de una nación dispersa (Cuenca: Universidad de Castilla-La Mancha), 193-263.

- (2011). «Séfer Hésec Šelomó: edición de Génesis / Berě̌it (cps. 1-10)" en E. Romero (ed.), Estudios sefardíes dedicados a la memoria de Iacob M. Hassán (z”l) (Madrid: CSIC), 433-478.

- (2012). "“Tu pueblo mi pueblo y tu Dio mi Dio": el libro de Rut en la Biblia de Abraham Asá», eHumanista 20, 263-295.

- (2013). «Méthode traditionnelle de traduction et alignement automatisé des sources pour le corpus biblique séfarade», en S. Rousssi, A. Stulic-EtcheVers (dir.), Recensement, analyse et traitement numérique des sources écrites pour les études séfarades (Bordeaux: Presses universitaires de Bordeaux), 343-365.

SACHS, G. E. (1948-1949). «Fragmento de un estudio sobre la Biblia medieval romanceada», Romance Philology 2, 217-228.

Schwarzwald, O. (Rodrigue) (2010). «On the Jewish Nature of Medieval Spanish Biblical Translations: Linguistic Differences Between Medieval and Post-Exilic Spanish Translations», Sefarad 70, 117-140. 
- (2012). «The Relationship Between Ladino Liturgical Texts and Spanish Bibles», en J. Decter - A. Prats (eds.) The Hebrew Bible in Fifteenth-Century Spain: Exegesis, Literature, Philosophy, and the Arts (Leiden - Boston: Brill), 223-244.

Sephina, H. V. (1973). Le ladino (judéo-espagnol calque), Deutéronome: versions de Constantinople (1547) et de Ferrare (1553) (Paris: Centre de Recherches Hispaniques).

Recibido: 30/04/2013

Aprobado: 24/06/2013 
ANEXO 


\begin{tabular}{|c|c|c|c|c|c|c|c|c|c|}
\hline \multicolumn{10}{|c|}{ צָדָָָא (ŝaba) } \\
\hline Parte & E3 & E19 & E7 & E5 & E4 & BNE & RAH & Arragel & Oxford \\
\hline Torá & $\begin{array}{l}\text { fonsado }[42 / 90=46.67 \%] \\
\text { hueste }[35 / 90=38.89 \%] \\
\text { condestable }[3 / 90=3.33 \%] \\
\text { tribu }[2 / 90=2.22 \%] \\
\text { compaña }[1 / 90=1.11 \%]\end{array}$ & $\begin{array}{l}\text { fonsado }[76 / 86=88.37 \%] \\
\text { contado }[2 / 86=2.3 \% \%] \\
\text { corte }[2 / 86=2.33 \%] \\
\text { pendón }[2 / 86=2.33 \%] \\
\text { compaña } 11 / 86=1.16 \%] \\
\text { tribu }[1 / 86=1.16 \%]\end{array}$ & $\begin{array}{l}\text { gente }[34 / 89=38.20 \%] \\
\text { batalla }[28 / 89= \\
31.46 \%] \\
\text { hueste }[14 / 89= \\
15.73 \%] \\
\text { real }[9 / 89=10.11 \%] \\
\text { cabdillo }[1 / 89=1.12 \%] \\
\text { compaña }[1 / 89= \\
1.12 \%]\end{array}$ & N/A & $\begin{array}{l}\text { hueste }[88 / 90= \\
97.78 \%] \\
\text { fonsado }[1 / 90= \\
1.11 \%] \\
\text { real }[1 / 90=1.11 \%]\end{array}$ & $\mathrm{N} / \mathrm{A}$ & $\mathrm{N} / \mathrm{A}$ & $\begin{array}{l}\text { hueste }[59 / 88=67.05 \%] \\
\text { fossado }[16 / 88=16.18 \%] \\
\text { cavallerí }[3 / 88=3.41 \%] \\
\text { mariscal [3/88 } 3.41 \%] \\
\text { servicio }[2 / 88=2.27 \%] \\
\text { corte }[1 / 88=1.14 \%] \\
\text { fonsado/cavallerí }[1 / 88= \\
1.14 \%] \\
\text { ornamento }[1 / 88=1.14 \%]\end{array}$ & $\mathrm{N} / \mathrm{A}$ \\
\hline PA & $\begin{array}{l}\text { condestable }[22 / 58=37.93 \%] \\
\text { sabaod }[14 / 58=24.14 \%] \\
\text { planeta }[6 / 58=10.34 \%] \\
\text { compana }[4 / 58=6.90 \%] \\
\text { fonsado }[4 / 58=6.90 \%] \\
\text { batalla }[2 / 58=3.45 \%] \\
\text { guerra }[2 / 58=3.45 \%] \\
\text { Dios }[1 / 58=1.72 \%] \\
\text { Señor }[1 / 58=1.72 \%] \\
\text { hueste }[1 / 58=1.72 \%]\end{array}$ & $\mathrm{N} / \mathrm{A}$ & $\begin{array}{l}\text { hueste }[18 / 58= \\
31.03 \%] \\
\text { sabaod }= \\
27.59 \% / 58= \\
\text { corte }[5 / 58=8.62 \%] \\
\text { gente } 5[58=8.62 \%] \\
\text { batalla }[4 / 58=6.90 \%] \\
\text { condestable }[4 / 58= \\
6.90 \%] \\
\text { Señor }[1 / 58=1.72 \%] \\
\text { adelantado } 1[1 / 58= \\
1.72 \%] \\
\text { baraja }[1 / 58=1.72 \%] \\
\text { capitan }[1 / 58=1.72 \%]\end{array}$ & N/A & $\begin{array}{l}\text { hueste }[29 / 57= \\
50.88 \%] \\
\text { condestable }[19 / 57= \\
33.33 \%] \\
\text { sabaot }[8 / 57= \\
14.04 \%]\end{array}$ & $\mathrm{N} / \mathrm{A}$ & $\mathrm{N} / \mathrm{A}$ & $\begin{array}{l}\text { cavallería }[40 / 58=68.97 \%] \\
\text { sabaod }[4 / 58=6.90 \%] \\
\text { corte }[3 / 35=5.17 \%] \\
\text { hueste }[2 / 58=3.45 \%] \\
\text { milicia }[2 / 58=3.45 \%] \\
\text { Dios }[1 / 58=1.72 \%] \\
\text { fonsado }[1 / 58=1.72 \%] \\
\text { guerra }[1 / 58=1.72 \%] \\
\text { mariscal }[1 / 58=1.72 \%]\end{array}$ & $\begin{array}{l}\text { hueste }[36 / 50=72.00 \%] \\
\text { fonsado }[7 / 50=14.00 \%] \\
\text { planeta }[3 / 50=6.00 \%] \\
\text { condestable }[2 / 50=4.00 \%] \\
\text { corte }[1 / 50=2.00 \%] \\
\text { sabaod }[1 / 50=2.00 \%]\end{array}$ \\
\hline PP & $\begin{array}{l}\text { sabaod }[236 / 262=90.08 \%] \\
\text { fonsado }[9 / 262=3.44 \%] \\
\text { Señor }[5 / 262=1.91 \%] \\
\text { planeta }[3 / 262=1.15 \%] \\
\text { Dios }[2 / 262=0.76 \%] \\
\text { cielo }[1 / 262=0.38 \%]\end{array}$ & N/A & N/A & $\begin{array}{l}\text { sabaod }[238 / 265=89.81 \%] \\
\text { Señor }[9 / 265=3.40 \%] \\
\text { corte }[8 / 265=3.02 \%] \\
\text { Dios }[2 / 265=0.75 \%] \\
\text { fonsado }[2 / 265=0.75 \%] \\
\text { cabdillo }[1 / 265=0.38 \%]\end{array}$ & N/A & $\begin{array}{l}\text { hueste }[255 / 266=95.87 \%] \\
\text { Dios }[3 / 266=1.13 \%] \\
\text { exército }[3 / 266=1.13 \%] \\
\text { Señor }[1 / 266=0.38 \%] \\
\text { condestable }[1 / 266=0.38 \%]\end{array}$ & $\begin{array}{l}\text { sabaod }[136 / 158=86.08 \%] \\
\text { cavalleria }[9 / 158=5.70 \%] \\
\text { hueste }[2 / 158=1.27 \%] \\
\text { corte }[1 / 158=0.63 \%] \\
\text { fonsado }[1 / 158=0.63 \%] \\
\text { ornamento }[1 / 158=0.63 \%] \\
\text { plazo }[1 / 158=0.63 \%] \\
\text { tiempo }[1 / 158=0.63 \%]\end{array}$ & $\begin{array}{l}\text { cavallería }[239 / 266=89.85 \%] \\
\text { Señor }[10 / 266=3.76 \%] \\
\text { sabaod }[6 / 266=2.26 \%] \\
\text { fonsado }[2 / 266=0.75 \%] \\
\text { hueste }[2 / 266=0.75 \%] \\
\text { milicia a } 22 / 266=0.75 \%] \\
\text { corte }[1 / 266=0.38 \%] \\
\text { estrella }[1 / 266=0.38 \%] \\
\text { orramento }[1 / 266=0.38 \%]\end{array}$ & $\mathrm{N} / \mathrm{A}$ \\
\hline Ketubim & $\begin{array}{l}\text { guerra }[19 / 73=26.03 \%] \\
\text { sabaod }[18 / 73=24.66 \%] \\
\text { planeta }[13 / 73=17.81 \%] \\
\text { compaña }[10 / 73=13.70 \%] \\
\text { tiempo }[4 / 73=5.48 \%] \\
\text { Dios }[2 / 73=2.74 \%] \\
\text { condestable }[2 / 73=2.74 \%] \\
\text { Señor }[1 / 73=1.37 \%] \\
\text { batalla }[1 / 73=1.37 \%] \\
\text { cielo }[1 / 73=1.37 \%]\end{array}$ & $\mathrm{N} / \mathrm{A}$ & N/A & $\begin{array}{l}\text { sabaod }[19 / 72=26.39 \%] \\
\text { hueste }[18 / 72=25.00 \%] \\
\text { alcavela }[10 / 72=13.89 \%] \\
\text { corte }[10 / 72=13.89 \%] \\
\text { fonsado }[3 / 72=4.17 \%] \\
\text { batalla }[2 / 72=2.77 \%] \\
\text { arma }[1 / 72=1.39 \%] \\
\text { armados }[1172=1.39 \%] \\
\text { escudo }[1 / 72=1.39 \%] \\
\text { fondón }[1 / 72=1.39 \%] \\
\text { guerra }[1 / 72=1.39 \%] \\
\text { plazo }[1 / 72=1.39 \%] \\
\text { tiempo }[1 / 72=1.39 \%]\end{array}$ & $\begin{array}{r}\text { hueste }[2 / 2= \\
100.00 \%]\end{array}$ & $\begin{array}{l}\text { hueste }[61 / 71=85.92 \%] \\
\text { condestable }[4 / 71=5.63 \%] \\
\text { sazón }[2 / 71=2.82 \%] \\
\text { Dios }[1 / 71=1.41 \%] \\
\text { Señor }[1 / 71=1.41 \%] \\
\text { plazo }[1 / 71=1.41 \%] \\
\text { tiempo }[1 / 71=1.41 \%]\end{array}$ & $\mathrm{N} / \mathrm{A}$ & $\begin{array}{l}\text { cavallería }[15 / 49=30.61 \%] \\
\text { hueste }[6 / 49=12.24 \%] \\
\text { batallante }[4 / 49=8.16 \%] \\
\text { batalla }[3 / 49=6.12 \%] \\
\text { corte }[3 / 49=6.12 \%] \\
\text { arma }[4 / 49=8.16 \%] \\
\text { milicia }[2 / 249=4.08 \%] \\
\text { tiempo }[2 / 49=4.08 \%] \\
\text { combatiente }[1 / 49=2.04 \%] \\
\text { plazo }[1 / 4=2.04 \%] \\
\text { príncipe }[1 / 49=2.04 \%]\end{array}$ & $\mathrm{N} / \mathrm{A}$ \\
\hline
\end{tabular}




\begin{tabular}{|c|c|c|c|c|c|c|c|c|c|}
\hline \multicolumn{10}{|c|}{ (sar) } \\
\hline Parte & E3 & E19 & E7 & E5 & E4 & BNE & RAH & Arragel & Oxford \\
\hline Torá & $\begin{array}{l}\text { mayoral }[48 / 57=84.21 \%] \\
\text { cabdillo }[3 / 57=5.26 \%] \\
\text { condestable }[3 / 57=5.26 \%] \\
\text { cabecera }[2 / 57=3.51 \%] \\
\text { vasallo }[1 / 57=1.75 \%]\end{array}$ & $\begin{array}{l}\text { mayoral }[28 / 53= \\
52.83 \%] \\
\text { mayor }[19 / 53= \\
35.85 \%] \\
\text { señor }[3 / 53=5.66 \%] \\
\text { carcelero }[1 / 53= \\
1.89 \%]\end{array}$ & 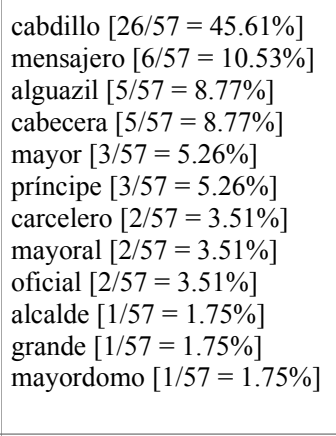 & N/A & $\begin{array}{l}\text { príncipe }[24 / 57=42.11 \%] \\
\text { capitán [14/57 }=24.56 \%] \\
\text { cabecera [9957 }=15.79 \%] \\
\text { cavallero [9957 }=15.79 \%] \\
\text { mercador }[1 / 57=1.75 \%]\end{array}$ & N/A & N/A & $\begin{array}{l}\text { mayor }[10 / 57=17.54 \%] \\
\text { mayoral }[9 / 57=15.79 \%] \\
\text { cavallero }[6 / 57=10.53 \%] \\
\text { príncipe }[6 / 57=10.53 \%] \\
\text { alguazil }[4 / 57=7.02 \%] \\
\text { copero }[4 / 57=7.02 \%] \\
\text { juez }[4 / 57=7.02 \%] \\
\text { carcelero }[3 / 57=5.26 \%] \\
\text { cósul }[3 / 57=5.26 \%] \\
\text { mariscal }[3 / 57=5.26 \%] \\
\text { panadero }[3 / 57=5.26 \%] \\
\text { cabdillo }[1 / 57=1.75 \%] \\
\text { mayordomo }[1 / 57=1.75 \%]\end{array}$ & $\mathrm{N} / \mathrm{A}$ \\
\hline PA & $\begin{array}{l}\text { mayoral }[65 / 93=69.89 \%] \\
\text { condestable }[21 / 93=22.58 \%] \\
\text { capitán }[4 / 93=4.30 \%] \\
\text { mayor }[1 / 93=1.08 \%] \\
\text { señor }[1 / 93=1.08 \%]\end{array}$ & $\mathrm{N} / \mathrm{A}$ & $\begin{array}{l}\text { cabdillo }[59 / 92=64.13 \%] \\
\text { duque }[5 / 92=5.43 \%] \\
\text { capitán }[4 / 92=4.35 \%] \\
\text { condestable }[4 / 92=4.35 \%] \\
\text { adelantado }[3 / 92=3.26 \%] \\
\text { cavallero }[3 / 92=3.26 \%] \\
\text { mayor }[3 / 92=3.26 \%] \\
\text { príncipe }[2 / 92=2.17 \%] \\
\text { alcalde }[1 / 92=1.09 \%] \\
\text { portero }[1 / 92=1.09 \%] \\
\text { príncipe }[1 / 92=1.09 \%] \\
\text { senoor }[1 / 192=1.09 \%] \\
\text { varón }[1 / 92=1.09 \%]\end{array}$ & $\mathrm{N} / \mathrm{A}$ & 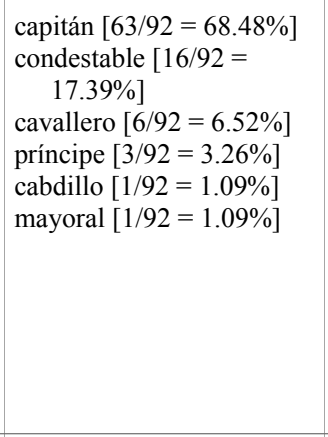 & $\mathrm{N} / \mathrm{A}$ & N/A & $\begin{array}{l}\text { príncipe }[69 / 92=75.00 \%] \\
\text { centurión }[6 / 92=6.52 \%] \\
\text { cavallero }[4 / 92=4.35 \%] \\
\text { mayoral [ }[3 / 92=3.26 \%] \\
\text { señor }[2 / 92=2.17 \%] \\
\text { alarife }[1 / 92=1.09 \%] \\
\text { cabdillo }[1 / 92=1.09 \%] \\
\text { capitán }[1 / 92=1.09 \%] \\
\text { corredor }[1 / 92=1.09 \%] \\
\text { mariscal }[1 / 92=1.09 \%] \\
\text { tribuno }[1 / 92=1.09 \%]\end{array}$ & $\begin{array}{l}\text { cabdillo }[71 / 83=85.54 \%] \\
\text { condestable }[3 / 83=3.61 \%] \\
\text { príncipe }[3 / 83=3.61 \%] \\
\text { alférez }[1 / 83=1.20 \%] \\
\text { cincuentenario }[1 / 83=1.20 \%] \\
\text { corregidor }[1 / 83=1.20 \%] \\
\text { mayordomo }[1 / 83=1.20 \%] \\
\text { varón }[1 / 83=1.20 \%]\end{array}$ \\
\hline PP & $\begin{array}{l}\text { mayoral }[70 / 88=79.55 \%] \\
\text { cavallero }[16 / 88=18.18 \%]\end{array}$ & N/A & N/A & $\begin{array}{l}\text { cabdillo }[77 / 89=86.52 \%] \\
\text { capitán }[3789=3.37 \%] \\
\text { principe }[3 / 89=3.37 \%] \\
\text { cabecera a } 1189=1.12 \%] \\
\text { grande }[1 / 89=1.12 \%] \\
\text { mayor }[1 / 89=1.12 \%] \\
\text { mayoral }[1 / 89=1.12 \%] \\
\text { profeta }[1 / 89=1.12 \%] \\
\text { rey }[1 / 89=1.12 \%]\end{array}$ & N/A & $\begin{array}{l}\text { capitán }[65 / 89=73.03 \%] \\
\text { cavallero }[13 / 89=14.61 \%] \\
\text { príncipe }[8 / 89=8.99 \%] \\
\text { profeta }[2 / 89=2.25 \%] \\
\text { condestable }[1 / 89=1.12 \%]\end{array}$ & $\begin{array}{c}\text { príncipe [72/74 = } \\
97.30 \%]\end{array}$ & $\begin{array}{l}\text { príncipe }[87 / 89=97.75 \%] \\
\text { amador }[1 / 89=1.12 \%]\end{array}$ & N/A \\
\hline Ketubim & $\begin{array}{l}\text { mayoral }[159 / 181=87.85 \%] \\
\text { señor }[9 / 181=4.97 \%] \\
\text { cavallero }[5 / 181=2.76 \%] \\
\text { condestable }[2 / 181=1.10 \%] \\
\text { mayor }[2 / 181=1.10 \%] \\
\text { cabecera }[1 / 181=0.55 \%] \\
\text { carga }[1 / 181=0.55 \%] \\
\text { planeta }[1 / 181=0.55 \%]\end{array}$ & $\mathrm{N} / \mathrm{A}$ & $\mathrm{N} / \mathrm{A}$ & $\begin{array}{l}\text { cabdillo }[153 / 180= \\
85.00 \%]] \\
\text { príncipe }[8 / 180=4.44 \%] \\
\text { grande }[5 / 180=2.78 \%] \\
\text { cabecera }[4 / 180=2.22 \%] \\
\text { mayoral }[3 / 180=1.67 \%] \\
\text { alguazil }[1 / 180=0.56 \%] \\
\text { capitan }[1 / 180=0.56 \%] \\
\text { cavallero }[1 / 180=0.56 \%]\end{array}$ & $\begin{array}{l}\text { capitán }[37 / 43=86.05 \%] \\
\text { cavallero }[6 / 43=13.95 \%]\end{array}$ & $\begin{array}{l}\text { capitán }[106 / 139=76.26 \%] \\
\text { principe }[19 / 139=13.67 \%] \\
\text { cavallero }[6 / 139=4.32 \%] \\
\text { condestable [3/139=2.16\%] } \\
\text { cabecera }[1 / 139=0.72 \%] \\
\text { centenal }[1 / 139=0.72 \%] \\
\text { concilio }[1 / 139=0.72 \%] \\
\text { gente d'armas }[1 / 139=0.72 \%] \\
\text { señor }[1 / 139=0.72 \%]\end{array}$ & N/A & $\begin{array}{l}\text { príncipe }[154 / 165=93.33 \%] \\
\text { centurión }[2 / 165=1.21 \%] \\
\text { mayor }[2 / 165=1.21 \%] \\
\text { duce }[1 / 165=0.61 \%] \\
\text { duque }[1 / 165=0.61 \%] \\
\text { mayoral }[1 / 165=0.61 \%] \\
\text { tribuno }[1 / 165=0.61 \%]\end{array}$ & N/A \\
\hline
\end{tabular}




\begin{tabular}{|c|c|c|c|c|c|c|c|c|c|}
\hline \multicolumn{10}{|c|}{ עִֹדָה ('olá) } \\
\hline Parte & E3 & E19 & E7 & E5 & E4 & BNE & RAH & Arragel & Oxford \\
\hline Torá & $\begin{array}{l}\text { alsación }[140 / 148=94.5 \% \%] \\
\text { sacrificioio }[4 / 148=2.70 \%] \\
\text { presente }[1 / 148=0.68 \%] \\
\text { templación }[1 / 148=0.68 \%]\end{array}$ & $\begin{array}{l}\text { alsación }[108 / 141= \\
76.60 \%] \\
\text { alçamiento }[27 / 141= \\
19.15 \%] \\
\text { alçar }[2 / 141=1.42 \%] \\
\text { ofrición }[2 / 1411.42 \%] \\
\text { tiempo }[1 / 141=0.71 \%]\end{array}$ & $\begin{array}{l}\text { alsación }[66 / 138=47.83 \%] \\
\text { sacrificio }[49 / 138=35.51 \%] \\
\text { alçamiento }[16 / 138= \\
11.59 \%] \\
\text { alçar }[1 / 138=0.72 \%] \\
\text { ensalçamiento }[1 / 138= \\
0.72 \%] \\
\text { paz }[1 / 138=0.72 \%] \\
\text { presente }[1 / 138=0.72 \%] \\
\text { safumerio }[1 / 138=0.72 \%]\end{array}$ & N/A & $\begin{array}{l}\text { holocausto }[139 / 148=93.92 \%] \\
\text { sacrificio }[7 / 148=4.73 \%] \\
\text { sacrificar }[2 / 148=1.35 \%]\end{array}$ & N/A & N/A & $\begin{array}{l}\text { holocausta }[135 / 137=98.54 \%] \\
\text { ofrenda }[1 / 137=0.73 \%]\end{array}$ & N/A \\
\hline PA & alsación $[42 / 44=95.45 \%]$ & N/A & $\begin{array}{l}\text { sacrificioio }[36 / 44=81.82 \%] \\
\text { alsación }[6 / 44=13.64 \%] \\
\text { ara }[1 / 44=2.27 \%]\end{array}$ & N/A & $\begin{array}{l}\text { holocausto }[41 / 44=93.18 \%] \\
\text { holocausto }[1 / 44=2.27 \%] \\
\text { sacrificio }[1 / 44=2.27 \%]\end{array}$ & $\mathrm{N} / \mathrm{A}$ & $\mathrm{N} / \mathrm{A}$ & holocausta [43/44 $=97.73 \%]$ & holocausto [ $37 / 38=97.37 \%$ ] \\
\hline PP & $\begin{array}{l}\text { alaación }[322 / 35=91.43 \%] \\
\text { asencio }[1 / 35=2.86 \%]\end{array}$ & N/A & N/A & $\begin{array}{l}\text { sacrificicio [27/35 =77.14\%] } \\
\text { infusión }[3 / 35=8.57 \%] \\
\text { presente }[1 / 35=2.86 \%]\end{array}$ & N/A & holocausto $[29 / 31=93.55 \%]$ & $\begin{array}{l}\text { holocausta }[10 / 11=90.91 \%] \\
\text { holocausto }[1 / 11=9.09 \%]\end{array}$ & holocausta $[33 / 35=94.29 \%]$ & $\mathrm{N} / \mathrm{A}$ \\
\hline Ketubim & $\begin{array}{l}\text { alsación [60/61 = 98.36\%] } \\
\text { alçar [1/61 } 1.64 \%]\end{array}$ & N/A & N/A & $\begin{array}{l}\text { sacrificio }[42 / 61=68.85 \%] \\
\text { alçamiento }[14 / 61=22.25 \%] \\
\text { alsación }[1 / 61=1.64 \%] \\
\text { alçar }[1 / 61=1.64 \%] \\
\text { holocausto }[1 / 61=1.64 \%] \\
\text { ofrenda }[1 / 61=1.64 \%]\end{array}$ & holocausto $[8 / 8=100.00 \%]$ & holocausto [52/52 $=100.00 \%]$ & N/A & holocausta [54/54 = 100.00\%] & $\mathrm{N} / \mathrm{A}$ \\
\hline
\end{tabular}




\begin{tabular}{|c|c|c|c|c|c|c|c|c|c|}
\hline \multicolumn{10}{|c|}{ הִ (maté) } \\
\hline Parte & E3 & E19 & E7 & E5 & E4 & BNE & RAH & Arragel & Oxford \\
\hline Torá & $\begin{array}{l}\text { vara }[41 / 42=97.6 \%] \\
\text { asoffimiento }[1 / 42=2,4 \%]\end{array}$ & $\begin{array}{l}\text { blago }[38 / 40=95 \%] \\
\text { asufrencia }[1 / 40=2,5 \%] \\
\text { verga }[1 / 40=2,5 \%]\end{array}$ & $\begin{array}{l}\text { blago }[39 / 41=95,1 \%] \\
\text { verdugo }[2 / 41=4,9 \%]\end{array}$ & $\mathrm{N} / \mathrm{A}$ & $\begin{array}{l}\text { blago }[21 / 44=47.7 \%] \\
\text { verga }[17 / 44=38,6 \%] \\
\text { vara }[4 / 44=9.1 \%] \\
\text { lança }[2 / 44=4.5 \%]\end{array}$ & N/A & N/A & $\begin{array}{l}\text { blago }[36 / 38=94,7 \%] \\
\text { cebtro }[2 / 38=5,3 \%]\end{array}$ & N/A \\
\hline PA & vara $[2 / 2=100 \%]$ & $\mathrm{N} / \mathrm{A}$ & $\operatorname{vara}[2 / 2=100 \%]$ & $\mathrm{N} / \mathrm{A}$ & lança [2/2 = 100\%] & $\mathrm{N} / \mathrm{A}$ & $\mathrm{N} / \mathrm{A}$ & $\begin{array}{l}\text { bastón }[1 / 2=50 \%] \\
\text { verga }[1 / 2=50 \%]\end{array}$ & vara $[2 / 2=100 \%]$ \\
\hline PP & $\begin{array}{l}\text { vara }[20 / 21=95.2 \%] \\
\text { sostenencia }[1 / 21=4.8 \%]\end{array}$ & $\mathrm{N} / \mathrm{A}$ & $\mathrm{N} / \mathrm{A}$ & 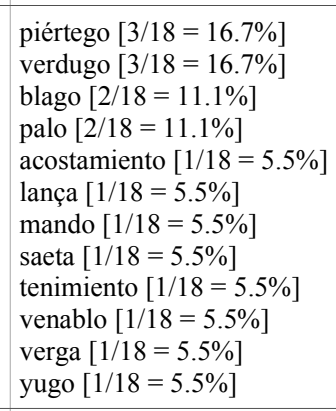 & $\mathrm{N} / \mathrm{A}$ & $\begin{array}{l}\text { vara }[10 / 20=50 \%] \\
\text { verga }[6 / 20==0 \%] \\
\text { adinctorio }[1 / 20=5 \%] \\
\text { blago }[1 / 20=5 \%] \\
\text { suffimiento }[1 / 20=5 \%] \\
\text { sustentación }[1 / 20=5 \%]\end{array}$ & $\begin{array}{l}\text { verga }[8 / 13=61.54 \%] \\
\text { báculo }[4 / 13=30.77 \%] \\
\text { palo }[1 / 13=7.69 \%]\end{array}$ & $\begin{array}{l}\text { verga }[8 / 19=42,1 \%] \\
\text { blago }[6 / 19=31,6 \%] \\
\text { cebtro }[3 / 19=15,8 \%] \\
\text { palo }[1 / 19=5,3 \%] \\
\text { saeta }[1 / 19=5,3 \%]\end{array}$ & $\mathrm{N} / \mathrm{A}$ \\
\hline Ketubim & $\begin{array}{l}\text { sostenencia }[1 / 2=50 \%] \\
\text { vara }[1 / 2=50 \%]\end{array}$ & $\mathrm{N} / \mathrm{A}$ & N/A & $\begin{array}{l}\text { sostenimiento }[1 / 2=50 \%] \\
\text { verga }[1 / 2=50 \%]\end{array}$ & {$[0 / 0=0.00 \%]$} & $\operatorname{verga}[1 / 1=100 \%]$ & $\mathrm{N} / \mathrm{A}$ & {$[0 / 0=0.00 \%]$} & N/A \\
\hline
\end{tabular}


פִ (bégued)

\begin{tabular}{|c|c|c|c|c|c|}
\hline Parte & E3 & E19 & E7 & E5 & \\
\hline Torá & $\begin{array}{l}\text { ropa }[55 / 113=48.67 \%] \\
\text { paño [52/113=46.02\%] } \\
\text { vestidura }[2 / 113=1.77 \%] \\
\text { vestido }[1 / 113=0.88 \%]\end{array}$ & paño $[110 / 111=99.10 \%]$ & $\begin{array}{l}\text { paño }[59 / 110=53.64 \%] \\
\text { ropa [23/110=20.91\%] } \\
\text { vestimenta }[23 / 110=20.91 \%] \\
\text { vestidura }[1 / 110=0.91 \%] \\
\text { vistuario }[1 / 110=0.91 \%]\end{array}$ & N/A & $\begin{array}{l}\text { paño } \\
\text { vestin } \\
\text { ropa } \\
\text { lino }\end{array}$ \\
\hline PA & $\begin{array}{l}\text { ropa }[22 / 42=52.38 \%] \\
\text { paño }[20 / 42=47.62 \%]\end{array}$ & $\mathrm{N} / \mathrm{A}$ & $\begin{array}{l}\text { ropa }[21 / 42=50.00 \%] \\
\text { paño }[14 / 42=33.33 \%] \\
\text { vestidura } 3[4 / 42=7.14 \%] \\
\text { falda [1/42=2.38\%] } \\
\text { vestimenta }[1 / 42=2.38 \%]\end{array}$ & $\mathrm{N} / \mathrm{A}$ & $\begin{array}{l}\text { paño } \\
\text { ropa } \\
\text { vestid } \\
\text { falda } \\
\text { vestin }\end{array}$ \\
\hline PP & $\begin{array}{l}\text { ropa }[22 / 40=55.00 \%] \\
\text { paño }[15 / 40=37.50 \%]\end{array}$ & $\mathrm{N} / \mathrm{A}$ & $\mathrm{N} / \mathrm{A}$ & $\begin{array}{l}\text { paño }[17 / 40=42.50 \%] \\
\text { ropa }[12 / 40=30.00 \%] \\
\text { vestimenta }[4 / 40=10.00 \%] \\
\text { vestidura }[2 / 40=5.00 \%] \\
\text { prenda }[1 / 40=2.50 \%] \\
\text { tela }[1 / 40=2.50 \%]\end{array}$ & $\mathrm{N} / \mathrm{A}$ \\
\hline Ketubim & $\begin{array}{l}\text { ropa }[17 / 23=73.91 \%] \\
\text { paño }[6 / 23=26.09 \%]\end{array}$ & $\mathrm{N} / \mathrm{A}$ & $\mathrm{N} / \mathrm{A}$ & $\begin{array}{l}\text { paño }[11 / 23=47.83 \%] \\
\text { ropa }[8 / 23=34.78 \%] \\
\text { vestidura }[3 / 23=13.04 \%] \\
\text { vestimenta }[1 / 23=4.35 \%]\end{array}$ & \\
\hline
\end{tabular}

$$
\text { E4 }
$$
a $[2 / 110=1.82 \%]$

ño $[32 / 42=76.19 \%]$

vestidura $[2 / 42=4.76 \%]$

alda $[1 / 42=2.38 \%]$
vestimenta $[1 / 42=2.38 \%]$
BNE

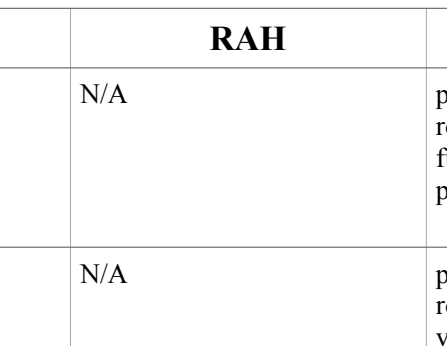

paño $[32 / 40=80.00 \%]$

vestimenta $[11 / 19=57.89 \%]$
paño $[3 / 19=15.79 \%]$

paño $[3 / 19=15.79 \%]$
capa $[1 / 19=5.26 \%]$

capa $[1 / 1 / 1=5.26 \%]$
ropa $[1 / 19=5.26 \%]$

paño [5/5= 100.00\%]

paño [11/18 = 61.11\%]

N/A vestimenta $[540=1250 \%]$

Arragel

paño $[102 / 111=91.89 \%]$

ropa $[6 / 111=5.41 \%]$

fuero $[1 / 111=0.90 \%]$

paño $[25 / 42=59.52 \%]$

vestimenta $[6 / 42=14.29 \%$

vestidura $[2 / 42=4.76 \%]$ almisquera $[1 / 42=2.38 \%$

vestidura $[25 / 41=60.98 \%$

manto $[2 / 41=4.88 \%]$

paño $[2 / 41=4.88 \%]$
falda $[1 / 41=2.44 \%]$
vest

falda $[1 / 41=2.44 \%]$
vestimenta $[1 / 41=2.44 \%$

paño $[18 / 40=45.00 \%$

N/A

capa $[1 / 40=2.50 \%]$
prenda $[1 / 40=2.50 \%$

vestimenta $[6 / 18=33.33 \%$
ensayar $[1 / 18=5.56 \%]$

vestimenta $[13 / 19=68.42 \%$

ropa $[2 / 19=10.53 \%]$ vestidura $[1 / 19=5.26 \%$ 


\begin{tabular}{|c|c|c|c|c|c|c|c|c|c|}
\hline \multicolumn{10}{|c|}{ 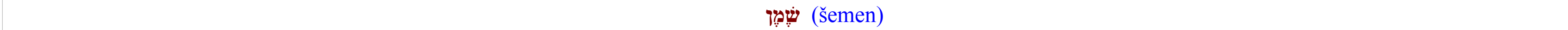 } \\
\hline Parte & $\mathbf{E 3}$ & E19 & E7 & E5 & E4 & BNE & RAH & Arragel & Oxford \\
\hline Torá & $\begin{array}{l}\text { azeite }[103 / 106=97.17 \%] \\
\text { gruesa }[1 / 106=0.94 \%] \\
\text { olio }[1 / 106=0.94 \%]\end{array}$ & $\begin{array}{l}\text { azeite }[102 / 106=96.23 \%] \\
\text { grueso }[1 / 106=0.94 \%] \\
\text { olio }[1 / 106=0.94 \%]\end{array}$ & $\begin{array}{l}\text { azeite }[68 / 105=64.76 \%] \\
\text { olio }[37 / 105=35.24 \%]\end{array}$ & N/A & $\begin{array}{l}\text { olio }[74 / 106=69.81 \%] \\
\text { azeite }[19 / 106=17.92 \%] \\
\text { ungüento }[11 / 106=10.38 \%] \\
\text { gruesa }[1 / 106=0.94 \%] \\
\text { ungimiento }[1 / 106=0.94 \%]\end{array}$ & $\mathrm{N} / \mathrm{A}$ & $\mathrm{N} / \mathrm{A}$ & $\begin{array}{l}\text { olio }[91 / 95=95.79 \%] \\
\text { azeite }[1 / 95=1.05 \%] \\
\text { gruesa }[1 / 95=1.05 \%] \\
\text { olor }[1 / 95=1.05 \%] \\
\text { tempre [1/95 }=1.05 \%]\end{array}$ & $\mathrm{N} / \mathrm{A}$ \\
\hline PA & $\begin{array}{l}\text { azeite }[13 / 18=72.22 \%] \\
\text { oliva }[4 / 18=22.22 \%]\end{array}$ & N/A & $\begin{array}{l}\text { olio }[9 / 20=45.00 \%] \\
\text { azeite }[7 / 20=35.00 \%] \\
\text { aciprés }[4 / 20=20.00 \%]\end{array}$ & N/A & $\begin{array}{l}\text { olio }[14 / 20=70.00 \%] \\
\text { azeite }[4 / 20=20.00 \%] \\
\text { ungüento }[1 / 20=5.00 \%]\end{array}$ & $\mathrm{N} / \mathrm{A}$ & $\mathrm{N} / \mathrm{A}$ & $\begin{array}{l}\text { olio }[17 / 21=80.95 \%] \\
\text { oliva }[2 / 21=9.52 \%] \\
\text { olivo }[2 / 21=9.52 \%]\end{array}$ & $\begin{array}{l}\text { olio }[10 / 21=47.62 \%] \\
\text { azeite }[7 / 21=33.33 \%] \\
\text { oliva }[4 / 21=19.05 \%]\end{array}$ \\
\hline PP & $\begin{array}{l}\text { azeite }[29 / 35=82.86 \%] \\
\text { grosura }[3 / 35=8.57 \%] \\
\text { grueso }[1 / 35=2.86 \%] \\
\text { pino }[1 / 35=2.86 \%]\end{array}$ & $\mathrm{N} / \mathrm{A}$ & N/A & $\begin{array}{l}\text { azeite }[16 / 35=45.71 \%] \\
\text { olio }[5 / 35=14.29 \%] \\
\text { ungüunto }[4 / 35=11.43 \%] \\
\text { grueso }[3 / 35=8.57 \%] \\
\text { gordura }[2 / 35=5.71 \%] \\
\text { grosura }[2 / 35=5.71 \%] \\
\text { gruesa a }[1 / 35=2.86 \%] \\
\text { unguiente }[1 / 35=2.86 \%]\end{array}$ & N/A & $\begin{array}{l}\text { olio }[20 / 35=57.14 \%] \\
\text { azeite }[7 / 73=20.00 \%] \\
\text { unguento }[4 / 35=11.43 \%] \\
\text { azeituno o } 11 / 35=2.86 \%] \\
\text { fertulidad }[1 / 35=2.86 \%] \\
\text { grueso }[1 / 35=2.86 \%]\end{array}$ & $\begin{array}{l}\text { grosura }[5 / 13=38.46 \%] \\
\text { olio }[4 / 13=30.77 \%] \\
\text { ungüento }[2 / 13=15.38 \%] \\
\text { samen }[1 / 13=7.69 \%]\end{array}$ & $\begin{array}{l}\text { olio }[26 / 35=74.29 \%] \\
\text { grosura }[2 / 35=5.71 \%] \\
\text { gruesa }[2 / 35=5.71 \%] \\
\text { unguento }[3 / 35=6.57 \%] \\
\text { oliva }[1 / 35=2.86 \%]\end{array}$ & $\mathrm{N} / \mathrm{A}$ \\
\hline Ketubim & $\begin{array}{l}\text { azeite }[28 / 31=90.32 \%] \\
\text { bálsamo }[1 / 31=3.23 \%] \\
\text { grosura a } 11 / 31=3.23 \%] \\
\text { oliva }[1 / 31=3.23 \%]\end{array}$ & N/A & N/A & $\begin{array}{l}\text { olio }[12 / 30=40.00 \%] \\
\text { azeite }[9 / 30=30.00 \%] \\
\text { afeite }[2 / 30=6.67 \%] \\
\text { gordura }[2 / 30=6.67 \%] \\
\text { ungüente }[2 / 30=6.67 \%] \\
\text { cillero }[1 / 30=3.33 \%] \\
\text { grosura }[1 / 30=3.33 \%] \\
\text { oliva }[1 / 30=3.33 \%]\end{array}$ & olio $[3 / 3=100.00 \%]$ & $\begin{array}{l}\text { olio }[12 / 28=42.86 \%] \\
\text { ungüunto }[7 / 28=25.00 \%] \\
\text { azeite }[6 / 28=21.43 \%] \\
\text { gruesa [2/28 } 2128.14 \%]\end{array}$ & N/A & $\begin{array}{l}\text { olio }[17 / 21=80.95 \%] \\
\text { ungüunto }[3 / 21=14.29 \%] \\
\text { grosura }[1 / 21=4.76 \%]\end{array}$ & $\mathrm{N} / \mathrm{A}$ \\
\hline
\end{tabular}




\begin{tabular}{|c|c|c|c|c|c|c|c|c|c|}
\hline \multicolumn{10}{|c|}{ 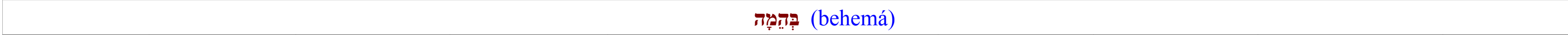 } \\
\hline Parte & E3 & E19 & E7 & E5 & $\mathrm{E} 4$ & BNE & RAH & Arragel & Oxford \\
\hline Torá & $\begin{array}{l}\text { bestia }[56 / 102=54.90 \%] \\
\text { cuatropea }[40 / 102= \\
39.22 \%] \\
\text { animalia }[4 / 102=3.92 \%] \\
\text { ganado }[1 / 102=0.98 \%]\end{array}$ & $\begin{array}{l}\text { cuatropedia }[50 / 85= \\
58.82 \%] \\
\text { bestia }[33 / 85=38.82 \%] \\
\text { ganado }[1 / 85=1.18 \%]\end{array}$ & $\begin{array}{l}\text { bestia }[41 / 88=46.59 \%] \\
\text { cuatropea }[34 / 86838.64 \%] \\
\text { animalia }[9 / 88=10.23 \%] \\
\text { ganado }[4 / 88=4.55 \%]\end{array}$ & $\mathrm{N} / \mathrm{A}$ & $\begin{array}{l}\text { bestia }[87 / 103=84.47 \%] \\
\text { animalia }[15 / 103=14.56 \%]\end{array}$ & N/A & N/A & $\begin{array}{l}\text { bestia }[66 / 103=64.08 \%] \\
\text { res }[22 / 103=21.36 \%] \\
\text { animalia }[7 / 103=6.80 \%] \\
\text { animal }[2 / 103=1.94 \%] \\
\text { cuatropedia }[2 / 103=1.94 \%] \\
\text { can }[1 / 103=0.97 \%] \\
\text { ganado }[1 / 103=0.97 \%]\end{array}$ & N/A \\
\hline PA & $\begin{array}{l}\text { bestia }[8 / 10=80.00 \%] \\
\text { animalia }[1 / 10=10.00 \%] \\
\text { villa }[1 / 10=10.00 \%]\end{array}$ & $\mathrm{N} / \mathrm{A}$ & $\begin{array}{l}\text { bestia }[4 / 10=40.00 \%] \\
\text { animalia }[2 / 10=20.00 \%] \\
\text { cuatropedia }[2 / 10=20.00 \%] \\
\text { ganado }[1 / 10=10.00 \%]\end{array}$ & N/A & bestia $[9 / 10=90.00 \%]$ & N/A & N/A & $\begin{array}{l}\text { bestia }[8 / 10=80.00 \%] \\
\text { ganado }[2 / 10=20.00 \%]\end{array}$ & bestia $[4 / 4=100.00 \%]$ \\
\hline $\mathbf{P P}$ & $\begin{array}{l}\text { bestia }[42 / 48=87.50 \%] \\
\text { animalia }[2 / 48=4.17 \%]] \\
\text { cuatropea }[1 / 48=2.08 \%]\end{array}$ & N/A & N/A & $\begin{array}{l}\text { bestia }[38 / 48=79.17 \%] \\
\text { animalia }[8 / 48=16.67 \%] \\
\text { ganado }[1 / 48=2.08 \%]\end{array}$ & N/A & $\begin{array}{l}\text { bestia }[47 / 48=97.92 \%] \\
\text { animalia }[1 / 48=2.08 \%]\end{array}$ & $\begin{array}{l}\text { bestia }[21 / 24=87.50 \%] \\
\text { animalia }[1 / 24=4.17 \%] \\
\text { ganado }[1 / 24=4.17 \%]\end{array}$ & $\begin{array}{l}\text { bestia }[44 / 48=91.67 \%] \\
\text { animalia }[3 / 48=6.25 \%]\end{array}$ & N/A \\
\hline Ketubim & $\begin{array}{l}\text { bestia }[26 / 29=89.66 \%] \\
\text { animalia }[2 / 29=6.90 \%] \\
\text { cuatropea }[1 / 29=3.45 \%]\end{array}$ & N/A & N/A & $\begin{array}{l}\text { bestia }[20 / 29=68.97 \%] \\
\text { animalia }[8 / 29=27.59 \%] \\
\text { animal }[1 / 29=3.45 \%]\end{array}$ & $\begin{array}{l}\text { bestia }[5 / 7=71.43 \%] \\
\text { animalia }[1 / 7=14.29 \%]\end{array}$ & bestia $[22 / 22=100.00 \%]$ & N/A & bestia $[18 / 18=100.00 \%]$ & N/A \\
\hline
\end{tabular}




\begin{tabular}{|c|c|c|c|c|c|c|c|c|c|}
\hline \multicolumn{10}{|c|}{ } \\
\hline Parte & E3 & E19 & E7 & E5 & E4 & BNE & RAH & Arragel & Oxford \\
\hline Torá & $\begin{array}{l}\text { mandamiento [64/65 = } \\
\text { 98.46\%] }\end{array}$ & $\begin{array}{l}\text { encomienda }[60 / 66= \\
90.91 \%] \\
\text { mandamiento }[4 / 66= \\
6.06 \%] \\
\text { encomendança }[1 / 66= \\
1.52 \%] \\
\text { mandado }[1 / 66=1.52 \%]\end{array}$ & $\begin{array}{l}\text { encomendança }[51 / 66= \\
77.27 \%]] \\
\text { mandamiento }[15 / 66= \\
22.73 \%]\end{array}$ & N/A & $\begin{array}{l}\text { precepto }[25 / 66=37.88 \%] \\
\text { mandamiento }[19 / 66=28.79 \%] \\
\text { encomienda }[14 / 66=21.21 \%] \\
\text { encomendança }[7 / 66=10.61 \%] \\
\text { fuero }[1 / 66=1.52 \%]\end{array}$ & N/A & N/A & $\begin{array}{l}\text { mandamiento }[56 / 65=86.15 \%] \\
\text { manda }[3 / 65=4.62 \%] \\
\text { mando }[3 / 65=4.62 \%] \\
\text { encomendar }=41 / 65=1.54 \%] \\
\text { guardar }[1 / 155=1.54 \%] \\
\text { ley }[1 / 65=1.54 \%]\end{array}$ & N/A \\
\hline PA & $\begin{array}{l}\text { mandamiento }[25 / 26= \\
96.15 \%]] \\
\operatorname{mandado}[1 / 26=3.85 \%]\end{array}$ & $\mathrm{N} / \mathrm{A}$ & $\begin{array}{l}\text { mandamiento }[20 / 26= \\
76.92 \%]] \\
\text { encomendança }[5 / 26= \\
19.23 \%]] \\
\text { mandado }[1 / 26=3.85 \%]\end{array}$ & N/A & $\begin{array}{l}\text { mandamiento }[19 / 26=73.08 \%] \\
\text { encomienda }[7 / 26=26.92 \%]\end{array}$ & N/A & N/A & $\begin{array}{l}\text { mandamiento }[25 / 26=96.15 \%] \\
\text { costodia }[1 / 26=3.85 \%]\end{array}$ & mandamiento $[23 / 23=100.00 \%]$ \\
\hline PP & $\begin{array}{l}\text { mandamiento }[9 / 10= \\
90.00 \%] \\
\text { poder }[1 / 10=10.00 \%]\end{array}$ & N/A & N/A & $\begin{array}{l}\text { mandamiento }[9 / 10= \\
90.00 \%] \\
\text { condición }[1 / 10= \\
10.00 \%]\end{array}$ & N/A & $\begin{array}{l}\text { mandamiento }[5 / 10= \\
50.00 \%] \\
\text { precepto }[4 / 10=40.00 \%]\end{array}$ & $\begin{array}{l}\text { mandado }[3 / 8=37.50 \%] \\
\text { mandamiento }[3 / 8=37.50 \%]\end{array}$ & $\begin{array}{l}\text { mandamiento }[9 / 10=90.00 \%] \\
\text { mandado }[1 / 10=10.00 \%]\end{array}$ & N/A \\
\hline Ketubim & $\begin{array}{l}\text { mandamiento }[69 / 82= \\
\quad 84.15 \%] \\
\text { mandado }[6 / 82=7.32 \%] \\
\text { mando }[6 / 82=7.32 \%]\end{array}$ & $\mathrm{N} / \mathrm{A}$ & N/A & $\begin{array}{l}\text { mandamiento [ }[58 / 82= \\
70.73 \%] \\
\text { encomendança }[16 / 82= \\
\quad 19.51 \%]] \\
\text { ordenanca }[3 / 82=3.66 \%] \\
\text { fuero }[1 / 82=1.22 \%] \\
\text { ley }[1 / 82=1.22 \%] \\
\text { mandado }[1 / 82=1.22 \%] \\
\text { ración }[1 / 182=1.22 \%] \\
\text { regla }[1 / 82=1.22 \%]\end{array}$ & $\begin{array}{l}\text { mandamiento }[16 / 19=84.21 \%] \\
\text { mandado }[2 / 19=10.53 \%] \\
\text { santificación }[1 / 19=5.26 \%] \\
\\
\end{array}$ & $\begin{array}{l}\text { precepto }[47 / 63=74.60 \%] \\
\text { mandado } 99 / 63=14.29 \%] \\
\text { mandamiento }[4 / 63= \\
6.35 \%] \\
\text { juizio }[2 / 63=3.17 \%] \\
\text { mando }[1 / 63=1.59 \%]\end{array}$ & N/A & $\begin{array}{l}\text { mandamiento }[42 / 56=75.00 \%] \\
\text { mandado }[4 / 56=7.14 \%] \\
\text { mando }[2 / 56=3.57 \%] \\
\text { dévido }[1 / 56=1.79 \%] \\
\text { ley }[1 / 56=1.79 \%] \\
\text { misericorida }[1 / 56=1.79 \%] \\
\text { ración }[1 / 56=1.79 \%]\end{array}$ & N/A \\
\hline
\end{tabular}




\begin{tabular}{|c|c|c|c|c|c|c|c|c|c|}
\hline \multicolumn{10}{|c|}{ פעִבִֶט (šébet) } \\
\hline Parte & E3 & E19 & E7 & E5 & E4 & BNE & RAH & Arragel & Oxford \\
\hline Torá & vara $[2 / 2=100 \%]$ & $\begin{array}{l}\text { verdugo }[3 / 32=9.38 \%] \\
\text { verga }[1 / 32=3.12 \%]\end{array}$ & $\begin{array}{l}\text { verga }[2 / 32=6.25 \%] \\
\text { cayado [1/32=3.12\%] } \\
\text { palo }[1 / 32=3.12 \%]\end{array}$ & N/A & $\begin{array}{l}\text { vara }[2 / 32=6.25 \%]] \\
\text { cetro }[1 / 32=3.12 \%] \\
\text { verga }[1 / 32=3.12 \%]\end{array}$ & $\mathrm{N} / \mathrm{A}$ & $\mathrm{N} / \mathrm{A}$ & $\begin{array}{l}\text { verga }[2 / 32=6.25 \%] \\
\text { cebtro }[1 / 32=3.12 \%]\end{array}$ & N/A \\
\hline PA & $\begin{array}{l}\text { vara }[2 / 80=2.50 \%] \\
\text { dardo }[1 / 80=1.25 \%]\end{array}$ & N/A & $\begin{array}{l}\text { dardo }[1 / 80=1.25 \%] \\
\text { lanç }[1 / 80=1.25 \%] \\
\text { verdugo }[1 / 80=1.25 \%]\end{array}$ & N/A & vara $[2 / 80=2.50 \%]$ & $\mathrm{N} / \mathrm{A}$ & N/A & $\begin{array}{l}\text { verga }[3 / 79=3.80 \%] \\
\text { lança }[1 / 79=1.27 \%]\end{array}$ & $\begin{array}{l}\text { alavesa }[1 / 47=2.13 \%] \\
\text { cabeça }[1 / 47=2.13 \%] \\
\text { palo }[1 / 47=2.13 \%] \\
\text { verdugo }[1 / 47=2.13 \%]\end{array}$ \\
\hline PP & $\operatorname{vara}[15 / 36=41.67 \%]$ & N/A & N/A & $\begin{array}{l}\text { verdugo }[8 / 36=22.22 \%] \\
\text { palo }[3 / 36=8.33 \%] \\
\text { arma }[2 / 36=5.56 \%] \\
\text { verga }[2 / 36=5.56 \%] \\
\text { acote }[1 / 36=2.78 \%] \\
\text { blago }[1 / 36=2.78 \%] \\
\text { cayada }[1 / 36=2.78 \%] \\
\text { vara }[1 / 36=2.78 \%]\end{array}$ & N/A & $\begin{array}{l}\text { vara }[11 / 37=29.73 \%] \\
\text { verga }[9 / 37=24.32 \%] \\
\text { brago }[1 / 37=2.70 \%]\end{array}$ & $\begin{array}{l}\text { verga }[7 / 14=50.00 \%] \\
\text { cebtro }[2 / 14=14.29 \%]\end{array}$ & $\begin{array}{l}\text { verga }[14 / 37=37.84 \%] \\
\text { cebtro }[7 / 37=18.92 \%] \\
\text { vara }[1 / 37=2.70 \%]\end{array}$ & N/A \\
\hline Ketubim & $\operatorname{vara}[18 / 40=45.00 \%]$ & N/A & N/A & $\begin{array}{l}\text { verdugo }[8 / 41=19.51 \%] \\
\text { açote }[7 / 71=17.07 \%] \\
\text { verga }[2 / 41=4.88 \%] \\
\text { amenaza }[1 / 41=2.44 \%] \\
\text { cayado }[1 / 14=2.44 \%] \\
\text { premia }[1 / 41=2.44 \%]\end{array}$ & {$[0 / 0=0.00 \%]$} & $\begin{array}{l}\text { vara }[11 / 41=26.83 \%] \\
\text { verga }[7 / 41=17.07 \%] \\
\text { lanca }[1 / 41=2.44 \%] \\
\text { palo }[1 / 41=2.44 \%]\end{array}$ & N/A & $\begin{array}{l}\text { verga }[10 / 28=35.71 \%] \\
\text { verdasca }[2 / 28=7.14 \%]\end{array}$ & N/A \\
\hline
\end{tabular}




\begin{tabular}{|c|c|c|c|c|c|c|c|c|c|}
\hline \multicolumn{10}{|c|}{ שְִָָָׁה (safá) } \\
\hline Parte & E3 & E19 & E7 & E5 & E4 & BNE & RAH & Arragel & Oxford \\
\hline Torá & $\begin{array}{l}\text { orilla }[18 / 19=94.7 \%] \\
\text { cerca }[1 / 19=5,3 \%] \\
\text { beço }[4 / 5=80 \%] \\
\text { labrio }[1 / 5=20 \%] \\
\text { fabla }[5 / 7=71,4 \%] \\
\text { lengua } 1[1 / 7=14,3 \%] \\
\text { juro }[1 / 7=14,3 \%]\end{array}$ & $\begin{array}{l}\text { orilla }[18 / 19=94,7 \%] \\
\text { ribera }[1 / 19=5,3 \%] \\
\text { boca }[4 / 4=100 \%] \\
\text { fabla }[2 / 3=66,7 \%] \\
\text { palabra }[1 / 3=33,3 \%]\end{array}$ & $\begin{array}{l}\text { orilla }[13 / 19=68,4 \%] \\
\text { ribera }[5 / 19=26,3 \%] \\
\text { cerco }[1 / 19=5,3 \%] \\
\text { boca }[4 / 6=66,7 \%] \\
\text { labrio }[2 / 6=33,3 \%] \\
\text { lenguaje }[5 / 6=83,3 \%] \\
\text { lengua }[1 / 6=16,7 \%]\end{array}$ & N/A & $\begin{array}{l}\text { orilla }[18 / 20=90 \%] \\
\text { ribera }[2 / 20=10 \%] \\
\text { beco }[4 / 5=80 \%] \\
\text { boca }[1 / 5=20 \%] \\
\text { lengua }[3 / 7=42,8 \%] \\
\text { lenguaje }[2 / 7=28,6 \%] \\
\text { fabla }[2 / 7=28,6 \%]\end{array}$ & $\mathrm{N} / \mathrm{A}$ & $\mathrm{N} / \mathrm{A}$ & $\begin{array}{l}\text { orilla }[20 / 20=100 \%] \\
\text { boca }[3 / 6=50 \%] \\
\text { labio }[3 / 6=50 \%] \\
\text { lengua }[5 / 6=83,3 \%] \\
\text { sermón }[1 / 6=16,7 \%]\end{array}$ & $\mathrm{N} / \mathrm{A}$ \\
\hline PA & $\begin{array}{l}\text { orilla }[15 / 15=100 \%] \\
\text { beço [2/2 = 100\%] } \\
\text { fabla [1/1 = 100\%] }\end{array}$ & N/A & $\begin{array}{l}\text { orilla }[6 / 13=46,1 \%] \\
\text { parte }[2 / 13=15,4 \%] \\
\text { ribera }[2 / 13=15,4 \%] \\
\text { cerco }[1 / 13=7,7 \%] \\
\text { puerto }[1 / 13=7,7 \%] \\
\text { obra }[1 / 13=7,7 \%] \\
\text { boca }[2 / 3=66,7 \%] \\
\text { beço }[1 / 3=33,3 \%]\end{array}$ & $\mathrm{N} / \mathrm{A}$ & $\begin{array}{l}\text { orilla }[9 / 11=81,8 \%] \\
\text { ribera }[1 / 11=9,1 \%] \\
\text { río }[1 / 11=9,1 \%] \\
\text { beço }[5 / 5=100 \%]\end{array}$ & $\mathrm{N} / \mathrm{A}$ & N/A & $\begin{array}{l}\text { orilla }[9 / 13=69,2 \%] \\
\text { rostro }[4 / 13=30,8 \%] \\
\text { labio }[3 / 3=100 \%] \\
\text { palabra }[1 / 1=100 \%]\end{array}$ & $\begin{array}{l}\text { orilla }[3 / 8=37,5 \%] \\
\text { ribera }[3 / 8=37,5 \%] \\
\text { cerco }[2 / 8=25 \%] \\
\text { beço }[3 / 6=50 \%] \\
\text { labio }[3 / 6=50 \%]\end{array}$ \\
\hline PP & $\begin{array}{l}\text { orilla }[3 / 4=75 \%] \\
\text { borda }[1 / 4=25 \%] \\
\text { beço }[24 / 24=100 \%] \\
\text { fabla }[9 / 9=100 \%]\end{array}$ & $\mathrm{N} / \mathrm{A}$ & N/A & $\begin{array}{l}\text { ribera }[3 / 4=75 \%] \\
\text { derredor }[1 / 4=25 \%] \\
\text { boca }[8 / 15=53,3 \%] \\
\text { beco }[6[15=40 \%] \\
\text { labrio }[1 / 15=6,7 \%] \\
\text { lenguje }[4 / 7=57,1 \%] \\
\text { lengua }[2 / 7=28,6 \%]\end{array}$ & $\mathrm{N} / \mathrm{A}$ & $\begin{array}{l}\text { orilla }[4 / 4=100 \%] \\
\text { beço }[16 / 16=100 \%] \\
\text { fabla }[2 / 6=33,3 \%] \\
\text { lengua }[2 / 6=33,3 \%] \\
\text { lenguaje }[2 / 6=33,3 \%]\end{array}$ & $\begin{array}{l}\text { labio }[10 / 11=90,9 \%] \\
\text { boca }[1 / 11=9,1 \%] \\
\text { lengua }[5 / 5=100 \%]\end{array}$ & $\begin{array}{l}\text { orilla }[2 / 3=66,7 \%] \\
\text { rostro }[1 / 3=33,3 \%] \\
\text { labio }[8]+\text { labrios }[2]+\text { labia }[1] \\
{[11 / 15=73,3 \%]} \\
\text { boca }[3 / 15=20 \%] \\
\text { beço }[1 / 15=6,7 \%] \\
\text { lengua }[7 / 7=100 \%]\end{array}$ & $\mathrm{N} / \mathrm{A}$ \\
\hline Ketubim & $\begin{array}{l}\text { orilla }[5 / 5=100 \%] \\
\text { beco }[83 / 84=98,8 \%] \\
\text { lengua }[1 / 84=1,2 \%] \\
\text { fabla }[8 / 11=72,7 \%] \\
\text { lengua }[3 / 11=27,3 \%]\end{array}$ & $\mathrm{N} / \mathrm{A}$ & N/A & $\begin{array}{l}\text { ribera }[3 / 3=100 \%] \\
\text { beço }[65 / 87=74,7 \%] \\
\text { labio }[12 / 87=13,8 \%] \\
\text { boca a } 8 / 87=9,2 \%] \\
\text { lengua }[2 / 87=2,3] \\
\text { palabra }[3 / 8=37,5 \%] \\
\text { lenguaje }[2 / 8=25 \%] \\
\text { lengua }[2 / 8=25 \%] \\
\text { enxemplo }[1 / 8=12,5 \%]\end{array}$ & {$[0 / 0=0.00 \%]$} & $\begin{array}{l}\text { orilla }[7 / 7=100 \%] \\
\text { beço }[78 / 80=97,5 \%] \\
\text { labio }[2 / 80=2,5 \%] \\
\text { fabla }[5 / 13=38,5 \%] \\
\text { palabra }[5 / 13=38,5 \%] \\
\text { lengua }[1 / 13=7,7 \%] \\
\text { lenguaje }[1 / 13=7,7 \%] \\
\text { verboso }[1 / 13=7,7 \%]\end{array}$ & N/A & $\begin{array}{l}\text { rostro }[4 / 7=57,1 \%] \\
\text { orilla }[3 / 7=42,9 \%] \\
\\
\text { labio }[55 / 62=88,7 \%] \\
\text { boca }[4 / 62=6,4 \%] \\
\text { lengua }[3 / 62=4,8 \%] \\
\text { fabla }[3 / 5=60 \%] \\
\text { lengua }[1 / 5=20 \%] \\
\text { palabra }[1 / 5=20 \%]\end{array}$ & $\mathrm{N} / \mathrm{A}$ \\
\hline
\end{tabular}




\begin{tabular}{|c|c|c|c|c|c|c|c|c|c|}
\hline \multicolumn{10}{|c|}{ עִדָה ('edá) } \\
\hline Parte & E3 & E19 & E7 & E5 & E4 & BNE & RAH & Arragel & Oxford \\
\hline Torá & $\begin{array}{l}\text { compaña }[51 / 105= \\
48,6 \%] \\
\text { concejo }[47 / 105=44,7 \%] \\
\text { gente }[3 / 105=2,8 \%] \\
\text { ayuntamiento }[2 / 105= \\
\quad 1,9 \%] \\
\text { pueblo }[2 / 105=1,9 \%] \\
\text { testimonio }[3 / 5=60 \%] \\
\text { testamiento }[1 / 5=20 \%] \\
\text { testigo }[1 / 5=20 \%]\end{array}$ & $\begin{array}{l}\text { compaña }[94 / 102=92,2 \%] \\
\text { aljama }[5 / 102=4,9 \%] \\
\text { ayuntar }[2 / 102=1,9 \%] \\
\text { colación }[1 / 102=0,9 \%] \\
\text { testamento }[4 / 5=80 \%] \\
\text { testimonio }[1 / 5=20 \%]\end{array}$ & $\begin{array}{l}\text { compaña [103/109= } \\
\quad 94,5 \%] \\
\text { colacion }[4 / 109=3.7 \%] \\
\text { gente }[1 / 109=0,9 \%] \\
\text { pueblo }[1 / 109=0,9 \%] \\
\\
\text { testimonio }[3 / 4=75 \%] \\
\text { testigo }[1 / 4=25 \%]\end{array}$ & N/A & $\begin{array}{l}\text { gente }[108 / 109=99,1 \%] \\
\text { pueblo }[1 / 109=0.9 \%] \\
\text { testimonio }[3 / 3=100 \%]\end{array}$ & N/A & N/A & 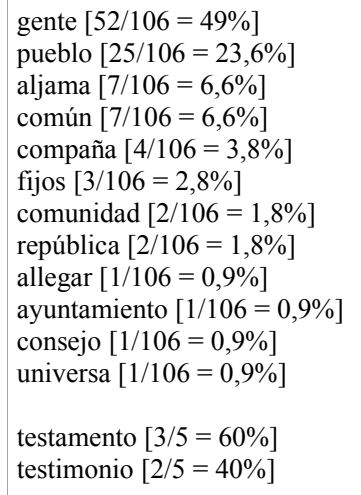 & N/A \\
\hline PA & $\begin{array}{l}\text { compaña }[21 / 22=95,4 \%] \\
\text { enxambre }[1 / 22=4,6 \%] \\
\text { testigo [2/2 }=100 \%]\end{array}$ & N/A & $\begin{array}{l}\text { compaña }[17 / 21= \\
\quad 80,9 \%] \\
\text { cabildo }[1 / 21=4,7 \%] \\
\text { colación [1/21=4,7\%] } \\
\text { muchidumbre }[1 / 21= \\
\quad 4,7 \%] \\
\text { pueblo }[1 / 21=4,7 \%] \\
\text { testigo }[1 / 1=100 \%]\end{array}$ & N/A & $\begin{array}{l}\text { gente }[19 / 23=82,6 \%] \\
\text { pueblo }[3 / 23=13 \%] \\
\text { ayuntamiento }[1 / 23=4,3 \%]\end{array}$ & N/A & N/A & $\begin{array}{l}\text { sinagoga }[7 / 23=30,4 \%] \\
\text { congregación }[6 / 23=26,1 \%] \\
\text { república }[4 / 23=17,4 \%] \\
\text { pueblo }[3 / 23=13 \%] \\
\text { gente }[2 / 23=8,7 \%] \\
\text { exambre }[1 / 23=4,3 \%]\end{array}$ & $\begin{array}{l}\text { compaña }[6 / 7=85.71 \%] \\
\text { enxambre }[1 / 7=14.29 \%]\end{array}$ \\
\hline PP & $\begin{array}{l}\text { compaña }[3 / 3=100 \%] \\
\text { testigo }[1 / 1=100 \%]\end{array}$ & N/A & N/A & $\begin{array}{l}\text { compaña }[1 / 2=50 \%] \\
\text { los que vinieren }[1 / 2= \\
50 \%] \\
\text { testimonio }[1 / 1=100 \%]\end{array}$ & N/A & $\begin{array}{l}\text { gente }[2 / 3=66.67 \%] \\
\text { compaña }[1 / 3=33.33 \%]\end{array}$ & $\begin{array}{l}\text { compaña }[1 / 2=50.00 \%] \\
\text { gente }[1 / 2=50.00 \%]\end{array}$ & $\begin{array}{l}\text { compañan }[1 / 3=33,3 \%] \\
\text { congregación }[1 / 3=33,3 \%] \\
\text { gente }[1 / 3=33,3 \%]\end{array}$ & N/A \\
\hline Ketubim & $\begin{array}{l}\text { compaña }[13 / 13=100 \%] \\
\text { testimonio }[16 / 19= \\
84,2 \%] \\
\text { testimiento }[3 / 19=15,8 \%]\end{array}$ & N/A & N/A & $\begin{array}{l}\text { compaña }[11 / 14=78,6 \%] \\
\text { cuadrilla }[2 / 14=14,3 \%] \\
\text { cabildo }[1 / 14=7,1 \%] \\
\text { testimonio }[19 / 21= \\
\quad 90,5 \%] \\
\text { fuero }[1 / 21=4,7 \%] \\
\text { mandamiento }[1 / 21= \\
\quad 4,7 \%]\end{array}$ & {$[0 / 0=0.00 \%]$} & $\begin{array}{l}\text { compaña }[12 / 14=85,7 \%] \\
\text { gente }[2 / 14=14,3 \%] \\
\text { testimonio }[19 / 19=100 \%]\end{array}$ & $\mathrm{N} / \mathrm{A}$ & $\begin{array}{l}\text { compaña }[1 / 4=25 \%] \\
\text { congregación }[1 / 4=25 \%] \\
\text { gente }[1 / 4=25 \%] \\
\text { sinagoga }[1 / 4=25 \%]\end{array}$ & N/A \\
\hline
\end{tabular}




\begin{tabular}{|c|c|c|c|c|c|c|c|c|c|}
\hline \multicolumn{10}{|c|}{ זְבְַח (zébaḥ) } \\
\hline Parte & E3 & E19 & E7 & E5 & E4 & BNE & RAH & Arragel & Oxford \\
\hline Torá & $\begin{array}{l}\text { sacrificio }[69 / 72= \\
95.83 \%] \\
\text { alsación }[1] 72=1.39 \%] \\
\text { sacrificar }[1 / 72=1.39 \%]\end{array}$ & $\begin{array}{l}\text { sacrificioi [67/72= } \\
93.06 \%] \\
\text { comer }[2 / 72=2.78 \%] \\
\text { allegamiento }[1 / 72= \\
1.39 \%] \\
\text { alsación }[1 / 72=1.39 \%] \\
\text { ofrición }[1 / 72=1.39 \%]\end{array}$ & $\begin{array}{l}\text { sacrificicio }[64 / 71= \\
\quad 90.14 \%] \\
\text { paz }[3 / 71=4.23 \%] \\
\text { degollanca }[1 / 71= \\
1.141 \%] \\
\text { presente }[1 / 71=1.41 \%] \\
\text { sacrificar }[1 / 71=1.41 \%]\end{array}$ & N/A & $\begin{array}{l}\text { sacrificioio }[69 / 72=95.83 \%] \\
\text { sacrificar }[1 / 72=1.39 \%]\end{array}$ & N/A & $\mathrm{N} / \mathrm{A}$ & $\begin{array}{l}\text { sacrificio }[58 / 61=95.08 \%] \\
\text { carnero [1/61 = } 1.64 \%] \\
\text { degollar }[1 / 161=1.64 \%] \\
\text { sacrificar }[1 / 61=1.64 \%]\end{array}$ & $\mathrm{N} / \mathrm{A}$ \\
\hline PA & sacrificio [31/31 = 100\%] & $\mathrm{N} / \mathrm{A}$ & $\begin{array}{l}\text { sacrificio }[25 / 31= \\
\quad 80.64 \%] \\
\text { fiesta }[2 / 31=6.45 \%] \\
\text { ofrenda }[1 / 31=3.22 \%] \\
\text { servicio }[1 / 31=3.22 \%]\end{array}$ & N/A & sacrificio [31/31 = 100\%] & $\mathrm{N} / \mathrm{A}$ & N/A & $\begin{array}{l}\text { sacrificio }[24 / 31=77.41 \%] \\
\text { hostia }[3 / 31=9.67 \%] \\
\text { fiesta }[2 / 31=3.22 \%] \\
\text { sacrificar }[2 / 31=3.22 \%]\end{array}$ & $\begin{array}{l}\text { sacrificioi }[24 / 26=92.30 \% \\
\text { ofrenda }[1 / 2=4.70 \%] \\
\text { sacrificar }[1 / 26=4.70 \%]\end{array}$ \\
\hline PP & $\begin{array}{l}\text { sacrificio }[29 / 30= \\
\quad 96.67 \%]\end{array}$ & N/A & N/A & $\begin{array}{l}\text { sacrificio }[15 / 30= \\
50.00 \%] \\
\text { presente }[4 / 30=13.33 \%] \\
\text { ofrenda }[3 / 30=10.00 \%] \\
\text { combite }[2 / 30=6.67 \%] \\
\text { degolladero }[2 / 30= \\
\quad 6.67 \%] \\
\text { degollación }[1 / 30=3.33 \%] \\
\text { prometimiento }[1 / 30= \\
\quad 3.33 \%]\end{array}$ & N/A & $\begin{array}{l}\text { sacrificio }[21 / 28=75.00 \%] \\
\text { degollamiento }[6 / 28= \\
21.43 \% \text { a } \\
\text { sacrificacion }[1 / 28= \\
3.57 \% \text { ] }\end{array}$ & $\begin{array}{l}\text { sacrificio }[10 / 13=76.92 \%] \\
\text { degolleo }[1 / 13=7.69 \%] \\
\text { holocausta }[1 / 13=7.69 \%]\end{array}$ & $\begin{array}{l}\text { sacrificio }[20 / 30=66.67 \%] \\
\text { degolleo }[4 / 30=13.33 \%] \\
\text { degollar }[2 / 30=6.67 \%] \\
\text { combite }[1 / 30=3.33 \%] \\
\text { santificar }[1 / 30=3.33 \%]\end{array}$ & N/A \\
\hline Ketubim & $\begin{array}{l}\text { sacrificioio }[29 / 30= \\
96.67 \%] \\
\operatorname{zebah}[1 / 30=3.33 \%]\end{array}$ & $\mathrm{N} / \mathrm{A}$ & $\mathrm{N} / \mathrm{A}$ & $\begin{array}{l}\text { sacrificio }[27 / 30= \\
\quad 90.00 \%] \\
\text { ofrenda }[1 / 30=3.33 \%] \\
\text { templamiento }[1 / 30= \\
\quad 3.33 \%]\end{array}$ & sacrificio $[1 / 1=100.00 \%]$ & $\begin{array}{l}\text { sacrificio }[27 / 29=93.10 \%] \\
\text { degollamiento }[1 / 29= \\
3.45 \%] \\
\text { zebaad }[1 / 29=3.45 \%]\end{array}$ & N/A & $\begin{array}{l}\text { sacrificio }[15 / 18=83.33 \%] \\
\operatorname{servir}[1 / 18=5.56 \%]\end{array}$ & $\mathrm{N} / \mathrm{A}$ \\
\hline
\end{tabular}




\begin{tabular}{|c|c|c|c|c|c|c|c|c|c|}
\hline \multicolumn{10}{|c|}{ 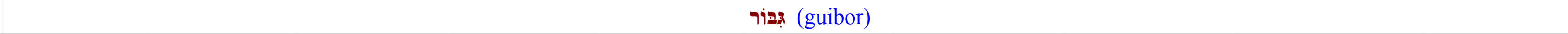 } \\
\hline Parte & E3 & E19 & E7 & E5 & E4 & BNE & RAH & Arragel & Oxford \\
\hline Torá & $\begin{array}{l}\text { barragán }[4 / 5=80.00 \%] \\
\text { gigante }[1 / 5=20.00 \%]\end{array}$ & barragán $[1 / 1=100.00 \%]$ & $\begin{array}{l}\text { barragán }[2 / 4=50.00 \%] \\
\text { caçador }[2 / 4=50.00 \%]\end{array}$ & $\mathrm{N} / \mathrm{A}$ & $\begin{array}{l}\text { estrenuo }[3 / 5=60.00 \%] \\
\text { potente }[2 / 5=40.00 \%]\end{array}$ & $\mathrm{N} / \mathrm{A}$ & $\mathrm{N} / \mathrm{A}$ & $\begin{array}{l}\text { barragán }[3 / 5=60.00 \%] \\
\text { poderoso }[2 / 5=40.00 \%]\end{array}$ & $\mathrm{N} / \mathrm{A}$ \\
\hline PA & $\begin{array}{l}\text { barragán [35/38 = } \\
\quad 92.11 \%] \\
\text { fuerte }[2 / 38=5.26 \%]\end{array}$ & N/A & $\begin{array}{l}\text { barragán [30/38 = } \\
78.95 \%] \\
\text { valiente }[2 / 38=5.26 \%] \\
\text { barraganía }[1 / 38= \\
2.63 \%] \\
\text { fazendado }[1 / 38= \\
2.63 \%] \\
\text { fuerte }[1 / 38=2.63 \%] \\
\text { fuerça }[1 / 38=2.63 \%] \\
\text { sano }[1 / 38=2.63 \%]\end{array}$ & $\mathrm{N} / \mathrm{A}$ & $\begin{array}{l}\text { potente }[30 / 38=78.95 \%] \\
\text { estrenuu }[5 / 38=13.16 \%] \\
\text { fuerte }[1 / 38=2.63 \%] \\
\text { perfecto }[1 / 38=2.63 \%] \\
\text { varón }[1 / 38=2.63 \%]\end{array}$ & $\mathrm{N} / \mathrm{A}$ & $\mathrm{N} / \mathrm{A}$ & $\begin{array}{l}\text { barragán }[233 / 38=60.53 \%] \\
\text { fuerte }[5 / 38=13.16 \%] \\
\text { rezio }[4 / 38=1.53 \%] \\
\text { fuerca }[2 / 38=5.26 \%] \\
\text { fortisimo }[1 / 38=2.63 \%] \\
\text { perfecto }[1 / 38=2.63 \%] \\
\text { potente }[1 / 38=2.63 \%] \\
\text { varón }[1 / 38=2.63 \%]\end{array}$ & 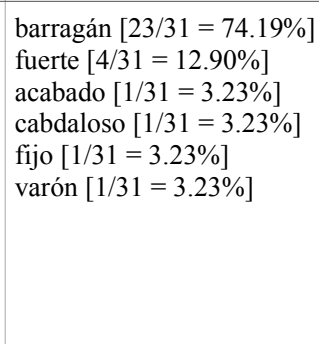 \\
\hline PP & $\begin{array}{l}\text { barragán }[45 / 48= \\
93.75 \%] \\
\text { fuerte }[1 / 48=2.08 \%]\end{array}$ & N/A & N/A & $\begin{array}{l}\text { barragán }[44 / 48= \\
\text { 91.67\%] } \\
\text { barragania }[3 / 48=6.25 \%]\end{array}$ & N/A & $\begin{array}{l}\text { potente }[41 / 48=85.42 \%] \\
\text { fuerte }[5 / 48=10.42 \%] \\
\text { barragan }[1 / 48=2.08 \%]\end{array}$ & $\begin{array}{l}\text { barragán }[14 / 28=50.00 \%] \\
\text { fuerte }[9 / 28=32.14 \%] \\
\text { poderoso }[1 / 28=3.57 \%] \\
\text { valioso }[1 / 28=3.57 \%] \\
\text { virtud }[1 / 28=3.57 \%]\end{array}$ & $\begin{array}{l}\text { barragán }[35 / 48=72.92 \%] \\
\text { fuerte }[8 / 48=16.67 \%] \\
\text { fortísimo }[5 / 48=10.42 \%]\end{array}$ & $\mathrm{N} / \mathrm{A}$ \\
\hline Ketubim & $\begin{array}{l}\text { barragán [ }[66 / 69= \\
\text { 95.65\%] } \\
\text { fuerte }[1 / 69=1.45 \%] \\
\text { grande }[1 / 69=1.45 \%]\end{array}$ & N/A & N/A & $\begin{array}{l}\text { barragán }[66 / 69= \\
95.65 \%] \\
\text { poderoso }[1 / 69=1.45 \%] \\
\text { valiente }[1 / 69=1.45 \%]\end{array}$ & $\begin{array}{l}\text { potente }[4 / 5=80.00 \%] \\
\text { estrenuo }[1 / 5=20.00 \%]\end{array}$ & $\begin{array}{l}\text { potente }[58 / 64=90.62 \%] \\
\text { estrenuo }[3 / 64=4.69 \%] \\
\text { cabecera }[1 / 64=1.56 \%] \\
\text { fuerte }[1 / 64=1.56 \%]\end{array}$ & $\mathrm{N} / \mathrm{A}$ & $\begin{array}{l}\text { barragán }[19 / 54=35.19 \%] \\
\text { fortísimo }[7 / 54=12.96 \%] \\
\text { fuerte }[7 / 54=12.96 \%] \\
\text { batallante }[5 / 54=9.26 \%] \\
\text { potente }[4 / 54=7.41 \%] \\
\text { poderoso }[3 / 54=5.56 \%] \\
\text { rezio }[3 / 54=5.56 \%] \\
\text { fuerça }[2 / 54=3.70 \%] \\
\text { potentísimo }[2 / 54=3.70 \%] \\
\text { ricosomnes }[1 / 54=1.85 \%]\end{array}$ & N/A \\
\hline
\end{tabular}


F. JAVIER PUeYo MENA Y ANDRÉS ENRIQUE-ARIAS

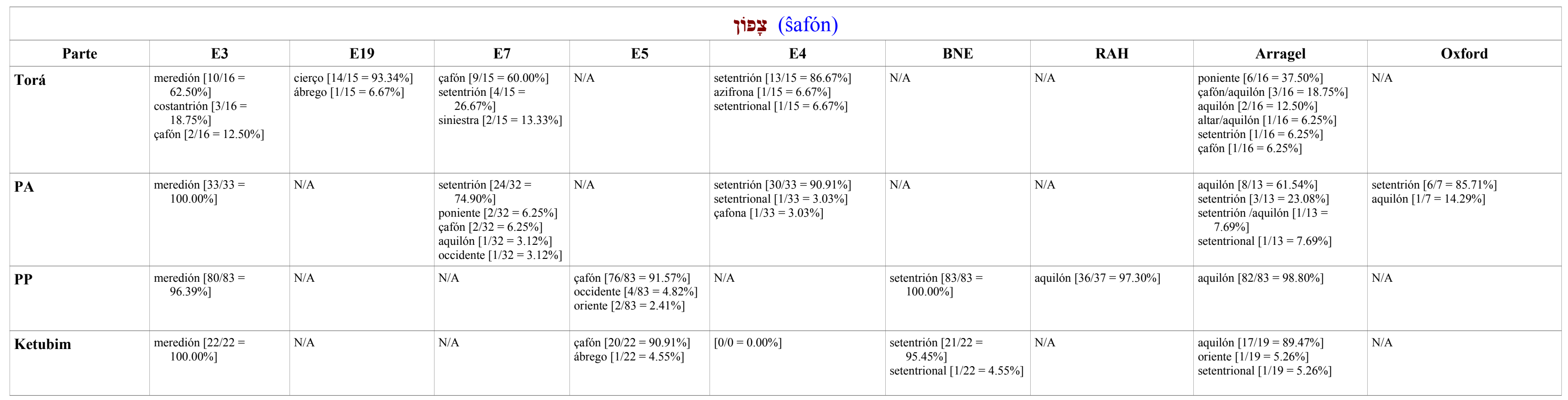

Sefarad, vol. 73:1, enero-junio 2013

14 


\begin{tabular}{|c|c|c|c|c|c|c|c|c|c|}
\hline \multicolumn{10}{|c|}{ 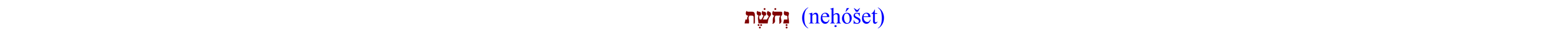 } \\
\hline Parte & E3 & E19 & E7 & E5 & E4 & BNE & RAH & Arragel & Oxford \\
\hline Torá & $\begin{array}{l}\text { cobre }[46 / 48=95.83 \%] \\
\text { latón }[2 / 48=4.17 \%]\end{array}$ & $\begin{array}{l}\text { alambre }[44 / 47=93.62 \%] \\
\text { estelo }[1 / 47=2.13 \%] \\
\text { grafio }[1 / 47=2.13 \%]\end{array}$ & $\begin{array}{l}\text { arambre }[45 / 47= \\
95.74 \%] \\
\text { armella }[1 / 47=2.13 \%] \\
\text { cobre }[1 / 47=2.13 \%]\end{array}$ & N/A & $\begin{array}{l}\text { cobre }[45 / 47=95.74 \%] \\
\text { azero }[1 / 47=2.13 \%]\end{array}$ & $\mathrm{N} / \mathrm{A}$ & N/A & $\begin{array}{l}\text { cobre }[30 / 48=62.50 \%] \\
\text { arambre }[12 / 48=25.00 \%] \\
\text { fierro }[3 / 48=6.25 \%] \\
\text { quicialera }[1 / 48=2.08 \%]\end{array}$ & N/A \\
\hline PA & $\begin{array}{l}\text { cobre }[17 / 37=45.95 \%] \\
\text { latón }[17 / 37=45.95 \%] \\
\text { cadena }[3 / 37=8.11 \%]\end{array}$ & N/A & $\begin{array}{l}\text { arambre }[13 / 38= \\
34.21 \%] \\
\text { latón }[12 / 38=31.58 \%] \\
\text { azero }[6 / 38=15.79 \%] \\
\text { fierro }[2 / 38=5.26 \%] \\
\text { encárcelado }[1 / 38= \\
2.63 \%] \\
\text { metal }[1 / 38=2.63 \%] \\
\text { prisión }[1 / 38=2.63 \%]\end{array}$ & N/A & $\begin{array}{l}\text { cobre }[28 / 38=73.68 \%] \\
\text { azero }[7 / 38=18.42 \%] \\
\text { cadena }[2 / 38=5.26 \%] \\
\text { fierro }[1 / 38=2.63 \%]\end{array}$ & N/A & N/A & $\begin{array}{l}\text { cobre }[28 / 38=73.68 \%] \\
\text { fierro }[6 / 38=15.79 \%] \\
\text { azero }[3 / 38=7.89 \%] \\
\text { loriga }[1 / 38=2.63 \%]\end{array}$ & $\begin{array}{l}\text { arambre }[17 / 27=62.96 \% \\
\text { cobre }[6 / 27=22.22 \%] \\
\text { aferrojado }[1 / 27=3.70 \%] \\
\text { cadena }[1 / 27=3.70 \%] \\
\text { latón }[1 / 27=3.70 \%] \\
\text { latonero }[1 / 27=3.70 \%]\end{array}$ \\
\hline PP & $\begin{array}{l}\text { latón }[10 / 25=40.00 \%] \\
\text { cobre }[9 / 25=36.00 \%] \\
\text { azero }[2 / 25=8.00 \%] \\
\text { cadena }[2 / 25=8.00 \%] \\
\text { estaño }[1 / 25=4.00 \%]\end{array}$ & N/A & N/A & $\begin{array}{l}\text { arambre }[11 / 25=44.00 \%] \\
\text { azero } 5 / 25=20.00 \%] \\
\text { cobre }[5 / 25=20.00 \%] \\
\text { latón n } 22 / 25=8.00 \%] \\
\text { cadena }[1 / 25=4.00 \%] \\
\text { prisión }[1 / 25=4.00 \%]\end{array}$ & N/A & $\begin{array}{l}\text { cobre }[19 / 25=76.00 \%] \\
\text { arambre }[2 / 25=8.00 \%] \\
\text { azero }[2 / 25=8.00 \%] \\
\text { cadena }[1 / 25=4.00 \%] \\
\text { fierro }[1 / 25=4.00 \%]\end{array}$ & $\begin{array}{l}\text { cobre }[15 / 18=83.33 \%] \\
\text { fierro }[2 / 18=11.11 \%]\end{array}$ & $\begin{array}{l}\text { cobre }[18 / 25=72.00 \%] \\
\text { fierro }[3 / 25=12.00 \%] \\
\text { azero }[1 / 25=4.00 \%] \\
\text { latón }[1 / 25=4.00 \%]\end{array}$ & N/A \\
\hline Ketubim & $\begin{array}{l}\text { latón }[16 / 27=59.26 \%] \\
\text { cobre }[8 / 27=29.63 \%] \\
\text { cadena }[2 / 27=7.41 \%] \\
\text { azero }[1 / 27=3.70 \%]\end{array}$ & N/A & N/A & $\begin{array}{l}\text { arambre }[10 / 28=35.71 \%] \\
\text { cobre }[8 / 28=28.57 \%] \\
\text { latón [4/28 }=14.29 \%]] \\
\text { cadena }[2 / 28=7.14 \%] \\
\text { azero }[1 / 28=3.57 \%] \\
\text { açorar }[1 / 28=3.57 \%] \\
\text { fierro }[1 / 28=3.57 \%] \\
\text { prisión }[1 / 28=3.57 \%]\end{array}$ & cobre $[1 / 1=100.00 \%]$ & $\begin{array}{l}\text { cobre }[24 / 28=85.71 \%] \\
\text { cadena [3/28 }=10.71 \%] \\
\text { azero }[1 / 28=3.57 \%]\end{array}$ & $\mathrm{N} / \mathrm{A}$ & $\begin{array}{l}\text { cobre }[18 / 28=64.29 \%] \\
\text { fierro }[3 / 28=1.71 \%] \\
\text { latón }[2 / 28=7.14 \%] \\
\text { cadena }[1 / 28=3.57 \%] \\
\text { cárcel }[1 / 28=3.57 \%] \\
\text { cobreña }[1 / 28=3.57 \%] \\
\text { combre }[1 / 28=3.57 \%]\end{array}$ & N/A \\
\hline
\end{tabular}




\begin{tabular}{|c|c|c|c|c|c|c|c|c|c|}
\hline \multicolumn{10}{|c|}{ יָיִִיִין (yamín) } \\
\hline Parte & E3 & E19 & E7 & E5 & $\mathrm{E} 4$ & BNE & RAH & Arragel & Oxford \\
\hline Torá & $\begin{array}{l}\text { diestra }[17 / 30=56.67 \%] \\
\text { derecha }[10 / 30=33.33 \%] \\
\text { jamin }[3 / 30=10.00 \%]\end{array}$ & $\begin{array}{l}\text { diestra }[15 / 28=53.57 \%] \\
\text { derecha }[10 / 28=35.71 \%] \\
\text { jamin }[3 / 28=10.71 \%]\end{array}$ & $\begin{array}{l}\text { diestra }[18 / 30=60.00 \%] \\
\text { derecha }[9 / 30=30.00 \%] \\
\text { jamin }[3 / 30=10.00 \%]\end{array}$ & N/A & $\begin{array}{l}\text { derecha }[12 / 30=40.00 \%] \\
\text { diestra }[8 / 30=26.67 \%] \\
\text { manderecha }[6 / 30=20.00 \%] \\
\text { jamin }[3 / 30=10.00 \%] \\
\text { destrar }[1 / 30=3.33 \%]\end{array}$ & N/A & N/A & $\begin{array}{l}\text { derecha }[16 / 29=55.17 \%] \\
\text { diestra }[6 / 29=20.69 \%] \\
\text { parte }[3 / 29=10.34 \%] \\
\text { jamin }[3 / 29=10.34 \%]\end{array}$ & $\mathrm{N} / \mathrm{A}$ \\
\hline PA & $\begin{array}{l}\text { diestra }[18 / 27=66.67 \%] \\
\text { derecha }[7 / 27=25.93 \%]\end{array}$ & N/A & $\begin{array}{l}\text { diestra }[14 / 27=51.85 \%] \\
\text { derecha }[9 / 27=33.33 \%]\end{array}$ & N/A & $\begin{array}{l}\text { derecha }[12 / 27=44.44 \%] \\
\text { diestra }[7 / 27=25.93 \%] \\
\text { manderecha }[6 / 27=22.22 \%]\end{array}$ & N/A & N/A & $\begin{array}{l}\text { diestra }[19 / 26=73.08 \%] \\
\text { derecha }[4 / 26=15.38 \%] \\
\text { parte }[2 / 26=7.69 \%]\end{array}$ & $\begin{array}{l}\text { diestra }[22 / 23=95.65 \%] \\
\text { derecha }[1 / 23=4.35 \%]\end{array}$ \\
\hline PP & $\begin{array}{l}\text { derecha }[13 / 23=56.52 \%] \\
\text { diestra }[10 / 23=43.48 \%]\end{array}$ & N/A & N/A & $\begin{array}{l}\text { diestra }[18 / 23=78.26 \%] \\
\text { derecha }[4 / 23=17.39 \%] \\
\text { mano }[1 / 23=4.35 \%]\end{array}$ & N/A & $\begin{array}{l}\text { derecha }[13 / 23=56.52 \%] \\
\text { manderecha }[6 / 23= \\
26.09 \%] \\
\text { diestra }[4 / 23=17.39 \%]\end{array}$ & $\begin{array}{l}\text { diestra }[9 / 12=75.00 \%] \\
\text { derecha }[3 / 12=25.00 \%]\end{array}$ & $\begin{array}{l}\text { diestra }[18 / 23=78.26 \%] \\
\text { derecha }[5 / 23=21.74 \%]\end{array}$ & N/A \\
\hline Ketubim & $\begin{array}{l}\text { diestra }[58 / 67=86.57 \%] \\
\text { jamin }[3 / 67=4.48 \%] \\
\text { derecha }\left[\begin{array}{l}{[/ 67=2.99 \%]} \\
\text { costantrión }[1 / 67=1.49 \%]\end{array}\right.\end{array}$ & N/A & N/A & $\begin{array}{l}\text { diestra }[59 / 67=88.06 \%] \\
\text { derecha }[1 / 67=1.49 \%] \\
\text { josmin }[1 / 167=1.49 \%] \\
\text { cafón }[1 / 67=1.49 \%]\end{array}$ & $\begin{array}{l}\text { manderecha }[2 / 3=66.67 \%] \\
\operatorname{jamin}[1 / 3=33.33 \%]\end{array}$ & $\begin{array}{l}\text { diestra }[45 / 64=70.31 \%] \\
\text { derecha }[9 / 64=14.06 \%] \\
\text { manderecha }[6 / 64=9.38 \%] \\
\text { jamín }[2 / 64=3.12 \%] \\
\text { meredión }[1 / 64=1.56 \%]\end{array}$ & N/A & $\begin{array}{l}\text { diestra }[12 / 25=48.00 \%] \\
\text { derecha }[6 / 25=24.00 \%] \\
\text { jamin }[2 / 25=8.00 \%] \\
\text { parte } 2[25=8.00 \%] \\
\text { austro }[1 / 25=4.00 \%]\end{array}$ & N/A \\
\hline
\end{tabular}




\begin{tabular}{|c|c|c|c|c|c|c|c|c|c|}
\hline \multicolumn{10}{|c|}{ 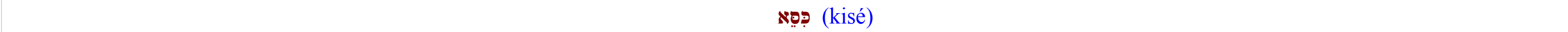 } \\
\hline Parte & E3 & E19 & E7 & E5 & E4 & BNE & RAH & Arragel & Oxford \\
\hline Torá & silla $[4 / 4=100.00 \%]$ & $\begin{array}{l}\text { silla [3/4 }=75.00 \%] \\
\text { catreda }[1 / 4=25.00 \%]\end{array}$ & silla $[4 / 4=100.00 \%]$ & N/A & $\begin{array}{l}\text { cátedra }[2 / 4=50.00 \%] \\
\text { silla [2/4=50.00\%] }\end{array}$ & N/A & N/A & $\begin{array}{l}\text { silla [3/4 }=75.00 \%] \\
\text { cátedra }[1 / 4=25.00 \%]\end{array}$ & N/A \\
\hline PA & silla $[50 / 50=100.00 \%]$ & N/A & $\begin{array}{l}\text { silla }[47 / 50=94.00 \%] \\
\text { asiento }[1 / 50=2.00 \%]\end{array}$ & N/A & $\begin{array}{l}\text { cátedra }[48 / 50=96.00 \%] \\
\text { silla }[1 / 50=2.00 \%]\end{array}$ & N/A & N/A & $\begin{array}{l}\text { trono }[28 / 50=56.00 \%] \\
\text { cátedra } 110 / 50=20.00 \%] \\
\text { silla }[10 / 50=20.00 \%] \\
\text { cadira }[1 / 50=2.00 \%]\end{array}$ & $\begin{array}{l}\text { silla }[45 / 48=93.75 \%] \\
\text { cátedra [2/48 }=4.17 \%] \\
\text { cabeca [1/48 }=2.08 \%]\end{array}$ \\
\hline PP & $\begin{array}{l}\text { silla }[32 / 34=94.12 \%] \\
\text { cabeça }[1 / 34=2.94 \%]\end{array}$ & N/A & N/A & $\begin{array}{l}\text { silla }[31 / 32=96.88 \%] \\
\text { asentar }[1 / 32=3.12 \%]\end{array}$ & N/A & $\begin{array}{l}\text { cátedra }[27 / 34=79.41 \%] \\
\text { silla }[7 / 34=20.59 \%]\end{array}$ & $\begin{array}{l}\text { silla }[15 / 28=53.57 \%] \\
\text { cátedra }[13 / 28=46.43 \%]\end{array}$ & $\begin{array}{l}\text { silla }[22 / 34=64.70 \%] \\
\text { trono }[11 / 34=32.35 \%] \\
\text { asiento }[1 / 34=2.94 \%]\end{array}$ & N/A \\
\hline Ketubim & silla [44/44 $=100.00 \%]$ & N/A & N/A & $\begin{array}{l}\text { silla }[39 / 46=84.78 \%] \\
\text { cátedra }[3 / 46=6.52 \%] \\
\text { asentar }[1 / 46=2.17 \%] \\
\text { casa }[1 / 46=2.17 \%]\end{array}$ & cátedra $[4 / 4=100.00 \%]$ & $\begin{array}{l}\text { cátedra }[24 / 42=57.14 \%] \\
\text { silla }[18 / 42=42.86 \%]\end{array}$ & N/A & $\begin{array}{l}\text { silla }[14 / 27=51.85 \%] \\
\text { trono }[10 / 27=37.04 \%] \\
\text { cátedra }[3 / 27=11.11 \%]\end{array}$ & N/A \\
\hline
\end{tabular}




\begin{tabular}{|c|c|c|c|c|c|c|c|c|c|}
\hline \multicolumn{10}{|c|}{ 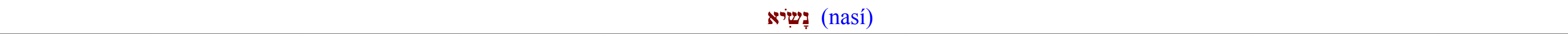 } \\
\hline Parte & E3 & E19 & E7 & E5 & E4 & BNE & RAH & Arragel & Oxford \\
\hline Torá & $\begin{array}{l}\text { mayoral }[68 / 71=95.77 \%] \\
\text { mayor }[2 / 71=2.82 \%]\end{array}$ & $\begin{array}{l}\text { capitán }[51 / 68=75.00 \%] \\
\text { mayoral }[11 / 68=16.18 \%] \\
\text { mayor }[3 / 68=4.41 \%] \\
\text { cabeçón }[1 / 68=1.47 \%]\end{array}$ & $\begin{array}{l}\text { escogido }[29 / 69= \\
42.03 \%] \\
\text { cabdillo }[16 / 69= \\
23.19 \%] \\
\text { capitán }[10 / 69= \\
14.49 \%] \\
\text { mayor }[5 / 69=7.25 \%] \\
\text { mayoral }[2 / 69=2.90 \%] \\
\text { cabecera }[1 / 69=1.45 \%] \\
\text { contado }[1 / 69=1.45 \%] \\
\text { grande }[1 / 69=1.45 \%] \\
\text { juez }[1 / 69=1.45 \%] \\
\text { príncipe }[1 / 69=1.45 \%] \\
\text { real }[1 / 69=1.45 \%] \\
\text { varon }[1 / 69=1.45 \%]\end{array}$ & $\mathrm{N} / \mathrm{A}$ & príncipe $[70 / 70=100 \%]$ & N/A & N/A & $\begin{array}{l}\text { mayoral }[32 / 71=45.07 \%] \\
\text { principe }[28771=39.44 \%] \\
\text { mayor }[3 / 71=4.23 \%] \\
\text { señor }[1 / 71=1.41 \%]\end{array}$ & N/A \\
\hline PA & $\begin{array}{l}\text { mayoral }[13 / 15=86.67 \%] \\
\text { mayor }[1 / 15=6.67 \%]\end{array}$ & N/A & $\begin{array}{l}\text { cabdillo }[12 / 15= \\
80.00 \%] \\
\text { capitán }[1 / 15=6.67 \%] \\
\text { escogido }[1 / 115=6.67 \%] \\
\text { rey }[1 / 15=6.67 \%]\end{array}$ & N/A & $\begin{array}{c}\text { príncipe }[15 / 15= \\
100.00 \%]\end{array}$ & N/A & N/A & $\begin{array}{l}\text { príncipe }[8 / 15=53.33 \%] \\
\text { mayoral }[6 / 15=40.00 \%] \\
\text { caudillo }[1 / 15=6.67 \%]\end{array}$ & $\begin{array}{l}\text { cabdillo }[1 / 2=50.00 \%] \\
\text { príncipe }[1 / 2=50.00 \%]\end{array}$ \\
\hline PP & $\begin{array}{l}\text { mayoral }[37 / 39=94.87 \%] \\
\text { nuve }[2 / 39=5.13 \%]\end{array}$ & N/A & N/A & $\begin{array}{l}\text { mayoral }[20 / 39=51.28 \%] \\
\text { cabdillo }[10 / 39=25.64 \%] \\
\text { familiar }[2 / 39=5.13 \%] \\
\text { nuve }[2 / 39=5.13 \%] \\
\text { cabecera }[1 / 39=2.56 \%] \\
\text { grande }[2 / 39=5.12 \%] \\
\text { mayor }[1 / 39=2.56 \%] \\
\text { mayoria }[1 / 39=2.56 \%]\end{array}$ & N/A & $\begin{array}{l}\text { príncipe }[35 / 39=89.74 \%] \\
\text { viento }[2 / 39=5.13 \%] \\
\text { profecia }[1 / 39=2.56 \%]\end{array}$ & $\begin{array}{l}\text { príncipe }[3 / 5=60.00 \%] \\
\text { nuve }[2 / 5=40.00 \%]\end{array}$ & $\begin{array}{l}\text { príncipe }[37 / 39=94.87 \%] \\
\text { nuve }[2 / 39=5.13 \%]\end{array}$ & N/A \\
\hline Ketubim & $\begin{array}{l}\text { mayoral }[7 / 9=77.78 \%] \\
\text { nuve }[2 / 9=22.22 \%]\end{array}$ & N/A & N/A & $\begin{array}{l}\text { cabdillo }[3 / 9=33.33 \%] \\
\text { capitán }[2 / 9=22.22 \%] \\
\text { alférez }[1 / 9=11.11 \%] \\
\text { nublo }[1 / 9=11.11 \%] \\
\text { nuve }[1 / 9=11.11 \%]\end{array}$ & príncipe $[1 / 1=100.00 \%]$ & $\begin{array}{l}\text { príncipe }[6 / 8=75.00 \%] \\
\text { viento }[2 / 8=25.00 \%]\end{array}$ & N/A & $\begin{array}{l}\text { príncipe }[7 / 8=87.50 \%] \\
\text { nuve }[1 / 8=12.50 \%]\end{array}$ & N/A \\
\hline
\end{tabular}




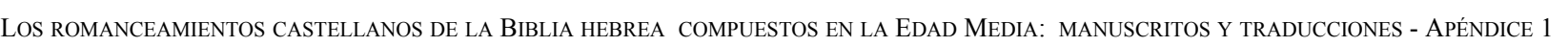

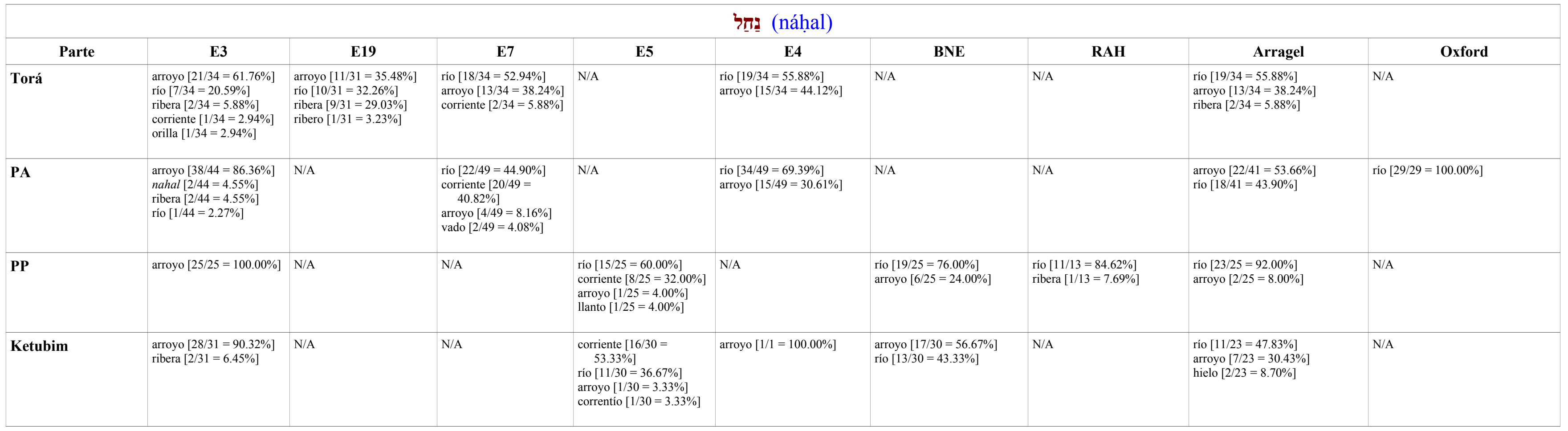

Sefarad, vol. 73:1, enero-junio 2013

19 


\begin{tabular}{|c|c|c|c|c|c|c|c|c|c|}
\hline \multicolumn{10}{|c|}{ פַ (par) } \\
\hline Parte & E3 & E19 & E7 & E5 & E4 & BNE & RAH & Arragel & Oxford \\
\hline Torá & $\begin{array}{l}\text { toro }[77 / 92=83.70 \%] \\
\text { bezerro }[3 / 92=3.26 \%] \\
\text { novillo }[3 / 92=3.26 \%] \\
\text { ternero }[3 / 92=3.26 \%] \\
\text { carnero }[2 / 92=2.17 \%] \\
\text { borrego }[1 / 92=1.09 \%]\end{array}$ & $\begin{array}{l}\text { toro }[91 / 92=98.91 \%] \\
\text { vaca }[1 / 92=1.09 \%]\end{array}$ & $\begin{array}{l}\text { toro }[54 / 92=58.70 \%] \\
\text { novillo }[30 / 92=32.61 \%] \\
\text { ternero }[8 / 92=8.70 \%]\end{array}$ & N/A & toro [91/92 = 98.91\%] & N/A & N/A & toro $[81 / 81=100.00 \%]$ & N/A \\
\hline PA & toro $[11 / 12=91.67 \%]$ & N/A & $\begin{array}{l}\text { toro }[10 / 12=83.33 \%] \\
\text { novillo }[2 / 12=16.67 \%]\end{array}$ & $\mathrm{N} / \mathrm{A}$ & toro $[12 / 12=100.00 \%]$ & N/A & $\mathrm{N} / \mathrm{A}$ & toro $[12 / 12=100.00 \%]$ & $\begin{array}{l}\text { ternero }[8 / 12=66.67 \%] \\
\text { novillo }[4 / 12=33.33 \%]\end{array}$ \\
\hline PP & $\begin{array}{l}\text { toro }[16 / 17=94.12 \%] \\
\text { vaca }[1 / 17=5.88 \%]\end{array}$ & N/A & N/A & $\begin{array}{l}\text { novillo }[15 / 17=88.24 \%] \\
\text { fruto }[1 / 17=5.88 \%]\end{array}$ & $\mathrm{N} / \mathrm{A}$ & $\begin{array}{l}\text { toro }[15 / 17=88.24 \%] \\
\text { barvez }[1 / 17=5.88 \%]\end{array}$ & toro $[3 / 3=100.00 \%]$ & $\begin{array}{l}\text { toro }[15 / 17=88.24 \%] \\
\text { cabrón }[1117=5.88 \%] \\
\text { vacuno }[1 / 17=5.88 \%]\end{array}$ & $\mathrm{N} / \mathrm{A}$ \\
\hline Ketubim & toro $[12 / 12=100.00 \%]$ & N/A & N/A & $\begin{array}{l}\text { novillo }[11 / 12=91.67 \%] \\
\text { toro }[1 / 12=8.33 \%]\end{array}$ & toro $[1 / 1=100.00 \%]$ & toro $[10 / 11=90.91 \%]$ & $\mathrm{N} / \mathrm{A}$ & toro $[8 / 8=100.00 \%]$ & $\mathrm{N} / \mathrm{A}$ \\
\hline
\end{tabular}




\begin{tabular}{|c|c|c|c|c|c|c|c|c|c|}
\hline \multicolumn{10}{|c|}{ 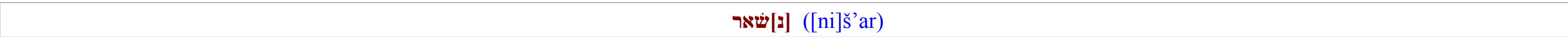 } \\
\hline Parte & E3 & E19 & E7 & E5 & $\mathbf{E} 4$ & BNE & RAH & Arragel & Oxford \\
\hline Torá & $\begin{array}{c}\text { quedar }[19 / 29=65.52 \%] \\
\text { fincar/fincable }[3 / 29= \\
10.35 \%] \\
\text { remanecerremaniente } \\
{[3 / 29=10.35 \%]} \\
\text { dexar }[1 / 29=3.45 \%] \\
\text { quitar }[1 / 29=3.45 \%] \\
\text { sobrar }[1 / 29=3.45 \%]\end{array}$ & $\begin{array}{l}\text { remanecer/remaniente } \\
{[15 / 27=55.55 \%]} \\
\text { quedar }[4 / 27=14.81 \%] \\
\text { dexar }[3 / 27=11.11 \%] \\
\text { fincar }[3 / 27=14.82 \%] \\
\text { sobrar }[1 / 27=3.70 \%]\end{array}$ & $\begin{array}{l}\text { quedar }[15 / 28=53.57 \%] \\
\text { remanecer/remaniente } \\
{[7728=25.00 \%]} \\
\text { sobrar }[3 / 28=10.71 \%] \\
\text { dexar }[1 / 28=3.57 \%] \\
\text { escapar }[1 / 28=3.57 \%]\end{array}$ & N/A & $\begin{array}{l}\text { quedar }[20 / 29=68.97 \%] \\
\text { dexar }[3 / 29=10.34 \%] \\
\text { escapar }[1 / 29=3.45 \%] \\
\text { fincar }[1 / 29=3.45 \%] \\
\text { sobrar }[1 / 29=3.45 \%]\end{array}$ & $\mathrm{N} / \mathrm{A}$ & N/A & $\begin{array}{l}\text { quedar }[19 / 29=65.52 \%] \\
\text { dexar }[5 / 29=17.24 \%] \\
\text { remanecerr/remanente/romanecer } \\
{[4 / 29=13.80 \%]}\end{array}$ & $\mathrm{N} / \mathrm{A}$ \\
\hline PA & $\begin{array}{l}\text { quedar }[33 / 49=67.35 \%] \\
\text { dexar }[3 / 49=18.37 \%] \\
\text { remanecer/remaniente } \\
{[5 / 49=10.20 \%]} \\
\text { escapar }[1 / 49=2.04 \%] \\
\text { fincar }[1 / 49=2.04 \%]\end{array}$ & N/A & $\begin{array}{l}\text { quedar }[36 / 49=73.47 \%] \\
\text { dexar }[7 / 49=14.29 \%] \\
\text { escapar }[3 / 49=6.12 \%] \\
\text { apartadar }[1 / 49=2.04 \%]\end{array}$ & N/A & $\begin{array}{l}\text { quedar }[38 / 49=77.55 \%] \\
\text { dexar }[9 / 49=18.37 \%]\end{array}$ & $\mathrm{N} / \mathrm{A}$ & N/A & $\begin{array}{l}\text { quedar }[23 / 49=46.94 \%] \\
\text { remanecer/remaner }[14 / 49= \\
28.57 \%] \\
\text { dexar }[12 / 49=24.49 \%]\end{array}$ & $\begin{array}{l}\text { remanecer }[11 / 27=40.74 \%] \\
\text { dexar }[6 / 27=22.22 \%] \\
\text { fincar [6/27 }=22.22 \%] \\
\text { quedar }[2 / 27=7.41 \%]\end{array}$ \\
\hline PP & $\begin{array}{l}\text { quedar }[15 / 39=38.46 \%] \\
\text { fincar }[9 / 39=23.08 \%] \\
\text { fincable }[2 / 39=5.13 \%] \\
\text { dexar }[6 / 39=15.38 \%] \\
\text { remanecer/remaniente } \\
{[6 / 39=15.38 \%]}\end{array}$ & N/A & N/A & $\begin{array}{l}\text { quedar }[29 / 39=74.35 \%] \\
\text { dexar }[5 / 39=12.82 \%] \\
\text { remanecer/remaniente } \\
{[5 / 39=12.82 \%]}\end{array}$ & N/A & $\begin{array}{l}\text { quedar }[32 / 39=82.05 \%] \\
\text { dexar }[7 / 39=17.95 \%]\end{array}$ & $\begin{array}{l}\text { remanecer/remanente }[17 / 28 \\
=60.71 \%] \\
\text { quedar }[7 / 28=25.00 \%] \\
\operatorname{dexar}[4 / 28=14.29 \%]\end{array}$ & $\begin{array}{l}\text { remanecer/remanente/remaner } \\
{[32 / 39=82.05 \%]} \\
\text { dexar }[5 / 39=12.82 \%] \\
\text { quedar }[1 / 39=2.56 \%]\end{array}$ & $\mathrm{N} / \mathrm{A}$ \\
\hline Ketubim & $\begin{array}{l}\text { quedar }[12 / 16=75.00 \%] \\
\text { remanecer/remaniente } \\
{[3 / 16=18.75 \%]} \\
\text { dexar }[1 / 16=6.25 \%]\end{array}$ & N/A & N/A & $\begin{array}{l}\text { quedar }[12 / 16=75.00 \%] \\
\text { dexar }[2 / 16=12.50 \%] \\
\text { remanecer/remaniente } \\
{[1 / 16=6.25 \%]}\end{array}$ & $\begin{array}{l}\text { quedar }[6 / 8=75.00 \%] \\
\text { dexar }[1 / 8=12.50 \%] \\
\text { escapar }[1 / 8=12.50 \%]\end{array}$ & quedar $[8 / 8=100.00 \%]$ & N/A & $\begin{array}{l}\text { remanecer/remanente/remaner } \\
{[14 / 16=88.50 \%]} \\
\text { quedar }[2 / 16=12.50 \%]\end{array}$ & $\mathrm{N} / \mathrm{A}$ \\
\hline
\end{tabular}




\begin{tabular}{|c|c|c|c|c|c|c|c|c|c|}
\hline \multicolumn{10}{|c|}{ זٓק (hoc) } \\
\hline Parte & E3 & E19 & E7 & E5 & E4 & BNE & RAH & Arragel & Oxford \\
\hline Torá & fuero $[45 / 45=100.00 \%]$ & $\begin{array}{l}\text { fuero }[39 / 47=82.98 \%] \\
\text { ración }[6 / 47=12.77 \%] \\
\text { ley }[1 / 47=2.13 \%]\end{array}$ & $\begin{array}{c}\text { fuero }[34 / 47=72.34 \%] \\
\text { parte }[4 / 47=8.51 \%] \\
\text { costumbre }[3 / 47= \\
6.38 \%] \\
\text { juizio }[2 / 47=4.26 \%] \\
\text { ración }[2 / 47=4.26 \%]\end{array}$ & $\mathrm{N} / \mathrm{A}$ & $\begin{array}{l}\text { fuero }[40 / 47=85.11 \%] \\
\text { ración }[6 / 47=12.77 \%] \\
\text { prevenda }[1 / 47=2.13 \%]\end{array}$ & $\mathrm{N} / \mathrm{A}$ & $\mathrm{N} / \mathrm{A}$ & $\begin{array}{l}\text { fuero [39/46 }=84.78 \%] \\
\text { ración }[4 / 46=8.70 \%] \\
\text { administración }[1 / 1 / 4=2.17 \%] \\
\text { ley }[1 / 46=2.17 \%]\end{array}$ & $\mathrm{N} / \mathrm{A}$ \\
\hline PA & fuero $[9 / 10=90.00 \%]$ & $\mathrm{N} / \mathrm{A}$ & $\begin{array}{l}\text { fuero }[8 / 10=80.00 \%] \\
\text { costumbre } 1[1 / 10= \\
10.00 \%]\end{array}$ & $\mathrm{N} / \mathrm{A}$ & $\begin{array}{l}\text { fuero }[9 / 10=90.00 \%] \\
\text { aforador }[1 / 10=10.00 \%]\end{array}$ & $\mathrm{N} / \mathrm{A}$ & N/A & $\begin{array}{l}\text { fuero }[7 / 10=70.00 \%] \\
\text { costumbre }[1 / 10=100.00 \%] \\
\text { juizio }[11 / 10=10.00 \%]\end{array}$ & $\begin{array}{l}\text { establecimiento }[7 / 9=77.78 \%] \\
\text { costumbre }[1 / 9=11.11 \%]\end{array}$ \\
\hline PP & $\begin{array}{l}\text { fuero }[14 / 17=82.35 \%] \\
\text { cavacadura }[1 / 17= \\
55.88 \%] \\
\text { fuerte }[1 / 17=5.88 \%]\end{array}$ & N/A & N/A & $\begin{array}{l}\text { fuero [12/18=66.67\%] } \\
\text { costumbre [2/18 = } \\
11.111 \%] \\
\text { costumbrado [1/18 = } \\
5.56 \%] \\
\text { derecha }[1 / 18=5.56 \%] \\
\text { dicho [1/18=5.56\%] } \\
\text { significación [1/18 } \\
5.56 \%]\end{array}$ & N/A & $\begin{array}{l}\text { fuero }[17 / 18=94.44 \%] \\
\text { institución }[1 / 18=5.56 \%]\end{array}$ & $\begin{array}{l}\text { fuero }[3 / 7=42.86 \%] \\
\text { costumbre }[1 / 7=14.29 \%] \\
\text { escriptura }[117=14.29 \%] \\
\text { ley }[1 / 7=14.29 \% \text { ] }\end{array}$ & $\begin{array}{l}\text { fuero }[11 / 18=61.11 \%] \\
\text { juizio } 11 / 18=5.56 \%] \\
\text { letra }[1 / 18=5.56 \%] \\
\text { ley }[1 / 18=5.56 \%] \\
\text { publicación }[1 / 18=5.56 \%]\end{array}$ & N/A \\
\hline Ketubim & $\begin{array}{l}\text { fuero }[49 / 56=87.50 \%] \\
\text { sentencia }[3 / 56=5.36 \%] \\
\text { mandamiento }[1 / 56= \\
1.79 \%] \\
\text { mantenimiento }[1 / 56= \\
1.79 \%]\end{array}$ & N/A & $\mathrm{N} / \mathrm{A}$ & 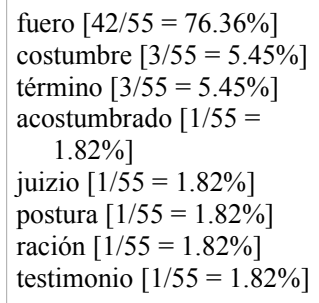 & $\begin{array}{l}\text { fuero }[5 / 6=83.33 \%] \\
\text { ley }[1 / 6=16.67 \%]\end{array}$ & $\begin{array}{l}\text { fuero }[48 / 50=96.00 \%] \\
\text { ración }[1 / 50=2.00 \%]\end{array}$ & N/A & $\begin{array}{l}\text { fuero }[12 / 25=48.00 \%] \\
\text { ley }[3 / 25=12.00 \%] \\
\text { término }[3 / 25=12.00 \%] \\
\text { costumbre }[1 / 25=4.00 \%] \\
\text { juizio }[1 / 25=4.00 \%] \\
\text { mandamiento }[1 / 25=4.00 \%] \\
\text { plazo }[1 / 25=4.00 \%] \\
\text { testamento }[1 / 25=4.00 \%]\end{array}$ & $\mathrm{N} / \mathrm{A}$ \\
\hline
\end{tabular}




\begin{tabular}{|c|c|c|c|c|c|c|c|c|c|}
\hline \multicolumn{10}{|c|}{ פַn (kóaḥ) } \\
\hline Parte & $\mathbf{E 3}$ & E19 & E7 & E5 & $\mathrm{E} 4$ & BNE & RAH & Arragel & Oxford \\
\hline Torá & fuerça $[13 / 14=92.86 \%]$ & $\begin{array}{l}\text { fuerca }[10 / 13=76.92 \%] \\
\text { fuerte }[1 / 13=7.69 \%] \\
\text { poder }[1 / 13=7.69 \%]\end{array}$ & $\begin{array}{l}\text { fuerca }[8 / 13=61.54 \%] \\
\text { poderio }[2 / 13==15.38 \%] \\
\text { apoderado }[1 / 13= \\
7.69 \%] \\
\text { trabajo }[1] 13=7.69 \%]\end{array}$ & N/A & $\begin{array}{l}\text { fuerca }[7 / 14=50.00 \%] \\
\text { coa }[11 / 14=7.14 \%] \\
\text { fortificada }[1 / 14=7.14 \%] \\
\text { fuerte }[1 / 14=7.14 \%] \\
\text { grandeza }[1 / 14=7.14 \%] \\
\text { poder }[1 / 14=7.14 \%] \\
\text { poderio }[1 / 14=7.14 \%] \\
\text { virtud }[1 / 14=7.14 \%]\end{array}$ & N/A & N/A & $\begin{array}{l}\text { fuerca }[8 / 14=57.14 \%] \\
\text { fortaleza }[1 / 14=7.14 \%] \\
\text { fuerte }[1 / 14=7.14 \%] \\
\text { potencia }[1 / 14=7.14 \%] \\
\text { virtud }[1 / 14=7.14 \%]\end{array}$ & N/A \\
\hline PA & fuerça $[18 / 18=100.00 \%]$ & N/A & $\begin{array}{l}\text { fuerca }[12 / 17=70.59 \%] \\
\text { esfuerco }[2 / 17= \\
11.76 \%] \\
\text { fortaleza } 1[1 / 17=5.88 \%] \\
\text { fuerte }[1 / 17=5.88 \%]\end{array}$ & N/A & $\begin{array}{l}\text { fuerça }[17 / 18=94.44 \%] \\
\text { fuerte }[1 / 18=5.56 \%]\end{array}$ & N/A & N/A & $\begin{array}{l}\text { fuerca }[15 / 18=83.33 \%] \\
\text { esfuerço }[1 / 18=5.56 \%] \\
\text { fortaleza }[1 / 18=5.56 \%]\end{array}$ & $\begin{array}{l}\text { fortaleza }[10 / 15=66.67 \%] \\
\text { fuerça }[4 / 15=26.67 \%] \\
\text { esfuerço }[1 / 15=6.67 \%]\end{array}$ \\
\hline PP & $\begin{array}{l}\text { fuerca }[23 / 24=95.83 \%] \\
\text { fortaleza }[1 / 24=4.17 \%]\end{array}$ & N/A & N/A & $\begin{array}{l}\text { fuerca }[16 / 24=66.67 \%] \\
\text { fortaleza }[8 / 24=33.33 \%]\end{array}$ & N/A & $\begin{array}{l}\text { fuerca }[12 / 24=50.00 \%] \\
\text { potencia }[9 / 24=37.50 \%] \\
\text { esfuerca }[1 / 24=4.17 \%] \\
\text { poder }[1 / 24=4.17 \%] \\
\text { potente }[1 / 24=4.17 \%]\end{array}$ & $\begin{array}{l}\text { fuerca }[9 / 17=52.94 \%] \\
\text { virtud }[8 / 17=47.06 \%]\end{array}$ & $\begin{array}{l}\text { fuerca }[20 / 24=83.33 \%] \\
\text { virtud }[3 / 24=12.50 \%] \\
\text { fuerte }[1 / 24=4.17 \%]\end{array}$ & N/A \\
\hline Ketubim & fuerça $[71 / 71=100.00 \%]$ & N/A & $\mathrm{N} / \mathrm{A}$ & 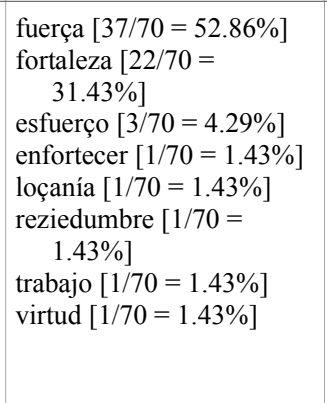 & $\begin{array}{l}\text { poder }[2 / 4=50.00 \%] \\
\text { fuerca a } 11 / 4=25.00 \%] \\
\text { potencia }[1 / 4=25.00 \%]\end{array}$ & $\begin{array}{l}\text { fuerca }[34 / 67=50.75 \%] \\
\text { potencia }[21 / 167=31.34 \%] \\
\text { virtud }[7 / 67=10.45 \%] \\
\text { fortificar }[1 / 67=1.49 \%] \\
\text { fuerte }[1 / 67=1.49 \%] \\
\text { mano }[1 / 67=1.49 \%] \\
\text { poderí }[1 / 67=1.49 \%]\end{array}$ & N/A & 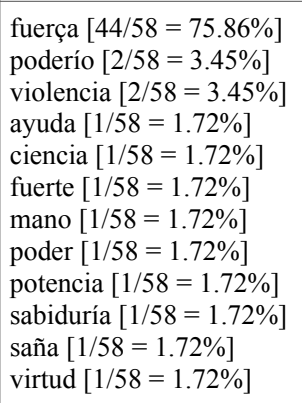 & N/A \\
\hline
\end{tabular}




\begin{tabular}{|c|c|c|c|c|c|c|c|c|c|}
\hline \multicolumn{10}{|c|}{ קָדָל (cahal) } \\
\hline Parte & E3 & E19 & E7 & E5 & E4 & BNE & RAH & Arragel & Oxford \\
\hline Torá & $\begin{array}{l}\text { compaña }[24 / 32= \\
75.00 \%] \\
\text { ayuntamiento }[2 / 32= \\
6.25 \%]] \\
\text { concejo }[2 / 32=6.25 \%] \\
\text { ayuntar }[1 / 32=3.12 \%] \\
\text { pueblo }[1 / 32=3.12 \%]\end{array}$ & $\begin{array}{l}\text { compaña }[28 / 34=82.35 \%] \\
\text { ayuntamiento }[3 / 34= \\
\quad 8.82 \%] \\
\text { aljama }[2 / 34=5.88 \%] \\
\text { ayuntado }[1 / 34=2.94 \%]\end{array}$ & $\begin{array}{l}\text { compana }[23 / 34= \\
67.65 \%] \\
\text { comarca }[3 / 34=8.82 \%] \\
\text { ayuntado }[2 / 34=5.88 \%] \\
\text { ayuntamiento }[2 / 34= \\
5.88 \%] \\
\text { consej }[1 / 34=2.94 \%] \\
\text { gente }[1 / 34=2.94 \%] \\
\text { pueblo }[1 / 34=2.94 \%]\end{array}$ & N/A & $\begin{array}{l}\text { pueblo }[15 / 34=44.12 \%] \\
\text { ayuntamiento }[10 / 34= \\
29.41 \%] \\
\text { concilio }[3 / 34=8.82 \%] \\
\text { gente }[3 / 34=8.82 \%] \\
\text { ayuntado }[2 / 34=5.88 \%] \\
\text { comarca }[1 / 34=2.94 \%]\end{array}$ & N/A & N/A & $\begin{array}{l}\text { colación }[12 / 34=35.29 \%] \\
\text { gente }[7 / 34=20.59 \%] \\
\text { común }[3 / 34=8.82 \%] \\
\text { comunidad }[3 / 34=8.82 \%] \\
\text { junta }[2 / 34=5.88 \%] \\
\text { compaña }[1 / 34=2.94 \%] \\
\text { comuna }[1 / 34=2.94 \%] \\
\text { concejo }[1 / 34=2.94 \%] \\
\text { juntamiento }[1 / 34=2.94 \%] \\
\text { pueblo }[1 / 34=2.94 \%]\end{array}$ & $\mathrm{N} / \mathrm{A}$ \\
\hline PA & $\begin{array}{c}\text { compaña }[11 / 111= \\
100.00 \%]\end{array}$ & N/A & $\begin{array}{l}\text { compaña [5/11 = } \\
45.45 \%] \\
\text { cabildo [2/11=18.18\%] } \\
\text { ayuntamiento }[1 / 11= \\
9.09 \%] \\
\text { comunidad [1/11= } \\
9.09 \%] \\
\text { gente [1/11 =9.09\%] } \\
\text { hueste }[1 / 11=9.09 \%]\end{array}$ & $\mathrm{N} / \mathrm{A}$ & $\begin{array}{l}\text { concilio }[7 / 11=63.64 \%] \\
\text { pueblo }[2 / 11=18.18 \%] \\
\text { gente }[1111=9.09 \%] \\
\text { gentio }[1111=9.09 \%]\end{array}$ & $\mathrm{N} / \mathrm{A}$ & N/A & $\begin{array}{l}\text { egleja }[3 / 11=27.27 \%] \\
\text { congregación }[2 / 11=18.18 \%] \\
\text { sinagoga a } 2 / 111=18.18 \%] \\
\text { eclesia }[1 / 11=9.09 \%] \\
\text { gente }[1 / 11=9.09 \%] \\
\text { pueblo }[1 / 11=9.09 \%] \\
\text { república }[1 / 11=9.09 \%]\end{array}$ & $\begin{array}{l}\text { cabildo }[5 / 10=50.00 \%] \\
\text { ayuntamiento }[3 / 10=30.00 \%] \\
\text { compaña }[2 / 10=20.00 \%]\end{array}$ \\
\hline PP & $\begin{array}{c}\text { compaña }[18 / 21= \\
85.71 \%]\end{array}$ & N/A & N/A & $\begin{array}{l}\text { ayuntamiento }[13 / 21= \\
\quad 61.90 \%] \\
\text { allegamiento }[1 / 21= \\
4.76 \%] \\
\text { cabildo }[1 / 21=4.76 \%] \\
\text { compaña }[1 / 21=4.76 \%] \\
\text { común }[1 / 21=4.76 \%] \\
\text { familia }[1 / 21=4.76 \%] \\
\text { gente }[1 / 21=4.76 \%] \\
\text { persona }[1 / 21=4.76 \%]\end{array}$ & $\mathrm{N} / \mathrm{A}$ & $\begin{array}{l}\text { concilio }[10 / 21=47.62 \%] \\
\text { concejo }[4 / 21=19.05 \%] \\
\text { ayuntamiento }[3 / 21= \\
14.29 \%] \\
\text { gente } 22 / 21=9.52 \%] \\
\text { gentio }[2 / 21=9.52 \%]\end{array}$ & $\begin{array}{l}\text { concilio }[2 / 4=50.00 \%] \\
\text { gente }[1 / 4=25.00 \%]\end{array}$ & $\begin{array}{l}\text { congregación }[5 / 21=23.81 \%] \\
\text { gente }[5 / 21=23.81 \%] \\
\text { muchedumbre }[3 / 21=14.29 \%] \\
\text { república }[3 / 21=14.29 \%] \\
\text { campaña }[1 / 21=4.76 \%] \\
\text { companã }[1 / 21=4.76 \%] \\
\text { generación }[1 / 21=4.76 \%] \\
\text { hueste }[1 / 21=4.76 \%]\end{array}$ & $\mathrm{N} / \mathrm{A}$ \\
\hline Ketubim & $\begin{array}{c}\text { compaña [53/53 }= \\
100.00 \%]\end{array}$ & N/A & N/A & $\begin{array}{l}\text { ayuntamiento }[29 / 57= \\
50.88 \%] \\
\text { compana }[14 / 57= \\
24.56 \%] \\
\text { cabildo }[[/ 57=10.53 \%] \\
\text { pueblot [2/57 }=3.51 \%] \\
\text { allegamiento }[1 / 57= \\
1.75 \%] \\
\text { alcamiento }[1 / 57=1.75 \%] \\
\text { común n } 1[/ 57=1.75 \%] \\
\text { gente }[1 / 57=1.75 \%] \\
\text { público }[1 / 57=1.75 \%]\end{array}$ & $\begin{array}{l}\text { concilio }[6 / 10=60.00 \%] \\
\text { pueblo }[3 / 10=30.00 \%] \\
\text { gente }[1 / 10=10.00 \%]\end{array}$ & $\begin{array}{l}\text { concilio }[46 / 47=97.87 \%] \\
\text { pueblo }[1 / 47=2.13 \%]\end{array}$ & N/A & $\begin{array}{l}\text { gente [26/48 }=54.17 \%] \\
\text { república [9/48=18.75\%] } \\
\text { pueblo [3/48 }=6.25 \%] \\
\text { eglesia [2/48 }=4.17 \%] \\
\text { allegar [1/48 }[1.08 \%] \\
\text { colación [1/48=2.08\%] } \\
\text { compaña }[1 / 48=2.08 \%] \\
\text { egleja }[1 / 48=2.08 \%] \\
\text { junta [1/48 }=2.08 \%] \\
\text { pública [1/48 }=2.08 \%] \\
\text { públicamente }[1 / 48=2.08 \%]\end{array}$ & N/A \\
\hline
\end{tabular}




\begin{tabular}{|c|c|c|c|c|c|c|c|c|c|}
\hline \multicolumn{10}{|c|}{ (bejor) } \\
\hline Parte & E3 & E19 & E7 & E5 & E4 & BNE & RAH & Arragel & Oxford \\
\hline Torá & $\begin{array}{l}\text { mayor }[38 / 72=52.78 \%] \\
\text { primero }[21 / 72=29.17 \%] \\
\text { primogénito }[7 / 72= \\
9.72 \%] \\
\text { primicia }[2 / 72=2.78 \%] \\
\text { mayoradogo }[1 / 72= \\
1.39 \%] \\
\text { mayorgar }[1 / 72=1.39 \%] \\
\text { primerizo }[1 / 72=1.39 \%]\end{array}$ & $\begin{array}{l}\text { mayor }[57 / 69=82.61 \%] \\
\text { primero }[8 / 69=11.59 \%] \\
\text { primogenitit }[2 / 26=2.90 \%] \\
\text { mayorgar }[1 / 69=1.45 \%]\end{array}$ & $\begin{array}{l}\text { primogénito [34/71= } \\
47.89 \%] \\
\text { primero }[14 / 71= \\
19.72 \%] \\
\text { primero-génito }[11 / 71= \\
15.49 \%] \\
\text { mayor [9/71 }=12.68 \%] \\
\text { mayoría } 2[2 / 71=2.82 \%] \\
\text { primerizos [1/71 } \\
1.41 \%]\end{array}$ & N/A & $\begin{array}{l}\text { primogénito }[69 / 72=95.83 \%] \\
\text { macho }[1 / 722=1.39 \%] \\
\text { mayor }[1 / 72=1.39 \%] \\
\text { primogenitura }[1 / 72=1.39 \%]\end{array}$ & N/A & N/A & $\begin{array}{l}\text { primos-génito }[41 / 72=56.94 \%] \\
\text { primogenito }[17 / 72=23.61 \%] \\
\text { mayor }[8 / 72=11.11 \%] \\
\text { primos-primo }[2 / 72=2.78 \%] \\
\text { génito-primo }[1 / 72=1.39 \%] \\
\text { mayoragdoo }[1 / 72=1.39 \%] \\
\text { primicia }[1 / 72=1.39 \%]\end{array}$ & N/A \\
\hline PA & mayor $[8 / 8=100.00 \%]$ & N/A & $\begin{array}{l}\text { mayor }[4 / 9=44.44 \%] \\
\text { primero }[2 / 9=22.22 \%] \\
\text { primogénito }[2 / 9= \\
22.22 \%]\end{array}$ & N/A & $\begin{array}{l}\text { primogénito }[8 / 9=88.89 \%] \\
\text { progénito }[1 / 9=11.11 \%]\end{array}$ & N/A & N/A & primogénito $[7 / 9=77.78 \%]$ & $\begin{array}{l}\text { primero-engendrado }[2 / 5=40.00 \%] \\
\text { primero-génito }[2 / 5=40.00 \%] \\
\text { primo-engendrado }[1 / 5=20.00 \%]\end{array}$ \\
\hline PP & $\begin{array}{l}\text { mayor }[3 / 4=75.00 \%] \\
\text { primogénito }[1 / 4= \\
25.00 \%]\end{array}$ & N/A & N/A & $\begin{array}{l}\text { primogénito }[3 / 4= \\
75.00 \%] \\
\text { primicia }[1 / 4=25.00 \%]\end{array}$ & N/A & primogénito $[4 / 4=100.00 \%]$ & primos-genito $[1 / 2=50.00 \%]$ & $\begin{array}{l}\text { primogénito }[2 / 4=50.00 \%] \\
\text { primos-genito }[1 / 4=25.00 \%] \\
\text { uno-génito }[1 / 4=25.00 \%]\end{array}$ & N/A \\
\hline Ketubim & $\begin{array}{l}\text { primogénito }[20 / 35= \\
57.14 \%] \\
\text { mayor }[14 / 35=40.00 \%] \\
\text { mayoral }[1 / 35=2.86 \%]\end{array}$ & N/A & N/A & $\begin{array}{l}\text { primogénito [22/35 = } \\
62.86 \%] \\
\text { mayor }[8 / 35=22.86 \%] \\
\text { bacor }[1 / 35=2.86 \%] \\
\text { primero }[1 / 35=2.86 \%] \\
\text { primicias }[1 / 35=2.86 \%]\end{array}$ & primogénito $[1 / 1=100.00 \%]$ & $\begin{array}{l}\text { primogénito }[32 / 34= \\
94.12 \%] \\
\text { primado }[1 / 34=2.94 \%]\end{array}$ & N/A & $\begin{array}{l}\text { primogénito }[29 / 30=96.67 \%] \\
\text { primos-génito }[1 / 30=3.33 \%]\end{array}$ & N/A \\
\hline
\end{tabular}




\begin{tabular}{|c|c|c|c|c|c|c|c|c|c|}
\hline \multicolumn{10}{|c|}{ תוֹעִּדבה (to ‘ebá) } \\
\hline Parte & $\mathbf{E 3}$ & E19 & E7 & E5 & E4 & BNE & RAH & Arragel & Oxford \\
\hline Torá & $\begin{array}{l}\text { aborrecimiento }[23 / 27= \\
85.19 \%] \\
\text { aborrecido }[3 / 27= \\
11.11 \%] \\
\text { boltura }[1 / 27=3.70 \%]\end{array}$ & $\begin{array}{l}\text { aborrición }[13 / 27=48.15 \%] \\
\text { aborrecer [9/27=33.33\%] } \\
\text { aborrida }[4 / 27=14.81 \%]\end{array}$ & $\begin{array}{l}\text { aborrecimiento }[9 / 27= \\
\quad 33.33 \%] \\
\text { heregiá }[3 / 27=11.11 \%] \\
\text { aborrición }[2 / 27=7.41 \%] \\
\text { creencia }[2 / 27=7.41 \%] \\
\text { aborrecedero }[1 / 27=3.70 \%] \\
\text { aborrecible }[1 / 27=3.70 \%] \\
\text { aborrimiento }[2 / 27=7.40 \%] \\
\text { maldad }[2 / 27=7.40 \%] \\
\text { contrario }[1 / 27=3.70 \%] \\
\text { defendido }[1 / 27=3.70 \%] \\
\text { enconamiento }[1 / 27=3.70 \%] \\
\text { falsedad }[1 / 27=3.70 \%] \\
\text { malicia }[1 / 27=3.70 \%]\end{array}$ & N/A & $\begin{array}{l}\text { abominación [24/27 = } \\
88.89 \% \text { ] } \\
\text { aborrescimiento [3/27 } \\
=11.11 \%]\end{array}$ & N/A & $\mathrm{N} / \mathrm{A}$ & $\begin{array}{l}\text { abominación }[9 / 27=33.33 \%] \\
\text { aborrecer }[5 / 27=18.52 \%] \\
\text { aborrida }[4 / 27=14.81 \%] \\
\text { aborrimiento }[4 / 27=14.81 \%] \\
\text { abominar }[1 / 27=3.70 \%] \\
\text { aborrecencia } 1[1 / 27=3.70 \%] \\
\text { aborrecimiento }[1 / 27=3.70 \%] \\
\text { aborrición }[1 / 27=3.70 \%] \\
\text { mala }[1 / 27=3.70 \%]\end{array}$ & $\mathrm{N} / \mathrm{A}$ \\
\hline PA & $\begin{array}{l}\text { aborrecimiento [4/5= } \\
\quad 80.00 \%] \\
\text { aborrición }[1 / 5=20.00 \%]\end{array}$ & N/A & $\begin{array}{l}\text { aborrecimiento }[2 / 5= \\
40.00 \%] \\
\text { aborrecencia }[1 / 5=20.00 \%] \\
\text { creencia }[1 / 5=20.00 \%] \\
\text { ídolo }[1 / 5=20.00 \%]\end{array}$ & N/A & $\begin{array}{l}\text { abominación [5/5= } \\
100.00 \%]\end{array}$ & $\mathrm{N} / \mathrm{A}$ & $\mathrm{N} / \mathrm{A}$ & abominación [5/5 = 100.00\%] & enconamiento $[4 / 4=100.00 \%]$ \\
\hline PP & $\begin{array}{l}\text { aborrecimiento [32/55= } \\
58.18 \%] \text { ] } \\
\text { aborrecencia }[7 / 55= \\
12.73 \% \text { ] } \\
\text { maldad }[6 / 55=10.91 \%] \\
\text { enconamiento }[4 / 55= \\
7.27 \% \text { ] } \\
\text { aborreceido }[2 / 55=3.64 \%] \\
\text { aborrición }[1 / 55=1.82 \%]\end{array}$ & $\mathrm{N} / \mathrm{A}$ & N/A & 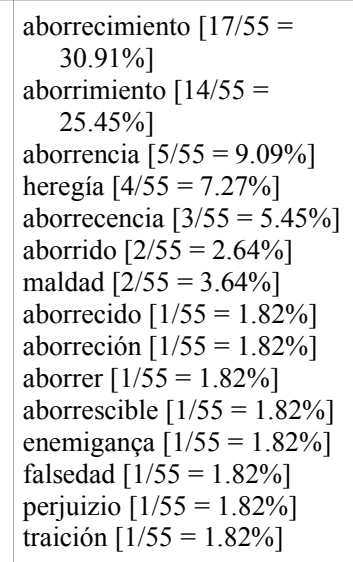 & $\mathrm{N} / \mathrm{A}$ & $\begin{array}{l}\text { abominación [51/55 = } \\
\text { 92.73\%] } \\
\text { abominable }[1 / 55=1.82 \%]\end{array}$ & $\begin{array}{l}\text { abominación }[30 / 30= \\
100.00 \%]\end{array}$ & $\begin{array}{l}\text { abominación }[53 / 55=96.36 \%] \\
\text { abominar }[1 / 55=1.82 \%]\end{array}$ & $\mathrm{N} / \mathrm{A}$ \\
\hline Ketubim & $\begin{array}{l}\text { aborrecer [13/31 = } \\
41.94 \%] \\
\text { aborrecimiento }[8 / 31= \\
25.81 \%] \\
\text { aborrecido }[7 / 31= \\
22.58 \%]= \\
\text { maldad [2/31 }=6.45 \%]\end{array}$ & N/A & $\mathrm{N} / \mathrm{A}$ & $\begin{array}{l}\text { aborrecimiento }[22 / 31= \\
\quad 70.97 \%] \\
\text { aborrer }[2 / 31=6.45 \%] \\
\text { aborresamiento }[2 / 31= \\
\quad 6.45 \%] \\
\text { aborrecer }[1 / 31=3.23 \%] \\
\text { aborrecido }[1 / 31=3.23 \%] \\
\text { creencia }[1 / 31=3.23 \%] \\
\text { traición }[1 / 31=3.23 \%] \\
\text { voluntad }[1 / 31=3.23 \%]\end{array}$ & $\begin{array}{l}\text { abominación [3/3 }= \\
100.00 \%]\end{array}$ & $\begin{array}{l}\text { abominación }[28 / 28= \\
100.00 \%]\end{array}$ & N/A & $\begin{array}{l}\text { abominación }[20 / 30=66.67 \%] \\
\text { abominar }[5 / 30=16.67 \%] \\
\text { aborrecer }[2 / 30=6.67 \%] \\
\text { abominable }[1 / 30=3.33 \%]\end{array}$ & N/A \\
\hline
\end{tabular}




\begin{tabular}{|c|c|c|c|c|c|c|c|c|c|}
\hline \multicolumn{10}{|c|}{ פְִִֶׁר (šéquer) } \\
\hline Parte & E3 & E19 & E7 & E5 & $\mathrm{E} 4$ & BNE & RAH & Arragel & Oxford \\
\hline Torá & $\begin{array}{l}\text { falsedad }[6 / 8=75.00 \%] \\
\text { falso }[1 / 8=12.50 \%] \\
\text { mentira }[1 / 8=12.50 \%]\end{array}$ & $\begin{array}{l}\text { falsedad }[5 / 8=62.50 \%] \\
\text { falso }[2 / 8=25.00 \%] \\
\text { baldia [1/8 }=12.50 \%]\end{array}$ & $\begin{array}{l}\text { falso }[2 / 8=25.00 \%] \\
\text { mentira }[2 / 8=25.00 \%] \\
\text { engañoso }[1 / 8= \\
12.50 \%] \\
\text { falsar }[1 / 8=12.50 \%] \\
\text { falsedad }[1 / 8=12.50 \%]\end{array}$ & N/A & $\begin{array}{l}\text { mentira }[7 / 8=87.50 \%] \\
\text { mentir }[1 / 8=12.50 \%]\end{array}$ & $\mathrm{N} / \mathrm{A}$ & $\mathrm{N} / \mathrm{A}$ & $\begin{array}{l}\text { falsedad }[4 / 8=50.00 \%] \\
\text { falsía }[2 / 8=25.00 \%] \\
\text { falso }[2 / 8=25.00 \%]\end{array}$ & N/A \\
\hline PA & $\begin{array}{l}\text { falso }[2 / 5=40.00 \%] \\
\text { balde }[1 / 5=20.00 \%] \\
\text { falsedad }[1 / 5=20.00 \%] \\
\text { mentira }[1 / 5=20.00 \%]\end{array}$ & N/A & $\begin{array}{l}\text { falso }[2 / 5=40.00 \%] \\
\text { balde }[1 / 5=20.00 \%] \\
\text { falsedad }[1 / 5=20.00 \%] \\
\text { traición }[1 / 5=20.00 \%]\end{array}$ & $\mathrm{N} / \mathrm{A}$ & $\begin{array}{l}\text { mentira }[4 / 5=80.00 \%] \\
\text { balde }[1 / 5=20.00 \%]\end{array}$ & $\mathrm{N} / \mathrm{A}$ & $\mathrm{N} / \mathrm{A}$ & $\begin{array}{l}\text { falso }[2 / 5=40.00 \%] \\
\text { falsa }[1 / 5=20.00 \%] \\
\text { traición }[1 / 5=20.00 \%]\end{array}$ & $\begin{array}{l}\text { falso }[2 / 5=40.00 \%] \\
\text { balde }[1 / 5=20.00 \%] \\
\text { falsedad }[1 / 5=20.00 \% \\
\text { mentira }[1 / 5=20.00 \%]\end{array}$ \\
\hline PP & $\begin{array}{l}\text { falsedad }[47 / 54=87.04 \%] \\
\text { falso }[4 / 54=7.41 \%] \\
\text { falsador }[1 / 5=1.85 \%] \\
\text { mesturero }[1 / 54=1.85 \%]\end{array}$ & N/A & N/A & $\begin{array}{l}\text { falsedad [27/54=50.00\%] } \\
\text { falso [8/54=14.81\%] } \\
\text { mentira }[5 / 54=9.26 \%] \\
\text { falsa }[4 / 54=7.41 \%] \\
\text { falsamente }=3 / 54=5.56 \%] \\
\text { falsiá }[2 / 54=3.70 \%] \\
\text { vanidat }[2 / 54=3.70 \%] \\
\text { engaño }[1 / 54=1.85 \%]\end{array}$ & N/A & $\begin{array}{l}\text { mentira }[50 / 54=92.59 \%] \\
\text { mentirosa }[2 / 54=3.70 \%] \\
\text { balde }[1 / 5=1.85 \%] \\
\text { injusticia }[1 / 54=1.85 \%]\end{array}$ & $\begin{array}{l}\text { mentira }[28 / 45=62.22 \%] \\
\text { falsedad }[99 / 45=2.00 \% \text { ] } \\
\text { falsia }[5 / 45=11.11 \%] \\
\text { falso } 2[1 / 45=4.44 \%] \\
\text { mentirosa }[1 / 45=2.22 \%]\end{array}$ & $\begin{array}{l}\text { mentira }[38 / 54=70.37 \%] \\
\text { falsiá }[7 / 54=12.96 \%] \\
\text { falso }[4 / 54=7.41 \%] \\
\text { mentir }[1 / 54=1.85 \%] \\
\text { mentirosa }[1 / 54=1.85 \%]\end{array}$ & N/A \\
\hline Ketubim & $\begin{array}{l}\text { falsedad [30/46 }=65.22 \%] \\
\text { falso }[15 / 46=32.50 \%] \\
\text { balde }[1 / 46=2.17 \%]\end{array}$ & N/A & N/A & $\begin{array}{l}\text { falsedad }[14 / 45=31.11 \%] \\
\text { falsa [11/145=24.44\%] } \\
\text { falso }[9 / 45=20.00 \%] \\
\text { mentira }[5 / 45=11.11 \%] \\
\text { falsia }[2 / 45=4.44 \%] \\
\text { mala }[1 / 45=2.2 \%] \\
\text { maldad }[1 / 45=2.22 \%] \\
\text { vanidat }[1 / 45=2.22 \%]\end{array}$ & {$[0 / 0=0.00 \%]$} & $\begin{array}{l}\text { mentira }[42 / 46=91.30 \%] \\
\text { mentirosa }[2 / 46=4.35 \%] \\
\text { falso }[1 / 46=2.17 \%]\end{array}$ & $\mathrm{N} / \mathrm{A}$ & 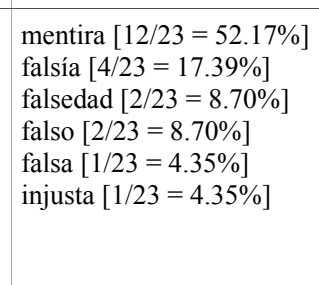 & N/A \\
\hline
\end{tabular}




\begin{tabular}{|c|c|c|c|c|c|c|c|c|c|}
\hline \multicolumn{10}{|c|}{ 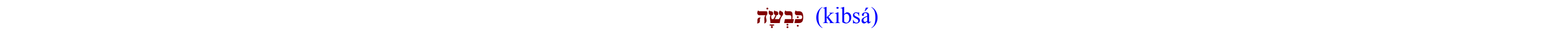 } \\
\hline Parte & $\mathbf{E 3}$ & E19 & E7 & E5 & E4 & BNE & RAH & Arragel & Oxford \\
\hline Torá & $\begin{array}{l}\text { cordera }[4 / 5=80.00 \%] \\
\text { carnero }[1 / 5=20.00 \%]\end{array}$ & cordera $[2 / 2=100.00 \%]$ & $\begin{array}{l}\text { oveja }[3 / 5=60.00 \%] \\
\text { borrega }[1 / 5=20.00 \%] \\
\text { ovejas }[1 / 5=20.00 \%]\end{array}$ & $\mathrm{N} / \mathrm{A}$ & $\begin{array}{l}\text { oveja }[4 / 5=80.00 \%] \\
\text { ganado }[1 / 5=20.00 \%]\end{array}$ & N/A & N/A & cordera $[5 / 5=100.00 \%]$ & $\mathrm{N} / \mathrm{A}$ \\
\hline PA & cordera $[3 / 3=100.00 \%]$ & N/A & oveja $[3 / 3=100.00 \%]$ & $\mathrm{N} / \mathrm{A}$ & oveja $[3 / 3=100.00 \%]$ & N/A & N/A & $\begin{array}{l}\text { cordera }[2 / 3=66.67 \%] \\
\text { corderuela }[1 / 3=33.33 \%]\end{array}$ & $\begin{array}{l}\text { oveja }[2 / 3=66.67 \%] \\
\text { ovejuela }[1 / 3=33.33 \%]\end{array}$ \\
\hline \multicolumn{10}{|c|}{ פֶבֶֶש (kebes) } \\
\hline Parte & E3 & E19 & E7 & E5 & E4 & BNE & RAH & Arragel & Oxford \\
\hline Torá & $\begin{array}{l}\text { carnero }[75 / 87=86.21 \%] \\
\text { borrego }[9 / 87=10.34 \%] \\
\text { cordero }[1 / 87=1.15 \%]\end{array}$ & $\begin{array}{l}\text { carnero }[85 / 87=97.70 \%] \\
\text { barvez }[1 / 87=1.15 \%]\end{array}$ & $\begin{array}{l}\text { carnero }[85 / 87=97.70 \%] \\
\text { alsación }[2 / 87=2.30 \%]\end{array}$ & $\mathrm{N} / \mathrm{A}$ & carnero $[87 / 87=100.00 \%]$ & $\mathrm{N} / \mathrm{A}$ & N/A & $\begin{array}{l}\text { cordero }[40 / 65=61.54 \%] \\
\text { carnero }[22 / 65=33.85 \%] \\
\text { ovejuno }[2 / 65=3.08 \%]\end{array}$ & N/A \\
\hline PP & $\begin{array}{l}\text { carnero }[9 / 12=75.00 \%] \\
\text { cordero }[3 / 12=25.00 \%]\end{array}$ & N/A & N/A & $\begin{array}{l}\text { carnero }[10 / 12=83.33 \%] \\
\text { cordero }[1 / 12=8.33 \%] \\
\text { ganado }[1 / 12=8.33 \%]\end{array}$ & N/A & carnero [12/12 = 100.00\%] & $\begin{array}{l}\text { carnero }[3 / 4=75.00 \%] \\
\text { cordero }[1 / 4=25.00 \%]\end{array}$ & $\begin{array}{l}\text { cordero }[7 / 12=58.33 \%] \\
\text { carnero }[3 / 12=25.00 \%] \\
\text { toro }[1 / 12=8.33 \%]\end{array}$ & $\mathrm{N} / \mathrm{A}$ \\
\hline Ketubim & $\begin{array}{l}\text { carnero }[7 / 8=87.50 \%] \\
\text { cordero }[1 / 8=12.50 \%]\end{array}$ & N/A & N/A & carnero $[8 / 8=100.00 \%]$ & carnero $[1 / 1=100.00 \%]$ & carnero $[7 / 7=100.00 \%]$ & $\mathrm{N} / \mathrm{A}$ & $\begin{array}{l}\text { cordero }[6 / 8=75.00 \%] \\
\text { carnero }[1 / 8=12.50 \%] \\
\text { vellezino }[1 / 8=12.50 \%]\end{array}$ & N/A \\
\hline
\end{tabular}

